Thomas Maissen

Die Bedeutung der christlichen Bildsprache für die Legitimation frühneuzeitlicher Staatlichkeit 


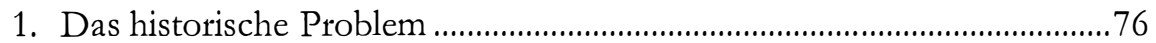

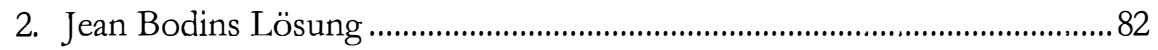

3. Ikonografische Vermittlung von politischer Theorie ..................................89

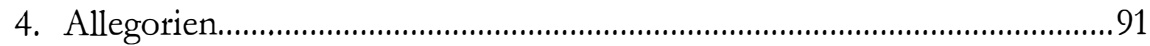

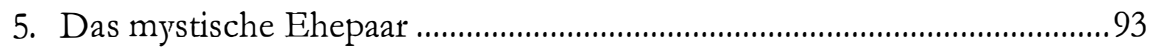

6. Die Paarbeziehung im Bild ..........................................................................109

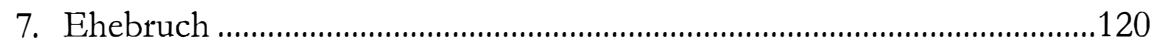

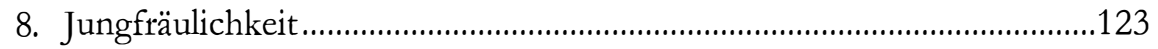

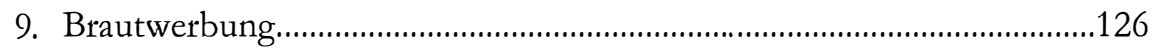

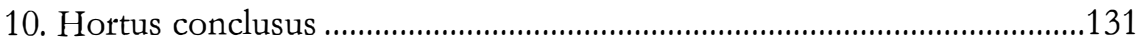

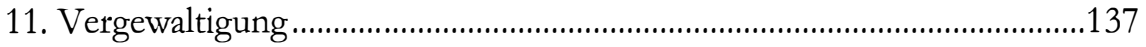

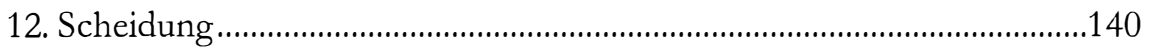

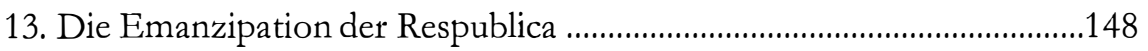

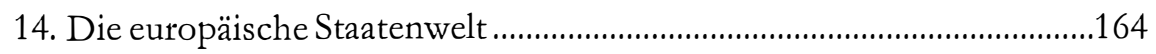

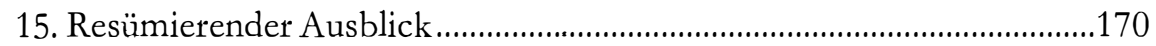


Die Entwicklung des Toleranzkonzepts und die Ausbreitung der Religionsfreiheit erfolgten im Rahmen des modernen Staats und als eine seiner Hauptleistungen: der Schutz individueller Rechte gegen kollektive Überzeugungen, selbst wenn es diejenigen der staatstragenden Bevölkerungsmehrheit sind. Um dies zu gewährleisten, mussten sich unterschiedliche Funktionssysteme herausdifferenzieren, Religion und Politik. Wohl konzentrierte Letztere einerseits die Gestaltungsvollmacht für die Rechtsordnung exklusiv bei Staatsdienern, die sich aber - andererseits - idealerweise Unparteilichkeit in der religiösen Sphäre auferlegten. Diese etwa in Lockes Epistola de tolerantia (1689) greifbare Trennung der Zuständigkeiten und der damit postulierte konfessionsneutrale Staat selbst waren allerdings ihrerseits auch erst das Ergebnis eines längeren Prozesses. An dessen Anfang stand dieselbe enge Verschränkung von spirituellen und politischen Gewalten und Funktionen, wie sie weltweit für vormoderne Zivilisationen typisch war, in denen das Wort «Religion» erst als missionarischer Import ein nur durch diese Begriffssetzung definiertes Funktionssystem eigener Qualität schuf.

Dieses folgende Kapitel beschreibt die frühneuzeitliche Transformation des Politischen als Herausbildung des staatlichen Gewaltmonopols und insbesondere dessen Erörterung und Legitimation in den zeitgenössischen Bildmedien. An diesen wird illustriert, wie der Bruch mit der bestehenden politischen Semantik, selbst wenn er in den Konsequenzen radikal war, sich der herkömmlichen (Bild-)Sprache bediente, um plausibel vermittelt und legitimiert zu werden. In der vormodernen Konstellation war dies die christliche Sprache und Symbolik. In diesem Sinn hat Ernst Kantorowicz die Bedeutung der Zwei-Naturen-Lehre für die Vorstellung von abstrakter Königsherrschaft und Staat(samt) herausgearbeitet, Louis Marin die Eucharistie als Modell für die Re-Präsẹtation des absoluten, aber abwesenden Monarchen vorgeführt. ${ }^{1}$ Oft zitiert wird Carl Schmitts Behauptung, dass «alle prägnanten Begriffe der modernen Staatslehre [...] säkularisierte theologische Begriffe» seien, ${ }^{2}$ wobei er allerdings, zumindest in Jacob Taubes' Einschätzung, auch einsehen musste, dass gleichzeitig «die Gewaltentrennung zwischen weltlich und geistlich absolut notwendig» sei. ${ }^{3}$ Schmitts

1 Kantorowicz, Zwei Körper; Marin, Porträt.

2 Schmitt, Politische Theologie, 43.

3 Taubes, Die politische Theologie des Paulus, München, 1993, 139, zitiert bei Prodi, Geschichte der Gerechtigkeit, 346. 
Formulierung ist wohl allzu kategorisch; doch für das Konzept der «Souveränitäts trifft sie zu. Die folgenden Ausführungen sollen zeigen, wie theologische Vorstellungen und die christliche Ikonografie Voraussetzungen lieferten dafür, dass eine säkulare Vorstellung der politischen Ordnung entworfen und bildlich vermittelt werden konnte.

\section{Das historische Problem}

Das abendländische Mittelalter ging von der Einheit des Corpus christianum aus: eine tendenziell universale, real auf das Abendland beschränkte Ordnung, die im Sinne des einen Gottes alle Bereiche umfasste und einander zuordnete. Die Körpermetapher brachte zum Ausdruck, dass es klare Hierarchien gab, wie das Haupt dem Magen übergeordnet ist; dass aber die verschiedenen Organe aufeinander angewiesen waren und komplementär zum Wohl des Ganzen beitrugen. ${ }^{4}$ Man mochte darüber streiten, wer übergeordnet war und wer gehorchen musste: die weltliche oder die geistliche Gewalt, imperium oder sacerdotium, Kaiser oder Papst. Wie auch die Antwort ausfiel und wie zerstritten die konkurrierenden Mächte auch sein mochten, es blieb unzweifelhaft, dass die beiden Universalgewalten aufeinander bezogen waren und letztlich eine geistliche und rechtliche Einheit bildeten, von Gott eingesetzt, um gemeinsam das Diesseits zu gestalten - weshalb im Hochmittelalter nicht nur der Papst, sondern auch der Kaiser den Titel vicarius Christi oder gar vicarius Dei reklamieren konnte. ${ }^{5}$ Diese Aufgabe legitimierte ihre Herrschaftsfunktion nicht nur in der jeweiligen Gegenwart, sondern mit der heilsgeschichtlichen Perspektive, die Augustins Lehren von den zwei civitates und den sieben Zeitaltern oder den vier Weltreichen und ihren Translationen (nach Daniel) innewohnte.

In der graduellen Abstufung sowohl der Lehnsordnung wie auch der scholastischen Theorie kam diese Legitimation aber auch den anderen Ordnungsmächten zu, die mittelbar Macht ausübten: Könige, Herzöge, Barone und so weiter bis zu städtischen Räten und dörflichen Schulzen; und Kardinäle, Erzbischöfe, Bischöfe, Äbte, Prioren oder Domherren in der geistlichen Hierarchie. Sie alle waren privilegierte Herrschaftsträger in einer ständisch fein und ebenfalls graduell gegliederten Gesellschaft, die vom

4 Grundlegend dazu 1Kor 12,12-31; vgl. auch Dohrn-van Rossum, Art. Organ, 552;

Paravicini Bagliani, Leib des Papstes, 68f.

5 Dolezalek/Bregger, Art. Vikar/Vikarin, 84. 
hochadligen Fürstenhaus bis zum Leibeigenen reichte und auch regional sehr unterschiedlich ausgeprägt war. Es gab also weder einen einheitlichen Untertanenverband noch eine einheitliche Staatsgewalt, und Herrschaft bezog sich auf Personengruppen, nicht auf ein bestimmtes Territorium. Es handelte sich um eine direkte personale Beziehung zwischen demjenigen, der Schutz leistete, und denjenigen, die ihm dafür zu Treue und Leistungen verpflichtet waren - adlige Vasallen ebenso wie bäuerliche Hörige oder Grundholden. Sowohl die pyramidale Struktur des Lehnswesens als auch die monotheistische Legitimation der Obrigkeiten als Stellvertreter eines Richtergottes liessen Einzelherrschaft von Fürsten als gleichermassen gottgewollte wie naturgegebene Regel und den Kaiser als oberste Spitze in einer Hierarchie irdischer Rechtsprecher erscheinen. So erschien noch im Vorfeld der Französischen Revolution Joseph II., der laut Kaunitz als «Schirmherr der Christenheit» und «oberster Richter» den übrigen gekrönten Häuptern übergeordnet war. ${ }^{6}$

Die in der Realität klar beschränkten politischen Gestaltungsräume machten jedoch selbst Kaiser und Könige abhängig von Ratschlägen und Hilfsbereitschaft (consilium et auxilium) einflussreicher Adliger, kirchlicher Würdenträger und zunehmend auch von Städtebürgern, etwa Kaufleuten und Juristen. Institutionalisiert wurde dieser Rat in Form von Generalständen oder Landständen. Dazu kam, dass es zwar eine Quelle allen Rechts Gott - gab und die Rechtsordnung deshalb im Kern als universal und einheitlich gedacht wurde, aber auf Erden die vielen Obrigkeiten auf den unterschiedlichsten Foren zahlreiche verschiedene Rechte, im Plural, ausübten: niedere und hohe Gerichtsbarkeit, Steuerrechte und wirtschaftliche Rechte (darunter die ursprünglich königlichen Regalien), Mannschaftsrecht (für militärische Aushebung). ${ }^{7}$ Solche Herrschaftsrechte lagen oft in ganz unterschiedlichen Händen: Es konnte verschiedene Gerichte und gegebenenfalls Instanzenwege geben, wenn es sich um ein Vermögensdelikt oder eine Bluttat handelte, aber auch, wenn sie etwa von einem Laien oder einem Kleriker begangen wurde, denn Letzterer gehörte vor ein kirchliches Gericht. $\mathrm{Da}$ mittelalterliche Herrschaft im Wesentlichen in der Rechtsprechung bestand, war sie aus Sicht der Obrigkeiten, aber auch für viele Unterworfene geteilte Herrschaft: Je nach Rechtstitel war ein anderer Herrschaftsträger für obrigkeitliche Entscheidungen zuständig. Zumeist war dies ein

6 Zitiert nach Stollberg-Rilinger, Alte Kleider, 287.

7 Zur institutionellen Vielfalt in Verbindung mit einem umfassenden Rechtsgedanken Prodi, Geschichte der Gerechtigkeit, insbes. 82-99. 
Adliger; aber auch Korporationen konnten sich als kollektive Fürsten etablieren: Klöster oder Städte, selbst ländliche Kommunen (in der Eidgenossenschaft, aber auch etwa in Dithmarschen). Alle diese Herrschaft blieb auf der jeweils angemessenen Stufe eingebunden in ein universelles Ordnungsgefüge, das zwar einem monarchischen Grundprinzip verpflichtet war, aber wegen der skizzierten Aufteilung der Macht auf verschiedene einzelne und kollektive Obrigkeiten auch als Mischverfassung im aristotelischen Sinn gelten konnte - also eine graduell nach Stand und Status differenzierende, horizontale Verteilung von Kompetenzen und Privilegien, nicht eine vertikale Teilung der einen Staatsgewalt im modernen Sinn nach Montesquieu.

Der nominale Universalismus des Heiligen Römischen Reiches wurde im Spätmittelalter real immer spürbarer relativiert - nicht mehr durch den schwächelnden imperialen Konkurrenten in Byzanz, wohl aber durch autonome Nationalmonarchien, die nach dem Hundertjährigen Krieg in England und Frankreich, nach der Reconquista in Spanien und Portugal und nach dem Ende der Kalmarer Union in Skandinavien sich neu etablierten, während im Gefolge der Schlacht von Mohács 1526 Böhmen und (teilweise) Ungarn an den Habsburger Ferdinand I. fielen. Da sein älterer Bruder Karl V. - als Kaiser im Reich, König von Spanien (mit den Kolonien) und Herrscher über die Niederlande, erhebliche Teile Italiens und weitere Gebiete - seiner Devise Plıs ultra vollauf gerecht wurde, bestand in der ersten Hälfte des 16. Jahrhunderts Grund zur Vermutung, dass ein Kaiserreich in davor unvorstellbaren, wahrhaft universalen Dimensionen entstehen könnte.

Das Scheitern solcher Vorstellungen hing eng mit dem Ereignis zusammen, das auch der anderen Universalmacht, dem Papsttum, seine exklusive Stellung im Abendland raubte: die Reformation. Mit ihr wurde ein Proprium des Christentums reaktualisiert: die individuelle Entscheidung für die wahre Religion. ${ }^{8}$ Zuvor war in der dogmatisch vergleichsweise offenen Kirche des Mittelalters die generative Weitergabe des Glaubens die Regel gewesen, solange der päpstliche Primat in Lehre und Jurisdiktion nicht in Frage gestellt wurde - nicht also für die wenigen, aber im 14./15. Jahrhundert an Zahl und Bedeutung zunehmenden «Häretiker». In den Jahren nach Luthers Thesenanschlag wurde die Entscheidungssituation für Laien in einem kommunalen Rahmen dagegen alltäglich. Das war eine Entscheidung, die ebenso der Tradition und der heilsvermittelnden Autorität der

8 Vgl. den Beitrag von Helmut Zander in diesem Band, 39-71. 
bestehenden Kirche folgen wie sich für das Schriftprinzip und die Rechtfertigungslehre derer aussprechen konnte, die zur ursprünglichen, frühen Kirche zurückzukehren beanspruchten. Diese Option wählten vor allem viele Stadtbürger im Gefolge von volkssprachlichen Disputationen und Religionsgesprächen, durch deren Ausrufung sich die Räte und Bürgerschaften - selbst wenn sie altgläubig blieben - im Prinzip bereits auf der Grundlage des Priestertums aller Getauften das landesherrliche Kirchenregiment auch in dogmaticis anmassten. Auf derselben Grundlage entstand nach Vorläufern vor allem in Kursachsen und in der Landgrafschaft Hessen erst nach dem Augsburger Bekenntnis und verstärkt seit den späten dreissiger Jahren die eigentliche Fürstenreformation, in der es nun zusehends allein die Entscheidung des Landesherrn war, die den Ausschlag gab.?

Reichsrechtlich legitimiert wurde dieses Vorgehen im Augsburger Religionsfrieden von 1555 durch die Regelung, die mit der Formel «cuius regio, eius religio» zusammengefasst wird und das Ideal eines umfassenden Corpus christianum endgültig hinfällig werden liess: Landeskirchen mit spezifischen, vom Landesherrn festgelegten Bekenntnissen traten an die Stelle der «katholischen», also allumfassenden und vom einen Papst geführten Kirche. Im Unterschied zu seinem Bruder Ferdinand mochte Karl V. die Augsburger Regelung nicht unterzeichnen: Er sah eine der Hauptaufgaben des kaiserlichen Amtes im Schutz der Christenheit und damit der einen wahren Kirche und Religion. Ebenso bezeichnenderweise verweigerte auch die andere Universalmacht, Papst Paul IV., dem Augsburger Frieden die Zustimmung, womit es mit einer auf das Reichsrecht und den Reichsfrieden beschränkten Lösung sein Bewenden hatte.

Allerdings war das «ius reformandi», das dem Territorialherrn die Entscheidung über die Konfession seiner Untertanen überliess, keine reichsrechtliche Besonderheit. Faktisch etabliert hatte es sich bereits 1531 in der Eidgenossenschaft, als die katholischen Kantone zwar eine gewaltsame Reformation durch Zwingli verhindern und ihn bei Kappel besiegen und erschlagen konnten, aber im Kappeler Landfrieden anerkennen mussten, dass es in der Eidgenossenschaft fortan zwei Konfessionen geben würde. Welche das war, legten die kollektiven Obrigkeiten jeweils in ihrem Kanton oder - in ländlichen Gebieten wie Glarus, Appenzell oder Graubünden für die einzelne Gemeinde fest. Wie im Reich bedeutete dies, dass sich mit den jeweiligen Landeskirchen Staatlichkeit «föderalistisch», auf der Ebene 
der Partikulargewalten entfaltete und nicht, wie in Spanien, in Portugal oder in den skandinavischen Monarchien, unter einem nationalen Herrscher. Denn für die Staatsbildung war das Zusammenspiel von politischer und kirchlicher Macht entscheidend, das als «Konfessionalisierung» bezeichnet wird. ${ }^{10}$ Idealtypisch skizziert erlaubte sie es, über eine einheitliche, dogmatisch widerspruchsfrei begründete Orthodoxie Kleriker, Staatsdiener und Untertanen in - durch ein schnell wachsendes Bildungssystem - systematisch vermitteltem Glaubenswissen zu vereinen. Dies schuf, im Inneren, einen durch moralische Normen und wachsende priesterlich-obrigkeitliche Reglementierung (Kirchenordnungen) disziplinierten Untertanenverband und grenzte diesen gegen aussen klar ab, dank den religiösen Antagonismen mit klaren Unterscheidungsriten und multimedialer Polemik gegen andersgläubige, oft unmittelbar benachbarte Herrscher und ihre Untertanen.

Im Prinzip verliefen diese Entwicklungen - auch wegen der gegenseitigen Konkurrenz - in den unterschiedlichen Bekenntnissen ähnlich, weshalb man von "funktionaler Äquivalenz» der Konfessionen im Staatsbildungsoder gar Modernisierungsprozess gesprochen hat. ${ }^{11}$ Die funktionalistische Betrachtungsweise der Konfessionalisierungsthese vernachlässigt - bewusst die konfessionelle Binnenperspektiven und die - unbestrittenen - Eigentümlichkeiten der verschiedenen Konfessionskulturen, die in den letzten Jahren wieder verstärkte Aufmerksamkeit gefunden haben. ${ }^{12}$ Auch für das Obrigkeitsverständnis (und mittelbar für die politische Theorie) wurden die unterschiedlichen theologischen Grundüberzeugungen von einiger Bedeutung. Wie erwähnt, herrschte im Spätmittelalter ein graduelles Verständnis der weltlichen Ordnung in Politik und Gesellschaft vor. Dasselbe hat Berndt Hamm für den Bereich von Kirche und individueller Frömmigkeit skizziert als eine Leiter «vom Nützlich-Zeitlichen bis zum Himmlisch-Ewigen»». Der Mensch konnte demnach die einzelnen Stufen der Heiligung durch seine eigenen Leistungen - Tugend, Nächstenliebe, gute Werke erklimmen, da Gott und er bei diesem gemeinsamen Ziel zusammenwirkten. ${ }^{13}$ In der einen hierarchischen Kirche entsprach dem die Abstufung vom gewöhnlichen Sünder über die geweihten Amtsträger bis hinauf zum «vicarius Deì und dann zu den Heiligen mit Maria an der Spitze, die alle je nach

10 Vgl. die einschlägigen Aufsätze von Reinhard, Ausgewählte Abhandlungen, und Schilling, Ausgewählte Abhandlungen.

11 Schilling, Luther, 24; ders., Am Anfang, 8.

12 Kaufmann, Konfession; Maissen, Konfessionskulturen.

13 Hamm, Reformation, 78f.; ders., Einheit und Vielfalt, 69f. 
Nähe oder Distanz zu Gott unterschiedliche Heilsstufen repräsentierten. ${ }^{14}$ So war der einzelne Sünder über eine lange, aufsteigende Reihe von Mittlerfiguren mit Maria und über sie letztlich mit Gott verbunden, die ihm im Bemühen um ein gottgefälliges Leben beistanden.

Mit diesem Gradualismus brachen die Reformatoren, die dem Sünder «solus Christus» als Wegweiser zum Heil vor Augen führten und dieses von Gottes Gnade allein, «sola gratia», abhängig machten. Kein Sterblicher konnte die Allmacht seines Schöpfers einschränken oder beeinflussen, und in dieser unbedingten Abhängigkeit waren alle Menschen gleich. Insofern bereiteten die Reformatoren aus theologischen Gründen einer klaren Gegenüberstellung von allmächtigem Herrscher und einheitlichem Untertanenverband das Feld. Jean Calvin stellte in dieser völligen Unterwerfung ausdrücklich Könige (und Engel) allen anderen Menschen gleich: «[...] iusques aux rois de la terre, que tous se doyvent assuiettir, [...] il n'y a qu'un chef qui ait toute preeminence et empire souverain sur nous». ${ }^{15}$

Mit der Lehre von der doppelten Prädestination und in der Bezeichnung Gottes - wie des Kaisers oder französischen Königs - als «roy souverain» setzte Calvin auch sonst Zeichen, die für ein neues Herrschaftsverständnis charakteristisch waren. ${ }^{16}$ Anders als die Lutheraner richteten die Reformierten einen alttestamentlichen Fokus auf das Gesetz und auf seine Umsetzung auch zur Verchristlichung der diesseitigen Welt. Orientierungspunkt des Juristen Calvin war Gott als letztinstanzlicher Richter, dem die «iurisdiction souveraine» oblag. Das entsprechende Wort aus der französischen Gerichtssprache («cour souveraine») bezeichnete ursprünglich nicht als Superlativ, sondern als Komparativ (aus «superanus» nach «superior») eine «höher liegende», also die nächsthöhere Gerichtsinstanz; später dann die höchste und oberste. ${ }^{17}$ Für Calvin war der «souverain Seigneur» aber nicht nur im herkömmlichen Sinn Rechtsprecher, sondern auch und vor allem Gesetzgeber: «Createur, De tous hommes legislateur, Nostre Dieu souverain Roy». ${ }^{18}$ Gerade im Hinblick auf die Prädestinationslehre war es wichtig, dass Gott dabei einerseits seinen Willen verfügen und einfordern konnte, ohne von fremden Regeln oder Gesetzen beengt zu sein, «car la

14 Hamm, Einheit und Vielfalt, 70f.

15 Calvin, Sermons sur le deuteronome, Sp. 121; vgl. Beyerhaus, Studien, 87, 89f.

16 Für Calvin: Beyerhaus, Studien; Bernard, Du roi juge; Maissen, Souveräner Gesetzgeber.

17 Für die Begriffsgeschichte: Quaritsch, Souveränität; Klippel, Art. Souveränität; Miethke, Art. Souveränität.

18 Calvin, Tractatus minores 2, Sp. 221 (Psalmes, Les dix commandemens, Exode 20). 
volonté de Dieu est tellement la reigle supreme et souveraine de iustice, que tout ce qu'il veut, il le faut tenir pour iuste, d'autant qu'il le veuts. ${ }^{19}$ Andererseits handle Gott, obwohl weder «legibus subiectus» noch «legibus obstrictus», ${ }^{20}$ nicht aufgrund der «potestas absoluta», die ihm Scholastiker wie Ockham oder Duns Scotus zugestanden hatten. Calvin identifizierte absolute Gewalt noch mit der Willkür des Tyrannen, der nach eigenem Gutdünken handelte, während Gott als personifizierte Gerechtigkeit durchaus an das Gesetz gebunden blieb, das ja sein eigenes war: «Neque tamen hoc modo eum facio exlegem, etsi supra omnes leges eminet eius potestas, quia tamen voluntas eius certissima est perfectae aequitatis regula, rectissimum est quidquid facit: atque ideo legibus solutus est, quia ipse sibi et omnibus lex est..» ${ }^{21}$

Diese Zitate sollen nicht suggerieren, dass Calvin der Begründer des neuzeitlichen Souveränitätsbegriffs war oder dass dessen Begründer, der Katholik Jean Bodin, vom Genfer inspiriert wurde. Hingegen wird postuliert, dass das Souveränitätskonzept nur in einem christlichen Kontext entwickelt werden konnte, das - in der Reformationstheologie - einen Richtergott in einen gesetzgebenden Gott übergeführt hatte.

\section{Jean Bodins Lösung}

Kirchen und Kleriker waren als Künder der für ein Staatsvolk verbindlichen transzendentalen Wahrheit einerseits unverzichtbare Träger des frühneuzeitlichen Konfessionalisierungs- und Disziplinierungsprozesses, andererseits aber im Vertrauen auf ihre gestiegene Bedeutung auch eine stete Gefährdung für die sich entwickelnde und oft noch schwache Staatlichkeit. Im Wissen darum, dass Gott den Lauen ebenso zürnte wie den Falschgläubigen, und gestützt auf das Bibelwort, dass man Gott mehr gehorchen müsse als den Menschen (Apg 5,29), waren sie zu kompromissloser konfessioneller Polemik geradezu verpflichtet. Diese konnte sich, politisch zumeist erwünscht, gegen den äusseren Feind richten, so dass Staatsbildungskriege immer auch Konfessionskriege waren: England gegen Spanien, die Niederlande gegen die spanischen und Böhmen gegen die österreichischen Habsburger, die protestantischen Reichsstände gegen den Kaiser,

19 Calvin, Institutio, 2, Sp. 488.

20 Beyerhaus, Studien, 73f.

21 Calvin, Commentarius in Exodi librum, Sp. 49. 
Polen gegen Schweden und Russen, die protestantischen Mächte gegen Ludwig XIV. oder Preussen gegen Österreich. Doch konsequent eingeforderte konfessionelle Einheitlichkeit einte nicht nur ein Volk gegen aussen, sondern konnte es auch im Inneren zerreissen, wenn verschiedene Bekenntnisse vorlagen. Die Eidgenossenschaft und weitgehend auch das Reich schieden insofern aus der Staatenwelt aus, als sie keine Offensivkriege führten, seitdem die zerstrittenen Kantone und Reichsstände keinen internen Konsens über gemeinsame aussenpolitische Ziele mehr finden konnten. Das war nicht zuletzt das Resultat von inneren Kriegen, in denen darum gerungen worden war, mit einer einheitlichen Konfession auch eine klare Führungsmacht zu etablieren: die erwähnten Kappeler Kriege in der Schweiz, der Schmalkaldische Krieg und dann vor allem der Dreissigjährige Krieg in Deutschland. Auch die anderen bi- oder plurikonfessionellen Gebilde wurden fast unvermeidlich Opfer von Bürgerkriegen: Frankreich in den Hugenottenkriegen von 1562 bis 1598; die siebzehn Provinzen der Niederlande in den Auseinandersetzungen ab 1568, die zur 1648 völkerrechtlich anerkannten Aufteilung in einen katholischen Süden und in die nördlichen Generalstaaten mit ihrer reformierten Dominanz führten; die Engländer (und mittelbar die anderen britischen Völker) durch den Bürgerkrieg ab 1642, der seinen revolutionären Höhepunkt 1649 in der Hinrichtung König Karls I. und der Ausrufung von Cromwells Commonwealth erlebte.

Der englische Bürgerkrieg entbrannte nicht zuletzt als Konflikt darüber, ob und wieweit der König die Kirche(n) kontrollieren und mit ihrer Hilfe, aber übergeordnet das Sittengericht wahrnehmen sollte. Die Position, dass die Kirche abhängig von der weltlichen Gewalt bleiben sollte, wurde als Erastianism bezeichnet, was auf Wurzeln im kontinentalen Reformiertentum verweist. Während der Calvinismus die Kirchenzucht zulasten der Politik einem autonomen Konsistorium der ältesten Laien und Geistlichen (Presbyter) überantwortete, sahen die Zwinglianer darin eine Aufgabe der Obrigkeit. In den Stapfen von Zwingli und vor allem von Heinrich Bullinger führte Thomas Erast im Heidelberger Disziplinisten-Streit von 1568/69 mit der Explicatio gravissimae quaestionis, utrum excommunicatio [...] mandato nitatur divino, an excognita sit ab bominibus (postum gedruckt 1589) die Position aus, dass der kirchlichen (Sitten-)Gerichtsbarkeit keine Rechtsprechung zukam, sondern diese vollumfänglich in der Hand der Obrigkeit lag. Für die calvinistischen Disziplinisten antwortete Calvins Nachfolger in Genf, Theodor de Bèze, im Tractatus pius et moderatus de Excommunicatione (1590), der die kirchliche Banngewalt mit Ausschluss vom Abendmahl behauptete. Doch 
obwohl die Antagonisten über die Autonomie der kirchlichen Institutionen unterschiedlicher Meinung waren, hielt auch Erast an der religiösen Legitimation des staatskirchlichen magistratus unicus fest, der von Gott in seinem Dienst für die Welt eingesetzt war und theologisch formulierte Ziele (Friede, Gerechtigkeit, reine Lehre, christliche Erziehung) umzusetzen hatte. ${ }^{22}$

Davon unterschied sich Jean Bodins Konzept der Souveränität, die der religiösen Rückbindung nicht entbehrte, aber im Wesentlichen innerweltlich begründet war und nicht mehr in der imitatio Christi auf die Rechtsprechung in einer ein für alle Mal geordneten Welt zielte, sondern auf die Gesetzgebung in dynamisierten Nationalgesellschaften. ${ }^{23}$ In der Notlage der französischen Religionskriege legte Bodin 1576 die Six livres de la république vor, die 1586 auch in seiner eigenen lateinischen Übersetzung De republica libri sex erschienen. Zum Kernbegriff machte Bodin das - wie erwähnt - bereits gebräuchliche Wort «souverain». Allerdings verstand er unter «souveraineté» nicht mehr (nur) die höchstrichterliche Entscheidungsgewalt, sondern die Kompetenz-Kompetenz desjenigen (oder derjenigen), von dem allein alle Gewalt und alle Hoheitsrechte im Staat ausgingen, also des Inhabers des Gewaltmonopols, das Bodin als Erster zur Grundlage politischer Ordnung erklärte. ${ }^{24}$

Im wichtigsten Kapitel 1, 8 definierte Bodin - als Erster, wie er bemerkt die «souveraineté» als "puissance absolue \& perpétuelle d'une République, que les Latins appellent maiestatem». ${ }^{25}$ Die lateinische Übersetzung von «souveraineté» durch «maiestas» war gleichsam ein usurpatorischer Akt: Der Titel «Sa Majesté» war herkömmlich dem Kaiser vorbehalten gewesen und wurde erst seit den 1550er Jahren auch vom französischen König beansprucht. ${ }^{26}$ Die Souveränität ist seit Bodin ungeteilt, zeitlich unbegrenzt, durch keine andere innere oder äussere Gewalt limitiert und dem gesetzten Recht nicht unterworfen. Im Unterschied zur Tradition und zum eigenen früheren Werk, insbesondere zur Metbodus ad facilem bistoriarum cognitionem von 1566, bildete die Souveränität nicht nur das zentrale, als neuartig erkannte und deklarierte Thema des Buches, sondern ihr Inhaber wurde auch

22 Wesel-Roth, Erastus, $120 \mathrm{f}$.

23 Spitz, Bodin, 21-23; Bernard, Du roi juge.

24 Quaritsch, Souveränität, 36.

25 Bodin, République, 1, 179 (1, 8); vgl. Bodin, De republica, 78: «Maiestas est summa in cives ac subditos legibusque soluta potestas.»

26 Giesey, The King Imagined, 230f. (51f.); für England: Wende, Herrscherbild, 68, wo "Your Majesty» offenbar schon unter Heinrich VII. üblich wurde. 
erklärtermassen absolut, über das Gesetz erhaben - was Calvin durchaus konventionell noch mit Willkür identifiziert hatte. Dagegen hielt Bodin in einem positiven Sinn nur den für «absolument souverain, qui ne tient rien, apres Dieu, que de l'espee» - «qui post Deum immortalem subditus sit neminis. ${ }^{27}$ Die oberste Gewalt war unmittelbar zu Gott, sie durfte durch keine fremde - geistliche oder weltliche - Macht eingeschränkt sein, insbesondere also nicht durch die Universalmächte Reich und Papstkirche. Ebenso waren die Souveräne nicht länger auf Rat und Zustimmung von ständischen Institutionen und anderen inneren Machtträgern angewiesen. Denn sie mussten ihre Kernkompetenz uneingeschränkt ausüben können, nämlich «qu'ils puissent donner loy aux sujects, et casser ou aneantir les loix inutiles, pour en faire d'autres» und zwar «selon l'exigence des cas, des temps, \& des personnes»). ${ }^{28}$ Altes Recht war nicht länger per se gutes Recht, sondern erst nach der Prüfung durch den Fürsten, der darüber entschied, ob es noch nützlich oder durch den politisch-gesellschaftlichen Wandel überholt war. Kriterium dafür war die salus publica, das Gemeinwohl im Sinn Ciceros (De Legibus, 3, 8), und die Zwänge, die sich ergaben, wenn sie bewahrt werden sollte, was stets oberste politische Priorität hatte: «necessité [...] n'a point de loy [...] et n'y a loix si excellentes soyent elles, qui ne souffrent changement, quand la necessité le requieros. ${ }^{29}$ Die Entscheidung darüber, was die salus publica erforderte, lag allerdings allein im freien Ermessen des Souveräns, das sich in der Ediktformel «Car tel est notre plaisir» am Ende einer grande lettre patente ausdrückte ${ }^{30}$ - eine Formulierung, die nicht nur an die kaiserliche Lex regia erinnerte, sondern auch an Calvins Antwort auf die Frage: «Weshalb hat Gott so gehandelt?» - «Pource qu'il l'a voulus, ${ }^{31}$

Die souverän, ohne Mitsprache der Untertanen ausgeübte Kompetenz der Gesetzgebung bildete, und hierin war Bodin tatsächlich ein wegweisender Pionier, das Wesen politischer Herrschaft: «le poinct principal de la majesté souveraine, et puissance absolüe, gist principalement à donner loy aux sujects en general sans leur consentement. $)^{32}$ Deshalb stand die Legisla-

27 Bodin, République, 1, 229 (1, 9); ders., De republica, 108 (1, 9).

28 Bodin, République, 1, 191f., 198f., 208 (1, 8).

29 Ebd., 4, 102f. (4, 3).

30 Ebd., 1, 191f., 198f. (1, 8).

31 Calvin, Institutio, 2, Sp. 488; für die Lex regia: Digesten, 1, 4, 1; für die beliebige Satzbarkeit vgl. den Beitrag von Raja Sakrani in diesem Band, 375-424.

32 Bodin, République, 1, 204 (1, 8). 
tive nicht nur an erster Stelle, sondern umfasste programmatisch alle anderen Kompetenzen, wo Bodin in Kapitel 1, 10 die «vrayes marques de la souveraineté» aufzählte : «à parler proprement on peut dire qu'il n'y a que ceste seule marque de souveraineté, attendu que tous les autres droits sont compris en cestui là». ${ }^{33}$ Ausdrücklich hielt er ebenfalls fest, dass das herkömmliche Hauptattribut der Obrigkeit, die Rechtsprechung («faire justice»), kein Zeichen der Souveränität sei. ${ }^{34}$ Dagegen zählte Bodin die vier nächstwichtigsten Kompetenzen auf: das exklusive Recht, Krieg zu führen und Bündnisse oder Frieden zu schliessen («bellum indicere, aut pacem inire»), die Einsetzung von Regierung und Beamten («magistratus mandare»), die Entscheidung als höchstrichterliche Berufungsinstanz («extrema provocatio») und das Begnadigungsrecht («contra vim legum ac iudiciorum liberare»). Darauf folgen die eigentlichen, fiskalischen Regalien und weniger zentrale Hoheitsrechte bis hin zum Titel «Majestät». ${ }^{35}$ Auch wenn dies zum Teil herkömmliche Majestätsrechte waren, verstand Bodin Herrschaft gerade nicht mehr als deren Summe, sondern als das eine, umfassende und ursprüngliche Recht, zugleich auch die Kompetenz-Kompetenz des Herrschers, der allein entschied, welche Bereiche staatlich waren und damit seiner Verantwortung oblagen.

Mit diesem Ansatz brachte Bodin erstmals die inneren, staatsrechtlichen Aspekte der Souveränität mit den äusseren, völkerrechtlichen in einer unauflöslichen Verbindung zusammen. Eine weitere Konsequenz der unteilbaren, von der Gesetzgebung ausgehenden Souveränität war die Absage an das aristotelisch-thomistische Ideal der Mischverfassung - und damit an die gängige Interpretation von Dauer und Erfolg der allgemein bewunderten Modelle Sparta, Rom und Venedig. Gar als absurd und, qua Majestätsverbrechen, als todeswürdig verwarf Bodin die Mischverfassung dann, wenn sie - wie in seiner Zeit oft üblich - zur Interpretation der gemässigten Monarchie in Frankreich herangezogen wurde. ${ }^{36}$ "L'estat de la France est simple, et pure Monarchie»: Weder die (angeblich demokratischen) Generalstände noch die (vermeintlich aristokratischen) Institutionen Parlament oder Cour des Pairs beschränkten den König in irgendeiner Weise - die

33 Ebd., 1, 309 (1, 10).

34 Ebd., 1, 299 (1, 10).

35 Ebd., 1, 306-340 (1, 10); auf Lateinisch ders., De republica, 153-173.

36 Vgl. für diese Deutung Frankreichs die Belege bei Maissen, Geburt, 48f., 78, 81, sowie unten, Anm. 99-127. 
ihnen angehörten, seien alle schlichte, demütige Untertanen. ${ }^{37}$ Nichtsdestoweniger handelte es sich, auch normativ, um eine «Monarchie royale ou legitime [...] demeurant la liberté naturelle et proprieté des biens aux sujects». Der König hielt sich aus freien Stücken an das Naturrecht, das ihm gebot, den Besitz der Untertanen zu respektieren, wie das weder in der despotischen «Monarchie seigneuriale» noch in der illegitimen «Monarchie tyrannique» der Fall war. ${ }^{38}$ Während die Untertanen dort sklavenähnlich lebten, herrschte in der «Monarchie royale» wahre Freiheit: «la vraye liberté populaire ne gist en autre chose sinon à jouïr de ses biens en seureté, et ne craindre qu'on face tort à l'honneur, ni à la vie de soy, de sa femme, ni de sa famille. $\aleph^{39}$ Die so verstandene personelle Freiheit und Sicherheit sei der Inhalt dessen, was der Souverän als salus publica anpeilen sollte, und bilde insofern auch die theoretische Grenze absoluter Herrschaft. Doch war es der Souverän allein, der im Zweifelsfall zwischen den Prinzipien Eigentumsgarantie und Staatsraison entschied: «Toutefois, si la necessité est urgente, en ce cas le Prince ne doit pas attendre l'assemblee des estats, ni le consentement du peuple, duquel le salut depend de la prevoyance, et diligence d'un sage Prince. $\rangle^{40}$

Konsequenterweise lehnte Bodin Widerstandsrecht und Tyrannenmord eindeutig ab. Ausnahmen gab es nur dann, wenn sich der Widerstand gleichsam aussenpolitisch gegen Usurpatoren richtete oder durch Gleichrangige, also Souveräne, vollzogen wurde. Die Argumentation hingegen, wie sie etwa die Hugenotten nach der Bartholomäusnacht vorbrachten, «fait revolter les vrais subjects de l'obeissance qu'ils doyvent a leur Prince souverains.4' Bei dieser schon rein formal stark - auf andere Souveräne, also auf den äusseren Krieg - eingeschränkten Befähigung zu Widerstand ging es Bodin nicht, um einen Freipass für den Souverän, dem die ethische Einbindung guter Herrschaft mit der allgemeinen Unterstellung unter göttliches und natürliches Recht deutlich gemacht wurde. Seine dezidierte Haltung war das Produkt der Religionskriege und der monarchomachischen Traktate, denen sich Bodin schon im Vorwort entgegenstellte, weil sie «sous voile d'une exemption de charges, et liberté populaire, font rebeller les sujets contre leurs Princes naturels, ouvrans la porte à une licentieuse

37 Bodin, République, 2, 21-23 (2, 1).

38 Ebd., 2, 34f. (2, 2), vgl. auch 35-67.

39 Ebd., 6, $161(6,4)$.

40 Ebd., 1, 201 (1, 8); auch $221 \mathrm{f}$.

41 Ebd., 1, 198 (1, 8). 
anarchie, qui est pire que la plus forte tyrannie du monde». ${ }^{42}$ Anarchie ist schlimmer als Tyrannis, und damit ist das exzessive Ausüben von kontraktualistischen Kontrollrechten gefährlicher als das exzessive Ausüben der Souveränität. Sie ist im schlimmsten Fall das geringere Übel als ihre Alternativen, im besten der grössere Gewinn. Damit brach Bodin dezidiert mit der mittelalterlichen, noch im 16. Jahrhundert dominierenden kontraktualistischen Tradition und namentlich mit ihrer monarchomachischen Erneuerung und Präzisierung, die etwa in den Vindiciae contra tyrannos den Herrscher durch zwei Verträge mit Gott und dem Volk band und damit auf einen Amtsträger reduzierte. ${ }^{43}$ Während im monarchomachischen Denken und in der ganzen politiktheoretischen Tradition die Tyrannis eine objektive Herausforderung war, deren Gefahr es durch moralische Anweisungen und eine kluge Verfassung einzuschränken galt, war sie für Bodin nur noch ein Schreckbild, das der sich selbst kontrollierende Fürst sich vor Augen halten musste.

Auch wenn Bodin ständische Mitspracherechte nicht schätzte, so erkannte er sie durchaus in seiner Zeit: «L'Empire d'Allemagne est une Aristocratie», da die im Reichstag vereinten, souveränen Stände den Kaiser wählten und einen Krönungseid schwören liessen. ${ }^{44}$ Was im mittelalterlichen Verständnis als Mittler zu Gott die Quelle aller irdischen Herrschaft und Rechtsprechung gewesen war, wurde so - da de facto nicht absolut - zu einer untergeordneten Regierungsinstanz in einem partikularen, wenig effizienten Verfassungsgebilde. Dieser Kaiser war keine Universalmacht mehr, ebenso wenig wie der Papst, sondern repräsentierte (bestenfalls) die Souveränität seines Reiches, nicht seine eigene, in einer Staatenwelt von gleichrangigen Souveränen. In noch umfassenderem Sinn erschien der Okzident nicht länger als Corpus cbristianum mit einer pyramidalen Ordnung der vor allem adligen Herrschaftsträger, deren Hierarchie sich aus ihren unterschiedlichen Privilegien und Freiheiten ergeben hatte. Stattdessen trennte Bodin streng dichotomisch zwischen ganz wenigen absolut Souveränen und deren vielen Untertanen: Zu Letzteren zählten auch Herzöge und Grafen, erst recht alle anderen Lehnsträger. Wie dem souveränen Gott Calvins der ohne Werkgerechtigkeit machtlose, aber mit guten Gründen auf Gnade hoffende Mensch gegenüberstand, so dem souveränen Fürsten Bodins der Untertan, der ohne die Mitspracherechte einer Mischverfassung, aber mit

42 Ebd., 1, 14 (préface); vgl. auch ebd., 6, 145f. (6, 4).

43 Brutus, Vindiciae.

44 Bodin, République, 1, 252-254 (1, 9); 2, $21(2,1), 99-106(2,6)$. 
guten Gründen auf eine das Naturrecht respektierende «Monarchie royale» hoffen konnte.

Diese Logik klang allerdings im 16. Jahrhundert kaum für alle Adressaten überzeugend. Mussten nicht die Hugenotten gerade von ihrem Souverän nicht eher eine Bartholomäusnacht befürchten als selbstlose Sorge um die salus publica? Drohte den Hochadligen, die mit ihren Privatheeren den wahren Glauben verteidigten, unter einem souveränen König nicht der Verlust ihrer jahrhundertealten regionalen Einflusssphären? War der Klerus nicht freier gewesen in seiner herkömmlichen Zwischenposition zwischen einem fernen, aber respektierten Papst und einem König, der nun im Namen der gallikanischen Landeskirche die Entscheidung über Pfründen und Steuern an sich zu ziehen wusste? Mussten nicht Städte und andere Kollektive ihre historischen Privilegien verlieren, wenn sie dem Monarchen nicht willfahrten? Auch wenn man vom universalistischen Anspruch von Papst und Kaiser schweigt, blieben zahlreiche Akteure, die von der Umsetzung des Souveränitätskonzepts wenig Gutes zu erwarten hatten. Wie konnten sie trotzdem dafür gewonnen oder mindestens ruhig gestellt werden?

\section{Ikonografische Vermittlung von politischer Theorie}

Bodins im Prinzip rein innerweltliche Begründung von Herrschaft schloss nicht aus, dass gerade den Kirchen im Zuge der Konfessionalisierung weite, ja wachsende Einflussbereiche zugestanden wurden. Entscheidend war allerdings, dass der Souverän kraft seiner Kompetenz-Kompetenz diese Sphären und die klerikalen Zuständigkeiten zusehends festlegen konnte. Umgekehrt blieb er aber wegen der auch für Bodin noch selbstverständlichen religiös-ethischen Rückbindung politischer Herrschaft weiter auf Legitimationshilfen angewiesen, die ihn etwa als «roi très chrétien» und Beschützer des wahren Glaubens auswiesen. Zumindest als Wahrer eines christlichen Friedens, in den der Souverän neben der (katholischen) Mehrheit auch eine (hugenottische) Minderheit einschliessen konnte, erschien der König auch in den Augen der (zumeist katholischen) französischen Politiques, zu denen Bodin zählte.

Die christliche Tradition lieferte aber nicht nur theologische und rhetorische Argumentationsmuster zur Legitimation zusehends säkularisierter Herrschaft, sondern auch Bilder - im Sinn der reichen biblischen und mittelalterlichen Metaphorik ebenso wie in einer vielfältigen und populären Ikonografie. Beides trug zu einem «Übergangsdiskurs» bei, in dem tradi- 
tionelle und namentlich religiöse Vorstellungen dabei halfen, das neuartige und erstmals klar definierte Konzept der Souveränität zu erklären, zu vermitteln und zu legitimieren. Berührungspunkte gab es viele, da die Analogien zwischen weltlichen Herrschern und Weltenherrscher seit langem die Bildrepertorien prägten. Zumindest die katholische Ikonografie hatte trotz dem zweiten Gebot keine Hemmungen bekundet, die absolute Gestalt und Macht Gottes bildlich zu fassen. Seit der Renaissance ergänzten und verstärkten Rekurse auf die antike Götterwelt und Ikonografie solche Bildtraditionen. Der Rückgriff darauf erlaubte eine sakrale Erhöhung und Legitimation des Säkularen, wie sie etwa im Islam nicht denkbar oder zumindest nicht darstellbar waren, weil die demiurgische Kraft des Malens als viel bedrohlicher empfunden wurde. Eine Vermischung von Weltlichem und Göttlichem blieb deshalb für Muslime nicht «nur» auf das Bild beschränkt, sondern galt auch in der Realität und musste deswegen unbedingt verhindert werden. ${ }^{45}$

Im Folgenden wird davon ausgegangen, dass die antike und vor allem die christliche Ikonografie für die politische Bildsprache des 16. und 17. Jahrhunderts eine entscheidende Rolle spielte, um die komplexen Aspekte der Souveränität durch vertraute Assoziationen gleichsam volkspädagogisch einer breiteren Bevölkerung zu vermitteln. An die Stelle der juristischen Ausführungen oder ergänzend $z u$ diesen trat die emotionale Sprache vor allem von Familienbeziehungen, die in einer durch fürstliche Dynastien geprägten Staatenwelt auf eingängige Weise das Verhältnis der Souveräne untereinander wie zu ihren Nationen repräsentierten. Personifikationen dienten bereits seit der Antike der allegorischen Vermittlung abstrakter Konzepte; nun erhielten sie neue politische Bedeutungen. Dasselbe galt für die christlich-biblische Sprache, die eine Fülle von erotischen Metaphern über Ehe, Jungfräulichkeit, Scheidung oder Vergewaltigung mitbrachte. Sie konnten als Analogien für diejenigen politischen Verhältnisse und Entwicklungen herangezogen werden, die als Staatsbildung gedeutet werden: Umsetzung des Souveränitätskonzepts durch die Errichtung des Gewaltmonopols, Entwicklung und Legitimation einer innerweltlichen Staatsräson, Trennung von Person und Amt sowie von Herrscher und Volk/Territorium, Ausbildung einer Staatenordnung.

Dies alles war kein zielstrebig gelenkter und teleologisch sich vollziehender Prozess, sondern eine Entwicklung mit vielen Alternativen, in der die heterogenen Ideen der Souveränitätslehrer kompromissreich mit den poli- 
tischen Realitäten von Tradition und Autonomie in provisorische Übereinstimmungen gebracht werden mussten. Insofern bot gerade eine ebenfalls vieldeutige und traditionsreiche Bilderwelt - zumal die Marienikonografie die Möglichkeit, die Probleme zu diskutieren und die Positionen zu markieren, die sich im Zusammenhang mit revidierten Machtkonstellationen und mit der Person des Souveräns ergaben. So hat Ernst Kantorowicz in seiner bahnbrechenden Studie über die zwei Körper des Königs gezeigt, dass eine selten explizit formulierte, in der christlichen Zweinaturenlehre («una persona, duae naturae») begründete politische Theologie eine Grundlage lieferte, um den sterblichen Körper des Herrschers von der in ihm vorübergehend verkörperlichten, aber unsterblichen dignitas und damit von der ihm unterstellten politischen Körperschaft nicht nur zu unterscheiden, sondern dieses Verhältnis künstlerisch $\mathrm{zu}$ inszenieren und $\mathrm{zu}$ repräsentieren. $^{46}$

\section{Allegorien}

Ähnlich wie in Kantorowicz' Arbeiten wird im Folgenden nicht grundsätzlich zwischen dem antik-heidnischen und dem mittelalterlich-christlichen Bildangebot unterschieden, die in der Frühen Neuzeit für politische Standortbestimmungen kreativ kombiniert wurden. Dieses Potenzial wird unten exemplarisch an einigen Motiven und an ihren Verwendungen vorgeführt, die mit den Metaphern von Familienstand, Ehe und auch gewalttätiger Erotik spielen. Grundlage dafür war die Personifikation des Gemeinwesens, wodurch dieses potenziell politisiert wurde, wie das in Antike und Mittelalter noch nicht denkbar gewesen war, obwohl hier die Anfänge der Allegorien lagen. Da abstrakte Begriffe im Lateinischen zumeist weiblich sind, wurde es bereits in der Antike üblich, sie als Frauen darzustellen. Nicht zuletzt durch die Verbindung von antiker Bildung und christlicher Lehre in den Werken etwa von Martianus Capella, Cassiodor oder Boethius blieb diese Praxis im ganzen Mittelalter populär: Trat bei Boethius Pbilosopbia dem Dichter tröstend entgegen, so triumphierte bei Petrarca Fama. Auch Herrschertugenden schmückten allegorisch manche Darstellung. So finden sich auf Ambrogio Lorenzettis Buon Governo in Siena neben den Charakteristika des guten Regiments wie Pax oder Concordia die Kardinal- und theo-

46 Kantorowicz, Zwei Körper; für das Athanasianische Symbol: ebd., 40f. Vgl, auch Boureau, Le simple corps du roi. 
logischen Tugenden sowie die Magnanimitas dargestellt. ${ }^{47}$ Ebenfalls weiblich sind die Personifikationen von Städten und Regionen, entsprechend ihrem grammatikalischen Geschlecht im Lateinischen. Antike Medaillen zeigten Antiochia, Roma oder Constantinopolis mit einer Mauerkrone oder gewappnet mit einem Helm. ${ }^{48}$ Gewisse Parallelen gibt es ferner zwischen dem römischen Genius einer Stadt und dem christlichen Patron, der als Stadtheiliger oder Landesheiliger kultische Verehrung genoss. Manche Stadtheilige waren weiblich. Insbesondere Maria wurde an sehr vielen Orten verehrt, etwa in Strassburg, Florenz oder Siena. ${ }^{49}$ Lokalspezifische Heilige wie Ursula in Köln brachten ebenfalls eine vielfältige ikonografische Tradition hervor.

Insofern ist die Landespersonifikation ein altes Phänomen: Eine unterwürfige Germania oder Britannia konnte man bereits in der Antike bewundern, wie die Römer auch sonst besiegte Völker und Provinzen in Allegorien darstellten. ${ }^{50}$ Ähnlich huldigt in dem berühmten Evangeliar Ottos III. Germania mit Sclavinia, Gallia und Roma dem Kaiser. In dem ebenso berühmten Perikopenbuch Heinrichs II. sieht man, wie Christus ihn und Kaiserin Kunigunde krönt, während Germania, Roma/Italia und Gallia den Tribut entrichten. $\mathrm{Zu}$ diesen antiken geografischen Allegorien traten im Spätmittelalter neue Personifikationen, die auf die Völkerwanderungsreiche zurückgingen und sich nicht nur auf die Region, sondern auch auf das politische Gemeinwesen bezogen. Dem entsprach, dass zeitgenössische Juristen wie Baldus de Ubaldis körperschaftlich verfasste Gemeinschaften wie die Kirche oder das Imperium als unsterbliche universitates und rechtsfähige personae fictae erfassten. ${ }^{51}$ So erklangen im Hundertjährigen Krieg bei Christine de Pisan, Jean de Montreuil und Nicolas de Clamanges die Wehklagen der Francia, die ihr Witwendasein beklagt oder von ihren eigenen Söhnen verletzt wird. Sehr wahrscheinlich erinnerten sich die Autoren dabei an das alttestamentliche Lamento etwa von Jeremia, dass die Jungfrau Israel wieder auf den rechten Weg zurückfinden möge. ${ }^{52}$ In Alain Chartiers Quadriloque invectif (1422) bittet France im Liliengewand ihre Kinder, die drei

47 Skinner, Macht.

48 Bühl, Constantinopolis und Roma.

49 Vgl. Sinding-Larsen, Christ in the Council Hall, 52f.; Wolters, Bilderschmuck, 237, und Skinner, Macht, 102. Möglicherweise ist die Heilige ebenfalls Maria, die auf einem Gemälde Andreas di Cione, entstanden zwischen 1323 und 1349, den Florentinern beisteht, die den vorübergehenden Stadtherren Walter von Brienne vertreiben.

50 Dresser, Britannia, 27, Abb. 4.

51 Koschorke, Staat, 85-88; Canning, The Political Thought, 93-130.

52 Jeremia $31,21$. 
Stände, sich wieder zu versöhnen. In illuminierten Handschriften bekam sie dank Chartiers genauer Beschreibung auch eine erste Gestalt: blond, gekrönt, mit Zepter und Lilienmantel. Manchmal war sie auch von ihren Kindern umgeben, so in einer Illumination von 1484, auf der sie Karl den Grossen und seinen Vater Pippin der Dreieinigkeit als ihre Söhne vorstellt. Als Vorbild der Muttergestalt, die wenig später auch im Reich zu greifen war, kann die Allegorie der Caritas gelten. ${ }^{53}$ Die metaphorische Rede von politischen Kindern war schon alt. Unter Berufung auf Seneca und die gleich zu erörternden Epheserverse bezeichnete Petrarca die Bürger als Kinder, wenn nicht als eigener Leib des Fürsten; er müsse die Respublica deshalb wie einen Sohn lieben, ja wie sich selbst. ${ }^{54}$

\section{Das mystische Ehepaar}

Doch wichtiger als die Mutterfigur sollte die Gattin werden. Schon im Alten Testament wurde das Verhältnis Israels zu seinem Schöpfer oft als Ehe gezeichnet. ${ }^{55}$ Für Ezechiel führte die Phase der Liebe zu einem Vertrag, wodurch die Geliebte sein wurde. Er schmückte sie mit einer Halskette, Ohrringen und einer schönen Krone, und sie blühte als Königreich auf. ${ }^{56}$ Doch das war stets eine krisenanfällige Liebesbeziehung, denn die schöne Gattin verehrte andere Götter, beging also Ehebruch. ${ }^{57}$ Bei Jeremia beklagt sich Gott, Israel habe ihn verachtet wie eine Frau ihren Liebhaber. ${ }^{58}$

Entscheidend für die Metaphorik der mystischen Ehe wurden allerdings weniger die alttestamentlichen Bezüge als der Epheserbrief 5,21-32. Paulus

53 Beaune, Naissance, 314-317, 334f.; für die beiden Söhne: Abb. 10 (vor 25); auch Blumenfeld, Enemies Without, 9-11. Für das Reich Heinrich Bebel, Oratio ad Regem Maximilianum (1501), wo Germania die Mutter des Kaisers ist, aber auch des Verfassers, vgl. Brandt, Germania, 42f. Paul Fleming, Epistula Germaniae Exsulis, Leipzig 1631, lässt die Personifikation ihre Kinder anreden, nämlich die Reichsstände und den Kaiser «als ein treuer Sohn»; vgl. ders., Lateinische Gedichte, 186-192, sowvie für die deutsche Version: Brandt, Germania, $52 \mathrm{f}$.

54 Petrarca, Epistole, 778: «Amandi tibi sunt igitur cives tui ut filii, imo, ut sic dixerim, tanquam corporis tui membra sive anime tue partes: unum enim corpus est res publica cuius tu caput es. [...] universamque rem publicam non quantum filium modo vel parentes, sed quantum temet ipsum amare debes.»

55 Jesaja 54,5f.

56 Ezechiel 16,8-14.

57 Ezechiel 16,20, 25-28.

58 Jeremia 3,20; als Heilsbotschaft für die Wiederaufnahme in die Ehe, s. Jesaja 62,3-5. 
postulierte die Unterordnung der Frau unter den Mann wie des Leibes unter das Haupt und der Kirche unter Christus. Zugleich forderte er die Männer auf, ihre Frauen so zu lieben wie Christus die Kirche geliebt habe, die heilig sein solle und makellos. «Keiner hat je seinen eigenen Leib gehasst, sondern er nährt und pflegt ihn, wie auch Christus die Kirche. Denn wir sind Glieder seines Leibes. Darum wird der Mann Vater und Mutter verlassen und sich an seine Frau binden und die zwei werden ein Fleisch sein. Dies ist ein tiefes Geheimnis; ich beziehe es auf Christus und die Kirche. $\rangle^{59}$ Augustin folgerte hieraus, dass die Kirche Christi Gattin sei, mit dem sie im Fleisch (dem Abendmahl) eins werde: «Omnis enim Ecclesia sponsa Christi est, cuius principium et primitiae caro Christi est: ibi iuncta est sponsa sponso in carne. $\rangle^{60}$ Bossuet erllärte das Mysterium später dahingehend, dass es erlaube, die Kirche mit Christus im Geist und in der Gnade vereint zu denken und zugleich getrennt von ihm, damit ihm die gebührenden Ehren erwiesen werden können: «Die Bezeichnung als Gattin unterscheidet, um zu verbinden; die Bezeichnung als Körper vereint ohne zu vermischen und eröffnet im Gegenteil die unterschiedlichen Zuständigkeiten: Einheit in der Vielfalt, ein Abbild der Trinität, das ist die Kirche..1 ${ }^{61}$

Dieselbe Beziehung wurde, im Kleineren, zwischen dem Bischof und seiner Kirche postuliert. Der Bischofsring galt insofern als Ehering, bei dessen Verleihung der Erzbischof dem neu Gewählten sagte, er empfange ihn als Zeichen desjenigen Glaubens, in dem er seine Gattin beschützen solle, die heilige Kirche («sponsam Dei sanctam videlicet ecclesiam»). ${ }^{62}$ Für Hugo von St. Viktor stellte der Ring ein Glaubenssakrament dar, in dessen Zeichen die Prälaten der Kirche als Lehrer und Beschützer vermählt würden. ${ }^{63}$ Gregor IX. (1167-1241) nannte diese Beziehung in den Dekretalen eine spirituelle Ehe, «spirituale coniugium, quod est inter episcopum et ecclesiam».$^{64}$ Huguccio da Pisa $(† 1210)$ führte das Bild weiter aus: Die Wahl

59 Epheser 5, 31 bezieht sich als Zitat auf die Schöpfungsgeschichte mit Adam und Eva und damit auf das Urbild der Ehebeziehung, Genesis 2,24: «erunt duo in carne una.» Vgl. auch Epheser 4,15f. für Christus als Haupt, von dem aus der Körper zusammengefügt sei.

60 Augustinus, In epistolam Ioannis ad Parthos, PL 35, Sp.1990 (II, 2).

61 Bossuet, Correspondance, Bd. 1, 70; übersetzt aus Descimon, Fonction, 1129.

62 Ordo 35 B.35, zitiert nach Benson, Bishop-Elect, 123.

63 Hugo von St. Viktor, De Sacramentis, PL 176, Sp. 438: «Anulus sacramentum fidei significat, quo sponsa Christi ecclesia subarrata est, cuius custodes et paedagogi episcopi sunt et praelati.»

64 Gregor IX., Decretales, 97 ( $\mathrm{X}, 1,7,2)$. 
des Bischofs schaffe zwvischen Wählenden und Gewähltem die Verlobung als Vertragsverhältnis aus wechselseitigem Einverständnis («vinculum ex mutuo consensur)), so dass der Bischof nun Gatte seiner Kirche oder ihrer Kleriker heisse und sie seine Gattin. Doch vorerst respekticrt er noch die Jungfräulichkeit der Verlobten; das heisst, er lässt die Rechte und Besitzungen seiner Kirche unversehrt. Wie in der weltlichen Ehe brauche es noch das Einverständnis dort der Eltern, hier des Papstes, damit er über Hab und Gut der Gattin verfügen kann, also eigentlich ihre Mitgift. Erst mit der päpstlichen Bestätigung werde die Ehe gleichsam fleischlich («quasi carnali commixtione») vollzogen, und die bischöfliche Verwaltung seiner Kirche entspreche dem regelmässigen Beischlaf. ${ }^{65}$ Organologisch betrachtet war der Bischof das Haupt; die Glieder waren diejenigen, welche die Konsensehe tatsächlich eingingen - also nicht die ganze Diözese, sondern die Wähler, das Domkapitel. ${ }^{66}$

Erotischen Analogien begegnen auch in der franziskanischen Liebestheologie, die sich vor allem auf das Hohelied stützte, wobei in unserem Zusammenhang vor allem die Verse 4,7-13 wichtig sind. Seit dem frühen 12. Jahrhundert wurden diese Passagen als Liebesbeziehung zwischen Christus und seiner Gattin interpretiert, die nun nicht mehr nur - wie seit den Kirchenvätern Origenes und Augustin - als Ecclesia oder Seele gedeutet vurde ${ }^{67}$ sondern neu, etwa bei Rupert von Deutz, mit Maria als Mater ecclesica und zugleich jungfräulicher Braut identifiziert wurde. ${ }^{68}$ In typologischer Parallele zur Beziehung Salomos (des vermeintlichen Verfassers des Hohelieds) mit seiner Geliebten beschrieb Honorius von Autun († ca. 1151) gar die Heilsgeschichte als Liebesgeschichte zwvischen Gott und Ecclesia. Diese Beziehung führe vom ersten Treffen der Verliebten (Gottes Bund mit Abraham) über erste Gespräche und Berührungen (Fleischwerdung Christi) zum Kuss (Friedensverkündigung an die Apostel) und zum Beischlaf, nämlich zur perfekten Einheit im Himmel. ${ }^{69}$

65 Huguccio da Pisa, Summa decretorum, D. 63 c. 10; zitiert nach Benson, Bishop Elect, $121 \mathrm{f}$.

66 Gierke, Genossenschaftsrecht, Bd. 3, 252f.

67 King, Origen, 266-270; auch Tromp, Ecclesia Sponsa, 5; und Schelkens, Ecclesia sponsa, 152.

68 Honorius von Autun, Sigillum beatac Mariac, PL 172, Sp. 499D: «Gloriosa virgo Maria typum Ecclesiae gerit», zitiert nach: Flor, Symbolik, 97f.; vgl. auch Verdier, Couronnement, $83 \mathrm{f}$.

69 Honorious von Autun, Expositio in Cantica Canticorum, PL 172, Sp. 350f.; vgl. Astell, Song, 31-33; Lavin, Maria-Ecclesia, 160. 


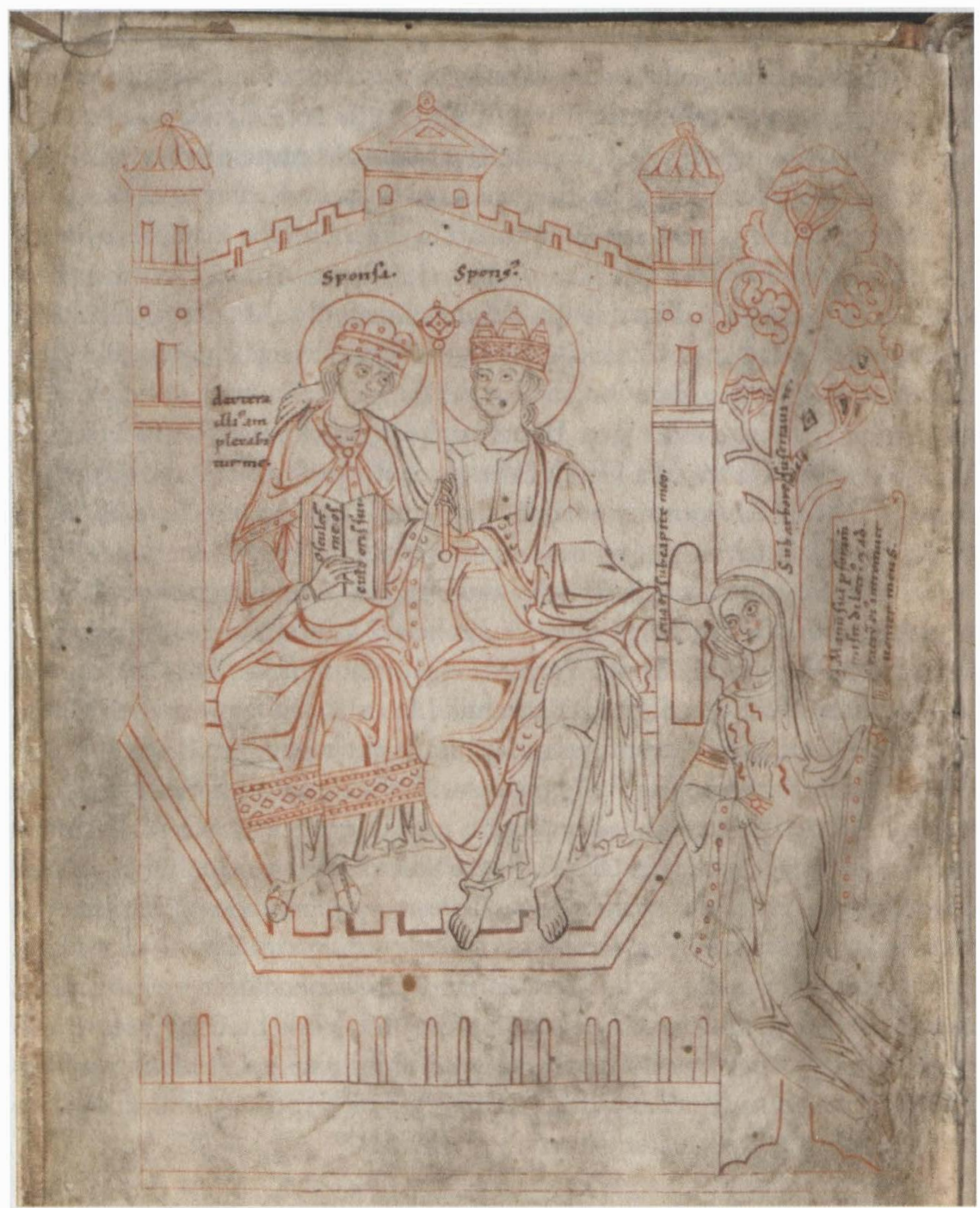

Abb. 1: Honorius von Autun, Expositio in Cantica Canticorum (Opera exegetica).

Um 1170 schmückte ein Abschreiber den Hoheliedkommentar des Honorius von Autun mit einem Bild des Königs (Salomo), der die Königin (von Saba) umschlungen hält - zugleich die Präfiguration von Jesus und Ecclesia. (Abb. 1) Zur Erläuterung des Bilds wird Hohelied 2,6 zitiert: «Laeva eius sub capite meo [...] et dextera illius amplexabitur me» - seine Linke liegt unter meinem Kopf, die Rechte wird mich umarmen. Hicr wird 
das so dargestellt, dass Salomo/Christus mit der Rechten die himmlische Kirche im Gebäude umarmt, während er die Linke auf die ausserhalb stehende weltliche Kirche legt. Die himmlische Kirche hält ein Buch mit den ersten Sätzen des Hohelieds in der Hand. ${ }^{70}$ Auf diese Stellen geht auch der Bildtyp von Jesus und Maria als Liebespaar zurück, deren erste grosse Version Pietro Cavallini um 1290 als Apsismosaik für Santa Maria in Trastevere schuf. Während Christus das Schriftband mit Veni electa mea hält, zeigt Maria den Text von Hohelied. 2,6: «Laeva eius sub capite meo». Nicht zuletzt über die Beschreibung von Mariä Himmelfahrt in der sehr populären Legenda aurea des Jacobus de Voragine (um 1260) verbreitete sich der Text des Antiphons, der bei dieser Feier gesungen wurde ( Veni electa mea et ponam in te thronum meum, quia concupivi speciem tuam»). Der Bezug wurde dabei erneut auch zum Hohelied und zu Salomo hergestellt (Hld 4,8: «Veni de Libano, sponsa, veni de Libano, veni, coronaberis»). ${ }^{71}$

Die Paarbeziehung von Jesus und Maria/Ecclesia liess sich nicht nur auf Bischof und Diözese übertragen, sondern auch auf die Gesamtkirche. Sie wurde seit dem 12. Jahrhundert mit einem ursprünglich auf die Hostie bezogenen Begriff als Corpus mysticum ecclesiae mit Christus als Haupt aufgefasst. Diese insbesondere durch Thomas von Aquin geprägte Wendung war nicht nur im spirituellen Sinn zu verstehen, sondern meinte auch einen institutionalisierten administrativen Organismus und eine überindividuelle, aber rechtsfähige und rechtlich unsterbliche Korporation (universitas): die persona ficta oder persona repraesentata als corpus iuridicum. ${ }^{72}$ Damit wurde das Corpus Christi, der in der Hostie verehrte und vermittelte persönliche Leib des Erlösers, getrennt von seinem unpersönlichen, kollektiven Körper, der weltlichen Kirche als Corpus mysticum, obwohl sie im Gefolge des Epheserbriefs noch als «ein Fleisch» bezeichnet worden waren. ${ }^{73}$ Das erleichterte die Säkularisierung des Ehemotivs in dem Sinn, dass nicht nur Christus, sondern auch sein menschlicher Stellvertreter als Partner der Rechtsperson Kirche auftreten, ja mit dem apostolischen Leib der Kirche gleichgesetzt werden konnte. Auf dem Apsismosaik von Alt St. Peter in Rom standen unterhalb von Jesus, Petrus und Paulus der Papst (Innozenz III.) und die

70 Staatsbibliothek München, clm 4550; Glanz, De arte honeste amandi, $140 \mathrm{f}$.

71 Jacobus de Voragine, Legenda aurea, 782f.

$72 \mathrm{Zu}$ den entsprechenden Übertragungen und Umdeutungen Kantorowicz, Zwei Körper, 206-217 und 306-316 («universitas non moritur»); auch Koschorke, Staat, 56f.

73 Kantorowicz, Zwei Körper, 212, hält fest, dass sakramental eigentlich nur die Rede vom Corpus mysticum Christi sinnvoll ist. 
Ecclesia Romana sich zugewandt, mit dem Lamm Gottes als verbindendem Element. ${ }^{74}$ Petrarca machte Roma und Ecclesia zu handelnden Personen, die als «coniunx» ihren «sponsus», nämlich die Päpste Benedikt XII. beziehungsweise Clemens VI., aufforderten, zu ihnen zurückzukehren. ${ }^{75}$ Ähnlich bat Oldradus de Ponte, der Papst möge von Avignon zu seiner Gattin («sponsa») zurückkehren und seine Mitgift wiederherstellen, nämlich das notleidende Patrimonium Petri. ${ }^{76}$ Wilhelm von Ockham hielt zugleich fest, dass dieser Kirchenbesitz nicht dem Papst persönlich gehöre, sondern Gott und der Kirche als mystischem Körper. Deshalb seien diese Besitzungen unveräusserlich. ${ }^{77}$

In der Mitte des 13. Jahrhunderts sprachen Autoren wie Vincent von Beauvais in Analogie zur Kirche vom Corpus reipublicae mysticum und analog vom Corpus morale et politicum oder im Englischen vom «body politic», wenn sie das weltliche Gemeinwesen als juristische Person meinten. ${ }^{78}$ Ebenso wurde das theologische Bild der mystischen Ehe zwischen Christus als dem Haupt und Maria/Ecclesia als dem Körper im 14. Jahrhundert in die politische Sphäre übertragen. ${ }^{79}$ In seinem Kommentar des Codex Iustinianus griff Cino da Pistoia um 1312/14 die Ehemetaphorik auf. Die Wahl des Kaisers durch das Gemeinwesen («respublica») und seine Annahme der Wahl entsprächen einer Ehe in wechselseitigem Einverständnis («consensu mutuo fit matrimonium»), so dass er bereits damit der Rechtsvertreter des Gemeinwesens («praepositus reipublicae») werde. Dieser Vergleich der fleischlichen Ehe mit der geistigen passe gut, meinte Cino; denn wie der Gatte der Verteidiger seiner Ehefrau sei, so sei der Kaiser derjenige des Gemeinwesens. ${ }^{80}$ Enea Silvio Piccolomini, der spätere Papst Pius II., ging 1446 in einem Traktat für Kaiser Friedrich III. so weit, dass der Fürst als Haupt des

74 Paravicini Bagliani, Leib des Papstes, 79f.

75 Petrarca, Epistulae metricae, 36-47 und 134-147.

76 Oldradus de Ponte, Consilia 85, Nr. 1, Lyon 1550, fol. 28v, zitiert nach Kantorowicz, Zwei Körper, 227, Anm. 71.

77 Kantorowicz, Zwei Körper, 216.

78 Ebd., 219-222.

79 Dazu neben De Mattei, Idea democratica, 35-44, und Kantorowicz, Zwei Körper, 218241, Hanley, Monarchic State.

80 Cino da Pistoia, In Codicem, f. 446 (c.7.37, n. 5): «quia ex electione Imperatoris et acceptione electionis reipublicae iam praepositus negari non potest et eum ius consecutum esse, sicut consensu mutuo fit matrimonium [...] Et bona est comparatio iliius corporalis matrimonii ad istud intellectuale: quia sicut maritus defensor uxoris dicitur [...] ita et Imperator Reipublicae.»; dazu Kantorowicz, Zwei Körper, 223f., und Viroli, From Politics, 64f.; vgl. auch Digesten 50, 17, 30: «Nuptias, non concubitus, sed consensus facit.» 
mystischen Körpers der Respublica gehalten sei, sein Leben zu opfern, wann immer das Gemeinwohl es verlange. Die Parallele zu Christus war klar, der als «caput ecclesiae, princeps et rector» sein Leben für die Menschen, also für den mystischen Körper der Kirche, geopfert habe. ${ }^{81}$

Der wohl 1390 verstorbene italienische Jurist Luca da Penne stellte im Rahmen seiner organologischen Verfassungslehre explizit die Analogie zur Ehemetaphorik her, die Huguccio da Pisa für die Bischofswahl genutzt hatte: «Der Fürst ist der Gatte des Gemeinwesens («respublica») gemäss dem Lucan-Zitat: «Der Stadt Vater und ihr Gatte〉. [...] Denn so wie zwischen Gatte und Gattin eine fleischliche und hauswirtschaftliche Ehe geschlossen wird, so wird zwischen dem Fürsten und dem Gemeinwesen eine moralische und politische Ehe geschlossen. Ebenso, wie zwischen der Kirche und dem Prälaten eine geistige und göttliche Ehe, so wird zwischen Fürst und Gemeinwesen eine zeitliche und irdische Ehe geschlossen. Und wie die Kirche im Prälaten und der Prälat in der Kirche ist, so ist der Fürst im Gemeinwesen und das Gemeinwesen im Fürsten. Daher ist die Kirche mit einer politischen Versammlung von Menschen zu vergleichen, und der Papst ist wegen seiner Machtfülle ((plenitudo potestatis) gleichsam ein König in seinem Reich. ${ }^{82}$ Luca da Penne zitierte Gratians Decretum, um die Metaphorik zu erläutern: «Der Bischof ist in der Kirche und die Kirche im Bischof.» Indirekt war das ein Bezug auf den Hl. Cyprian und das Johan-

81 Piccolomini, De ortu et auctoritate, 82: «[...] princeps, qui caput est mystici rei publicae corporis, cum salus communis expostulat, vitam ponere teneatur. Imitandus est enim Christus Jesus, qui [...] ipse quoque, cum esset caput ecclesiae, princeps et rector, ut nobis mortem demeret, voluntariam mortem subivit.» Vgl. Kantorowicz, Zwei Körper, 286. Ähnliche Gedanken finden sich 1607 bei Pierre de Belloy, nach dem der Fürst durch den Krönungseid seine eigene Freiheit dem Gemeinwohl aufopfere, vgl. Descimon, Fonction, 1138.

82 Luca da Penne, Super tres libros codicis, cod. 11, tit. 58, 7, n. 8 (De omni agro deserto): «Princeps est maritus reipublica iuxta illud Lucani [Pharsalia 2, 388, zu Cato] urbi pater urbique maritus. [...] Nam sicut inter virum et uxorem matrimonium carnalem contrahitur, et oeconomicum, sic inter principem et rempublicam matrimonium morale contrahitur et politicum. Item, sicut inter ecclesiam et praelatum matrimonium spirituale contrahitur et divinum [...] ita inter principem et rempublicam matrimonium temporale contrahiter et terrenum. Et sicut Ecclesia est in praelato et praelatus in Ecclesia [...] ita Princeps in republica, et respublica in principe. Unde et ecclesia comparatur congregationi hominum politicae et papa est quasi rex in regno propter plenitudinem potestatis.» Sinnentstellend ist der Fehler «casualem» statt «carnalem» bei De Mattei, Idea democratica, 39; vgl. auch Kantorowicz, Zwei Körper, 214, 224f., 433f.; und allgemein Ullmann, Medieval Idea, insbes. 165-167. 
nesevangelium $(14,10)$ : «Ich bin im Vater, und der Vater ist in mir. $\rangle^{83}$ Mit Blick auf Epheser 5,23 («Der Mann ist das Haupt des Weibes und das Weib der Leib des Mannes») schloss Luca daraus: «Auf dieselbe Art ist der Fürst das Haupt des Reiches und das Reich der Leib des Fürsten.» ${ }^{84}$

Geistliche und weltliche Hierarchie waren parallel gestaltet. Christus und sein Stellvertreter, der Papst, hatten nicht nur einen vorübergehenden, fleischlichen Körper, sondern waren zugleich vereint mit ihrem ursprünglich fremden, immateriellen, mystischen, spirituellen Körper: der Kirche als Gemeinschaft der Gläubigen; und diesem Körper waren sie zugleich als Kopf übergeordnet. ${ }^{85}$ Ebenso besass der Fürst neben seinem sterblichen Körper einen mystischen, moralischen, politischen Körper, die Respublica, die ihm zwar nicht gehörte, ihm jedoch in der Ehe untergeordnet wurde und mit ihm eins war. ${ }^{86}$ Diese mystische Gemahlin brachte Eigentum in die Ehe ein, ihre Mitgift, die der Gatte wohl nutzen, nicht aber veräussern konnte. Dies wurde im Ehegelöbnis festgehalten und analog bei der Weihe von Prälat oder König im Eid, dass er das Eigentum der Kirche oder des Fiskus nicht entfremden werde, das eben nicht ihm, sondern der Angetrauten gehörte. ${ }^{87}$

Die Verpflichtung zeigte sich nicht nur im Recht auf Widerstand und Tyrannenmord, wenn der Herrscher die Respublica wie eine Sklavin behandelte, also als sein Eigentum, und die Ehe auflöste, indem er der Gattin Freiheit und Mitgift raubte..$^{88}$ Auch spätere Autoren wiederholten die Über-

83 Gratian, Decretum, C. 7, VII, qu. 1, zitiert nach Kantorowicz, Zwei Körper, 226 und 434. Vgl. auch die oben erwähnten Stellen Genesis 2,24 und Epheser 5,31: «erunt duo in carne una.»

84 Luca da Penne, Super tres libros codicis, cod. 11, tit. 58, 7, n. 8: «[...] item, sicut vir est caput uxoris, uxor vero corpus viri $[\ldots]$ ita princeps caput reipublicae, et res publica eius corpus.»

85 Paravicini Bagliani, Leib des Papstes, 68-82.

86 Luca da Penne, Super tres libros codicis, cod. 11, tit. 58, 7, n. 8: «Item, sicut [...] homines spirituali corpori spiritualiter coniunguntur, cui corpori Christus est caput $[\ldots]$, sic moraliter et politice homines coniunguntur reipublicae quae corpus est: cuius caput est princeps [...] Amplius sicut Christus alienigenam, id est, gentilem ecclesiam sibi copulavit uxorem [...], sic et princeps rempublicam quae, quantum ad dominium, sua non est, cum ad principatum assumitur, sponsam sibi coniungit $[\ldots] »$.

87 Luca da Penne, Super tres libros codicis, cod. 11, tit. 58, 7, n. 9: «Ita et principi alienatio rerum fiscalium, quae in patrimonio imperii et reipublicae sunt et separate consistunt a privato patrimonio suo, iuste noscitur interdicta. [...] Nam et fiscus est pars reipublicae [...]». Vgl. Ullmann, Medieval Idea, 180-183, $187 f$.

88 Ullmann, Medieval Idea, 188f., 192; Viroli, From Politics, 67. 
zeugung, dass die Mitgift der Beitrag des Gemeinwesens war, damit der Herrscher seine Amtslasten tragen konnte; sie war also durch den Ehevertrag zweckgebunden. ${ }^{89}$ Insofern war es bezeichnend, dass Luca, anders als Cino, das Wort «politicus» zur Charakterisierung der Ehe brauchte. Aristo-

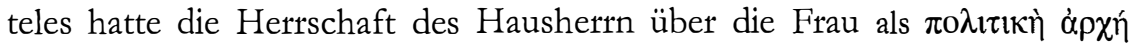
(politiké arché) charakterisiert - so wie ein Amtsträger in der Polis über seine Mitbürger herrscht, also über prinzipiell Gleichgestellte. ${ }^{90}$ Thomas von Aquin verdeutlichte dies: «Der Ehemann herrscht über seine Gattin durch politische Herrschaft, nämlich so wie jemand, der zum Oberhaupt gewählt worden ist, der Bürgerschaft voransteht [...] Doch der Mann hat nicht in jeder Hinsicht vollumfängliche Herrschaft über die Gattin, sondern nur soweit, wie es das Eherecht erfordert; wie auch das Oberhaupt der Bürgerschaft Macht über seine Mitbürger nur im gesetzlichen Rahmen hat.. $)^{91}$ In der Mitte des 15. Jahrhunderts nannte Sir John Fortescue die Herrschaft des Gatten über seine Gefährtin («socia») - und nicht Magd («ancilla») - unter Berufung auf die alten Autoritäten (Thomas, Augustin) ein «dominium yconomicum, et sociale vel civile». «Civile» setzte Fortescue wiederum mit «politicum» gleich, und als Wurzel definierte er «civitas» als Zitat aus Augustin: «hominum multitudo aliquo societatis vinculo sociata». Ehe und gemässigte Herrschaft unter Gleichen beruhten also auf einer (Rechts-)Gemeinschaft, in welcher ein Mann das gemeinsame Gut verwaltete («dispensare»). Die gottgewollte Hierarchien begründete Fortescue mit Verweis auf Evas Bestrafung (Genesis 3,16): «Eris sub potestate viri et ipse dominabitur tibi» - eine jede Frau unterstand der Macht eines einzelnen Mannes, sei es der Gatte oder der Vater. ${ }^{92}$ Im selben Werk De natura legis naturae führte Fortescue seine berühmte Wendung «dominium politicum et

89 Giulio Antonio Brancalasso, Philosophia Regia medulla politicorum, Neapel, 1609, 47, zitiert bei De Mattei, Idea democratica, 39f., Anm. 4: «Sponsalitium hoc inter Principem et Rempublicam contractum sua dote non caret; dat enim Respublica veluti sponsa suo Principi tanquam sponso tributum ad principatus onera subvehenda.»; ähnlich P. A. Canonieri, Introduzione alla Politica, 468 (Buch 7, Kap. 15), zitiert bei De Mattei, Idea democratica, 40.

90 Aristoteles, Politik, 1259a.

91 Thomas von Aquin, Sententia libri politicorum, A113; zitiert bei Viroli, From Politics, 66, und Rubinstein, History, 47, Anm. 38.

92 Fortescue, De natura, 163f. (Kap. 46); vgl. Rubinstein, History, 47, Anm. 38. Das leicht veränderte Zitat ist Augustin, De civitate Dei, CSEL 40, 2. Teil, 74 (15, 8). Es erinnert auch an Cicero, De republica, 1, 25: «coetus multitudinis iuris consensu et utilitatis communione sociatus»; diese Stelle zitiert Fortescue dann in De laudibus legum Angliae, 30 (Kap. 13). 
regale» ein, um die englische Verfassung zu charakterisieren. Damit kombinierte er zwei Adjektive, die trotz Ähnlichkeiten etwa bei Thomas von Aquin bislang unterschiedlich verwendet worden waren: «politicus» für den polyarchischen Stadtstaat («civitas»), wo Mitsprachegremien und Gesetze den Herrscher beschränken, dessen Macht vom Volk und einer Wahl herrührt; «regalis» dagegen für das monarchische Reich («regnum»), dessen König nach eigenem Gutdünken Gesetze erlassen und Steuern einfordern kann, weil er das Volk einst als Eroberer unterworfen hat. ${ }^{93}$ Die Kombination «dominium politicum et regale» bezeichnete den Monarchen, der - wie in England - durch unabänderliche Grundgesetze an den Willen des Volkes rückgebunden ist, das ihn ursprünglich gewählt hat.

Das bedeutete nicht, dass die Respublica (oder analog Ecclesia) selbständige rechtsfähige Personen waren. Vielmehr machte Fortescue deutlich, dass das Volk («populus») nicht als corpus politicum bezeichnet werden könne, bevor nicht aus ihm heraus ein Haupt, nämlich ein König, hervorgegangen sei. ${ }^{94}$ Den Übergang von einer blossen Ansammlung von Menschen («cetus hominum») zu einem politischen corpus mysticum erfolge durch das Gesetz, das die Glieder des Körpers zusammenhalte und damit auch Volk und König. Dieselbe Funktion erfüllten im Menschenkörper die Nerven. Wie diese seien auch die Gesetze vorgegeben, die der Herrscher im jeweiligen politischen Körper ebenso wenig ändern könne wie dessen Wesen. Denn von ihm, dem Volk, stamme seine Macht, die er unter keinem anderen Titel als dem der Landesgesetze ausüben könne, wenn er das Ideal eines «dominium politicum et regale» verwirklichen wolle. ${ }^{95}$ Für Fortescue war Frankreich ein reines «regimen regale», und entsprechend eindeutig fiel der Ver-

93 Rubinstein, History, 49-52; für die Abhängigkeit von Thomas von Aquin bzw. seinem Fortsetzer Ptolomäus da Lucca (De regimine principum, 3,12: «medium tenet inter politicum et regale»; vgl. auch 3,20) auch Viroli, From Politics, 69f.

94 Fortescue, De laudibus, 30 (Kap. 13): «Nec tamen Populus hujusmodi dum acephalus, sine Capite, esse Corpus vocari meretur. [...] in Politicis, sine Capite Communitas nullatenus corporatur. Quare Populum, se in Regnum aliunde Corpus Politicum erigere volentem, semper oportet unum praeficere totius Corporis illius regitivum, quem Regem nominare solitum est.»

95 Fortescue, De laudibus, 30 (Kap. 13): «Lex vero, sub qua Coetus Hominum Populus efficitur, Nervorum Corporis Physici tenet Rationem: Quia sicut per Nervos Campago Corporis solidatur, sic per Legem, quae a Ligando dicitur, Corpus hujusmodi Mysticum ligatur et servatur in unum [...] nec Rex, qui Caput Corporis Politici est, mutare potest Leges Corporis illius, nec ejusdem Populi substantias proprias subtrahere [...] et hanc Potestatem a Populo effluxam ipse habet, quo ei non licet Potestate alia suo Populo dominari». 
gleich der beiden Königreiche zugunsten des «dominium politicum et regale» in England aus. Zwar hätten die Generalstände dieselbe Funktion gehabt wie das englische Parlament, doch seien sie im Hundertjährigen Krieg nicht mehr zusammengekommen. So habe der französische König ohne deren Zustimmung willkürliche Steuern und ähnliche Schikanen verfügt, um den Anforderungen des Krieges zu genügen. ${ }^{96}$

Während Fortescue gleichsam die Formel «King-in-Parliament» vordachte, konnte sein Zeitgenosse Ludwig XI. tatsächlich schon sagen: «Je suis la France. $\rangle^{97}$ Im Sinn der Identitätsrepräsentation vertrat das Haupt allein den ganzen Körper. ${ }^{98}$ Doch das war noch mehr Anspruch als Realität, und kontraktualistische Vorstellungen der Königsherrschaft hatten durchaus auch ihre französischen Fürsprecher. In gewisser Analogie zu den gleichzeitigen Debatten, ob der Papst oder das Konzil die Kirche repräsentiere, konnten Autoren wie Jean Gerson, Jean de Terre Rouge oder - noch im späten 16. Jahrhundert - Guy Coquille daran festhalten, dass die drei Stände als «corpus civile sive mysticum regni» zumindest als Garanten der Grundgesetze eine politische Rolle spielten. ${ }^{99}$ War dies der Fall, so sprach Terre Rouge von corpus mysticum et civile; entschied allein der königliche Wille, wodurch die notwendige obrigkeitliche Gestaltungsfähigkeit erst entstand, so war vom corpus mysticum et politicum die Rede. ${ }^{100}$ Generell musste jeder Herrscher darauf achten, dass sein mystischer Körper am Leben blieb, etwa durch gleichmässig verteilte Steuern. Andernfalls, so Gerson, drohe Zerstörung, denn ein Haupt allein ohne Körper könne nicht Bestand haben. ${ }^{101}$

Die Ehemetaphorik wurde in Frankreich und unter Bezug auf Luca de Penne wohl schon vor dem Erstdruck seiner Werke (1509) aufgenommen. ${ }^{102}$ Schon um 1414 war von den Königen als «mariz et seigneurs» der

96 Fortescue, De laudibus, 80-89 (Kap. 35/36).

97 Zitiert nach Guenée, Politique, 23, Anm. 4.

98 Hierzu Hofmann, Repräsentation, 219-285; Koschorke, Staat, 89-92; Mager, Genossenschaft, 103-106.

99 Kantorowicz, Zwei Körper, 228-230.

100 Giesey, French Estates.

101 Jean Gerson, Vivat Rex: «Car aultrement ce seroit destruction; proprement, car chief sans corps ne peust durer.» Zitiert bei Krynen, Idéal, 327.

102 Descimon, Fonction, 1128; Gojosso, Concept de république, 48-51, 78-85; Hanley, Lit de Justice, 77-97. Wortwörtlich aus Luca de Penne stammt die Zusammenfassung von Barthélemy de Chasseneux, Catalogus gloriae mundi, f. 131 (5, 24,166); und ähnlich Charles de Grassaille, Regalium Franciae, 311 (I,20); vgl. Descimon, Fonction, 1135, und Gojosso, Concept de république, $78 \mathrm{f}$. 
France die Rede ${ }^{103}$, und 1440 sprach Jean Juvénal des Ursins vom König als «le vray espoux et mary de France». ${ }^{104}$ Auch die Herzöge heirateten symbolisch ihre Herzogtümer. ${ }^{105} 1479$ begründete ein Angehöriger des Parlaments von Paris die Unveräusserlichkeit des Kronguts mit dem «mariage moral et politicque qui est entre le roy et la chose publique». ${ }^{106}$ Viele Legisten übernahmen das Bild, so im späten 16. Jahrhundert René Choppin, der den König als mystischen Gatten des Gemeinwesens sah und damit nicht als Beherrscher, sondern als Treuhänder der Respublica: «curator Reipublicae ac mysticus [...] ipsius coniunx». ${ }^{107}$ Die Prinzen waren dann analog Kinder des Königs aus seiner Ehe mit dem französischen Volk, der «chose publique». ${ }^{108}$ Wichtiger war allerdings die Analogie, die Jean Papon 1566 aufgriff: Das Gemeinwesen («chose publique», «Republique») bringe die Krondomäne als Mitgift in die politische Ehe («mariage politic») ein. Der König allein könne sie nutzen, also unter Ausschluss seiner Geschwister, aber er dürfe sie nicht veräussern, entfremden oder teilen; und er müsse sie beschützen und pflegen. Im französischen Fall bedeutete dies historisch die Rückführung der Apanagen, später auch die Erweiterung der Domäne um das Erbe, das Heinrich von Navarra als Heinrich IV. gleichsam als männliche Mitgift einbrachte. Die Stände hatten laut Papon herkömmlich darüber gewacht, dass der König sich genauso um die Krondomäne kümmere wie ein Gatte um die Mitgift seiner Frau. Doch inzwischen komme diese Aufgabe allein dem Parlament von Paris zu, «veu que le Roy seul avec son Parlement representoit ladite Republique». ${ }^{109}$ Auch Bodin bediente sich derselben Metapho-

103 Descimon, Fonction, 1131.

104 Juvénal des Ursins, Loquar in tribulacione, 360; vgl. Krynen, Idéal, 256.

105 Descimon, Fonction, $1131 \mathrm{f}$.

106 Ebd., 1134.

107 Zitat nach Kantorowicz, Zwei Körper, 1990, 232f,; vgl. Choppin, De domanio Franciae, ऽ 328: «Ob id Reges non tam dicuntur Domini, quam Curatores Reipub. qui Feudisticis temporibus mamburgi nuncupabantur.» Weitere Beispiele bei Descimon, Fonction, 1135, und Hanley, Lit de Justice, 77-97.

108 Hanley, Lit de Justice, 78f., nach Godefroy, Cérémonial françois II, 493-499 ; vgl. Molé, Mémoires, Bd. 2, 221: «Il semble qu'jls ne recognoissent ni la personne d'un père, ni d'une mère, et qu'ils n'avouent autre auteur de leur vie que la France, puisqu'ils sont enfants de France.» Für die Kindermetaphorik oben, Anm. 53 und 54, sowie De Mattei, Idea democratica, 40, wonach Canonieri die Völker («i popoli») als Kinder von Fürst und Repubblica darstellte.

109 Papon, Recueil d'arestz, Buch 5, 10. Vgl. auch Descimon, Fonction, 1137, Gojosso, Concept de république, 80f., sowie Hanley, Lit de Justice, 171, für Karls IX. Lit de justice von 1563. 
rik. ${ }^{110}$ Und Cardin Le Bret, einer seiner wichtigsten Adepten im 17. Jahrhundert, ergänzte, dass alles, was der König erwarb, letztlich nicht ihm zukam, sondern der République als seiner mystischen Gattin. ${ }^{111}$

Die. Unveräusserlichkeit der Krondomäne war - analog zur erwähnten Forderung, der Papst müsse den Kirchenbesitz wahren - schon seit dem 14. Jahrhundert durch französische Juristen begründet worden. Karl V. von Frankreich nahm sie 1364 in den Krönungseid auf. Dem vorübergehenden Herrscher wurde damit die von ihm getrennt gedachte couronne übergeordnet, die Krone Frankreichs als unpersönliche und ewige Eigentümerin der Rechtsansprüche des Königreichs. Über diesen status coronae konnte das königliche Haupt allenfalls gemeinsam mit den ständischen Gliedern zusammen verfügen: Die Parlamente etwa kontrollierten die bestimmungsgerechte Verwaltung des Kronguts. Ähnlich stellten die französischen Theologen die im Konzil vereinte Kirche über den Papst. ${ }^{112}$ Der König war Diener, Verwalter und Vormund der Krone und musste bewahren, was ihre Essenz ausmachte; was also, mit Juvénal des Ursins, «inherent a la couronne» sei, Güter «ostés de la personne du roi, car ilz sont annexés a la couronne». ${ }^{113}$ Jean de Montreuil erklärte im frühen 15. Jahrhundert die Souveränität - im mittelalterlichen Sinn der höchsten Gerichtsbarkeit - zum Hauptcharakteristikum der Krone, die ihr anhafte wie der Schatten: «la couronne n'a point de plus grant droit que le droit de souvereineté». ${ }^{114}$

Diese Vorstellung erwies sich auch für den König als vorteilhaft, nachdem er im Frieden von Madrid 1526 unter anderem auf das Herzogtum Burgund verzichten musste. Im Lit de Justice vom 20. Dezember 1527 wurde nämlich erstmals in dieser Form festgehalten, dass der König als Haupt des mystischen Körpers mit seinen Gliedern, dem Volk, verheiratet sei und deswegen die Fundamentalgesetze wahren und also Burgund nicht veräus-

110 Bodin, République 6, 41 (Kap. 6,2): «[...] le domaine, que la république apporte au prince comme dot à son époux, pour la tuition, défense et entretenement d'icelle, et que les rois ne se peuvent approprier en sorte quelconque.»

111 Le Bret, Souveraineté, $47(I, 6):$ «[...] tout ce que les rois acquièrent tourne au profit de la république qui est leur épouse mystique et la plus privilégiée.»

112 Krynen, Idéal, 303-312; zur Unveräusserlichkeit auch Kantorowicz, Zıvei Körper, 348371.

113 Krynen, Idéal, 307; zur Vormundschaft Kantorowicz, Zwei Körper, 371-381, und Gierke, Genossenschaftsrecht, Bd. 3, 331-342, insbes. 332, Anm. 272; ausserdem Codex Justinianus 2,53,4: «Res publica minorum iure uti solet ideoque auxilium restitutionis implorare potest).

114 Krynen, Idéal, 308. 
sern dürfe, obwohl er es 1526 im Frieden von Madrid hatte abtreten müssen. Ähnlich wurden 1537 Flandern und Artois als Mitgift des «mari politique» für unveräusserlich erklärt. Das bedeutete zugleich eine kontraktualistische Rückbindung und Verpflichtung des Monarchen gegenüber seinem Volk und konkret gegenüber den Ständen als Garanten der Fundamentalgesetze. Insofern war es kein Zufall, dass gerade der Parlamentspräsident, Jean de Selve, 1527 erstmals diese Position formulierte und 1537 und 1563 ebenfalls bürgerliche Juristen, Jacques Cappel und Guillaume Ango, vom «vrai dot de la République» sprachen. ${ }^{115}$ Seinerseits benutzte Heinrich II. als erster König sogar im Krönungszeremoniell die Ehemetapher und gelobte bei der Annahme des Rings 1547, als Gatte des Königreichs dessen Fundamentalgesetze zu bewahren; das tat ihm auch noch Heinrich IV. nach. ${ }^{116}$

Die unsterbliche Krone war der Ort, wo ihr Träger und ihre Garanten, also Haupt und Glieder des politischen Körpers, als «Aggregat» zusammenkamen. ${ }^{117}$ Zugleich war es der Ort, wo kontraktualistisch die Mitsprache der Parlamente geltend gemacht werden konnte, weil - wie 1572 in einem Prozess festgehalten wurde - die Krondomäne Eigentum der Stände sei, die sich einen Erbkönig erkoren hätten, damit er diese Krone verwalte. ${ }^{118}$ Gegebenenfalls mussten sie also die Couronne gegen ihren Inhaber, einen eigennützigen König, schützen. ${ }^{119}$ Die für sich allein gedachte Krone als Trägerin zeitloser dignitas oder später der maiestas, mit einer vom sterblichen Throninhaber nicht veräusserbaren Krondomäne und mit vom König unabhängigen, ständischen Institutionen zur Überwachung dieses Grundgesetzes das war der Kern eines Staates als juristischer Person, die nicht den privaten Bedürfnissen der Dynastie (etwa der Versorgung nachgeborener Söhne) dienen sollte, sondern dem allgemeinen Wohl. ${ }^{120}$ So verstanden war der mystische, politische Körper des Königs keine Gegengewalt. Er umfasste das Gemeinwesen als Quelle und Hüterin der in der Couronne verankerten Grundgesetze, der lois fondamentales, und damit der Monarchie und des

115 Hanley, Lit de Justice, 77-85, 91-97, 171; Gojosso, Concept de république, 48f.

116 Hanley, Lit de Justice, 139; dies., Monarchic State, $111 \mathrm{f}$.

117 Kantorowicz, Zwei Körper, 380f.

118 Zitiert von Descimon, Fonction, 1136: «[...] le domaine de la Couronne appartient en propriété aux Estats qui ont esleu et constitué sur eux un Roy héréditaire pour estre administrateur de ceste Couronne. 'Tellement il est le mary politique de la Republique.»

119 Vgl. das Zitat von Jacques de la Gesle bei Descimon, Fonction, 1137 : «C'est ce que nous disons aujourd'huy au Roy et soustenons pour le Roy contre le Roy, c'est à dire pour les droits de la Couronne contre son intention représentée ès lettres patentes».

120 Descimon, Fonction, 1139. 
Herrscheramts selbst. Innerhalb dieses Rahmens, dem er sich selbst durch den Krönungseid freiwillig unterwarf, war der König im Prinzip uneingeschränkt handlungsfähig. Schon Baldus hatte festgehalten, «dass die respublica selber nichts tut, während derjenige, der die respublica regiert, kraft der respublica und der Würde, die ihm eben diese respublica übertragen hat, handelos. ${ }^{121}$ Die Respublica als theoretisch abstrahierte Körperschaft war also selbst nicht handlungsfähig und benötigte in dieser Passivität den Schutz ihres mächtigen Gatten, des konkreten Machthabers. Doch sie verdiente diesen Schutz als Gemahlin und Körper, denen das männliche Haupt seine Machtmittel wiederum verdankte und ohne die es nichts war. ${ }^{122}$

Obwohl die behandelten Vorstellungen in ihrer Vielfalt schwer systematisierbar und gerade in den verschiedenen nationalen politischen, theologischen, literarischen oder künstlerischen Traditionen nicht einheitlich sein konnten, ergibt sich doch ein allgemeiner Deutungsrahmen: das dominium politicum et regale als politische Ehe von männlichem Haupt und weiblichem Körper, deren Mitgift dem sterblichen body natural des Königs zur Verfügung stand, um im ewigen body politic das Gemeinwohl zu verwirklichen der Zweck, für den die Respublica ihn mit Vorrechten und Machtmitteln ausstattete, die aus ihr hervorgingen und seit Bodin als unteilbare «Souveränitäbs bezeichnet werden konnten. Für denselben Bodin waren aber die lois fondamentales mit dem göttlichen und dem natürlichen Recht zusammen der selbstverständliche Rahmen, an den souveränes Wirken sich halten musste - allerdings mit der wesentlichen Einschränkung, dass es keine weltliche Instanz ausser dem Souverän selbst gab, die sein Handeln auf ihre Recht-Mässigkeit in diesem übergeordneten Sinn beurteilen oder gar sanktionieren konnte. ${ }^{123}$

Während in den Nationalmonarchien die folgenden Theoretiker der Souveränität und insbesondere Thomas Hobbes diesen Aspekt immer stärker herausstrichen, entstand im Reichskontext mit seiner Wahlmonarchie und bedeutenden ständischen Kompetenzen und Institutionen ein öffentliches Recht, das der Gedankenwelt der mystischen Ehe stärker verbunden blieb. Der Unterscheidung zwischen dem Kaiser und dem Imperium als seinem Körper entsprach die Differenzierung, die Hermann Kirchner mit seiner Respublica von 1608 einführte: maiestas personalis (oder regnantis)

121 Baldus Ubaldis, Consilia, 3, 159, Nr. 5, zitiert bei Kantorowicz, Zwei Körper, 398.

$122 \mathrm{Vgl}$. herzu die überzeugenden Ausführungen von Möbius, Frauenbilder, 55, 60-66.

123 Giesey, Jurisprudence, 180-182; zu den Fundamentalgesetzen Bodin, République, 1, 197 $(1,8)$. 
einerseits, andererseits maiestas realis (oder regni). Letzterem entsprach ungefähr, in der älteren, scholastischen (und auf die Rechtsprechung beschränkten) Unterscheidung, der babitus jurisdictionis, der ursprüngliche Sitz der Rechtsprechung, Ersterem ihre konkrete Ausübung: actus/usus jurisdictionis. ${ }^{124}$ Man kann auch an die erwähnte französische Unterscheidung von ständischem corpus mysticum et civile und königlich dominiertem corpus mysticum et politicum (Terre Rouge) denken. ${ }^{125}$ Die Rede von der maiestas war nicht nur im Reichsrecht angelegt, sondern auch bei Bodin selbst, der wie erwähnt in seiner lateinischen Übersetzung souveraineté mit maiestas wiedergab. ${ }^{126}$ Bodins Herausforderung wollten Kirchner und die ihm folgenden Reichspublizisten denn auch entgegentreten, da nach seiner Souveränitätslehre das Heilige Römische Reich eine Aristokratie der Reichsfürsten war und damit den Erbmonarchien an Würde nachstand. ${ }^{127}$

Die Unterscheidung von zwei Aspekten der Souveränität, gleichsam ihrer ewigen Quelle und der sie vorübergehend praktizierenden Gewalt, erlaubte es, auch für das Reich vollwertige Souveränität und Staatlichkeit zu beanspruchen. Der Juspublizist Johannes Limnaeus brachte eine wichtige Präzisierung an, indem er das Heilige Römische Reich zusammen mit den christlichen Monarchien und Republiken dem Osmanischen Reich gegenüberstellte. Diese Differenzierung war bei Bodin angelegt, der die türkische «monarchie seigneuriale» ja dadurch charakterisierte, dass der Sultan über Land und Leute wie über sein Eigentum verfügte. In Limnaeus' Terminologie bildete die osmanische Dynastie damit für sich allein den Staat («status»). Im Abendland hingegen sei das personenrechtlich freie Volk als Quelle der maiestas realis ebenso Teil des «status» wie der Herrscher als Inhaber der maiestas personalis. Entsprechend definierte Limnaeus das im deutschsprachigen Kontext noch unvertraute Wort «status» im Sinn von «Staa๖» als ein Gemeinwesen, das auf Erden keinen Höheren anerkenne und über die maiestas realis verfüge, was bedeute, dass das Volk frei im Sinn von unabhängig sei. ${ }^{128}$ Konkret seien die Reichsstände dieses Volk und bildeten

124 Dazu Morel, Lex regia, 169, 173.

$125 \mathrm{Vgl}$. Giesey, French Estates, und oben, Anm. 100.

$126 \mathrm{Vgl}$. die oben, Anm. 26, zitierten Stellen in Bodin, République, 1, 179 (1, 8), und ders., Respublica, 78 (1,8).

127 Vgl. oben, Anm. 44 und Stolleis, Öffentliches Recht, 174-186, 204-207; Schubert, Reichstage, 477-513.

128 Limnaeus, Iuris publici imperii, Bd. 4, 92 (ad 1, 10): «Hoc sensu Respublicae Status dici merentur, quae superiorem in terris non recognoscunt, \& majestate, quae realis dicitur, pollent: ubi scilicet populus liber est.» 
das corpus mysticum, das als Inhaber der maiestas realis und gleichsam als Seele des Reiches sich des Kaisers als seines vornchmsten Glieds bedienc. ${ }^{129}$ Die ständische, «aristokratische» Position des Jenaer Professors und Prinzenerziehers Limnaeus widerspiegelte dic Bedrohung des deutschen Protestantismus in den Jahren von 1629 (Restitutionsedikt) bis 1635 (Prager Friede), in denen sein Werk crschien. Das zeigt sich auch darin, dass ein anderer lutherischer Juspublizist, Tobias Paurmcister, im Jahr 1608 dic Hierarchie noch nicht ständisch, sondern zugunsten des Kaiscrs ausgelegt hatte: «Die Fürsten und Stände bilden den Reichskörper, dessen Haupt der Kaiser ist, und wenn sie in einem compendilım repraesentativım zusammenkommen, sagt man, dass das ganzc Reich versammelt ist.. $)^{130}$

\section{Die Paarbeziehung im Bild}

Der skizzierte Bedeutungsrahmen bildet die Voraussetzung für die im Folgenden zu diskutierenden Bildprogramme. Die neutestamentlich begründete mystische Ehe von Christus mit Maria/Ecclesia diente Katholiken wie Protestanten dazu, das Verhältnis von Fürst und Gemeinwesen/Respublica zu deuten. ${ }^{131}$ Ikonografisch erwies sich wiederum das Verständnis des alttestamentlichen Hohelieds als Dialog zwischen Salomo und seiner Gcliebten als wichtig, die wie erwähnt mit der Königin von Saba identifizicrt wurde. Dieses Paar wurde oft am Anfang des Hohelieds abgebildet, so handschriftlich um 1180 als Initiale der Bibel der Kathedrale Winchester oder in der 1518 von Jacques Sagon in Lyon gedruckten Bibel. Diesen Bildtyp nahm 1559 Lucas de Heere auf, als er Philipp II. mit einer allegorischen Delegation der nicderländischen Provinzen darstclltc. (Abb. 2) Der Maler bezeichnete den thronenden König als zweiten Salomo («alter Salomo»), dem die Personifikation der Vereinigten Provinzen als würdigc

129 Ebd., Bd. 5, 189 (ad 1, 12); vgl. Dohrn-van Rossum, Art. Organ, 552; auch Høkc, Limnaeus, $104-107$.

130 Paurmcister, De jurisdictione imperii Romani, II, $1, \S 17$, zitiert nach Stollberg-Rilinger, Alte Kleider, 143.

131 Für die protestantische Übernahme der mystischen Ehe vgl. etwa Luther, Wider den falsch genannten geistlichen Stand, 121, 7. 4-8; Oxford Encyclopedia of the Reformation, Bd. 1, 238 (Calvin), 442-445 (Covenant); Major, Madam Britannia, 31 (John Knox). 
Königin von Saba gegenübertritt. ${ }^{132}$ So fasste Lucas de Heere dic Beziehung zwischen (männlichem) Haupt und (weiblichem) Körper als harmonische Eintracht, was zu diesem Zeitpunkt auch noch dem Verhältnis des Spaniers zu den ihm von Karl V. überlassenen Niederlanden entsprach. Zugleich wurde die Hicrarchie deutlich: Philipp thront erhöht, dic Königin steht vor den Stufen des Throns, ihre Augen richten sich nach oben zum Herrscher, dem sie respektvoll die Gaben ihrer Länder überreicht.

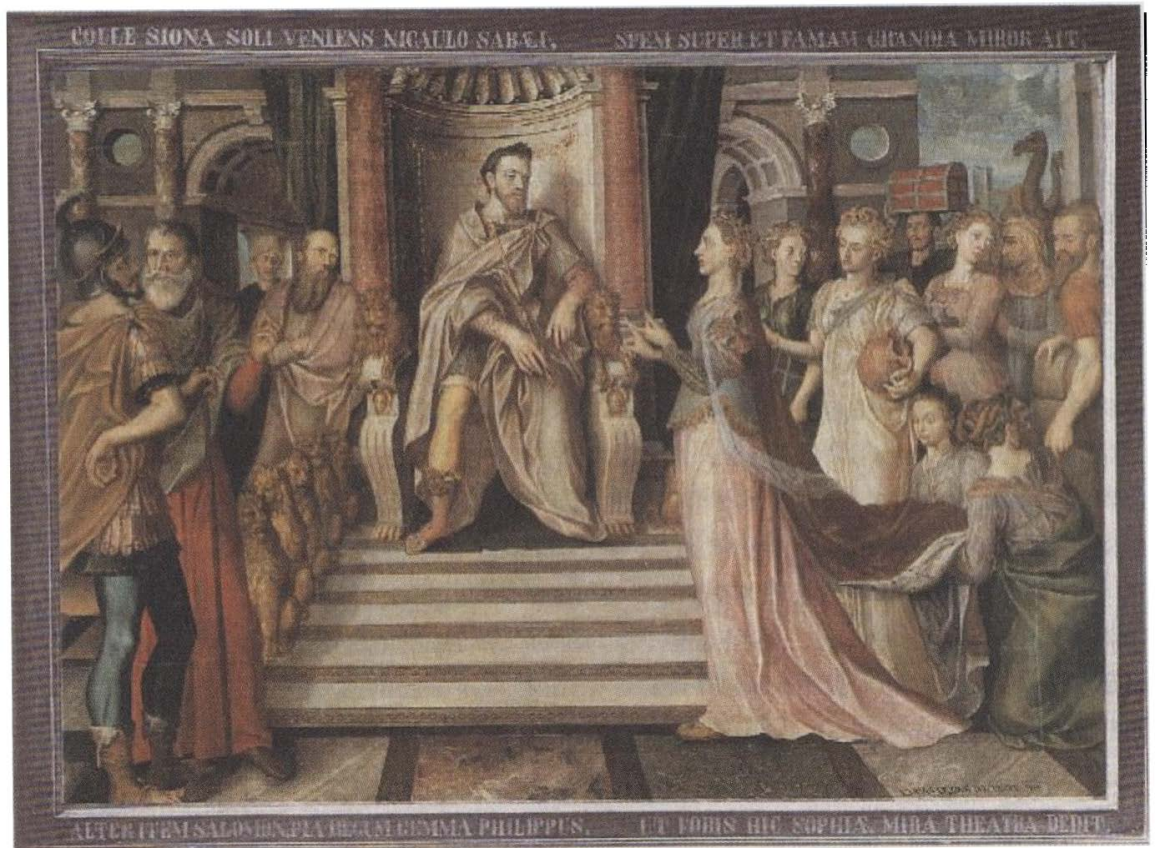

Abb. 2: Lucas de Heere, Salomo (Philipp II.) empfängt die Königin ron Saba, Kathedrale von Gent, 1559.

132 De Heere bezog sich dabei ausser auf das Hohelied auf Psalm 45, ein Liebeslied, in dem prächtige Königstöchter mit ihren Kleinodien einherschreiten, um den gerechten König zu verehren. 
Für diese Überordnung des Königs und eine mehr oder weniger demütige Huldigung des Gemeinwesens gibt es im 17. Jahrhundert eine rasch zunehmende Zahl von Beispielen bei der Darstellung der mystischen Ehe. So malte Simon Vouet Francia und Navarra kniend vor Ludwig XIII. und ohne ihre herkömmlichen Machtsymbole wie Krone, Zepter oder Hermelinmantel. Die Personifikationen tragen also selbst nichts zur mystischen Ehe bei, sondern hängen völlig von der Gnade und Macht des bewaffneten Königs ab, der dies durch seine schützende Rechte auf Francias Kopf zum Ausdruck bringt. ${ }^{133}$ Es überrascht kaum, dass Ludwig XIV. sich sehr oft und besonders auch auf weithin wirkenden Flugblättern thronend mit gebückten, knienden oder liegenden Personifikationen darstellen liess. Dabei war es nicht nur Francia, sondern auch andere - dankbare oder gedemütigte - Völker, die bei ihm Schutz und Frieden suchten. Auf einem Stich aus Anlass der Krönung (1654) bieten ihm verschiedene Nationen ihre Krone an. Er wählt die französische: «Je Recois [sic] en fils ta Coronne [sic] France et je te donne mon cœur.» Zwar nennt der (eben volljährige) König sich hier Sohn und nicht Gatte, doch auch als Mutter kniet France ehrfürchtig wie gewohnt zu seinen Füssen. ${ }^{134}$

Ludwigs Rolle als ordnender Beschützer wurde auch im Spiegelsaal zu Versailles deutlich, etwa auf dem Gemälde L'ordre rétabli dans les finances, wo Francia um Hilfe gegen ungerechte Steuerpächter bittet, oder auf Le roi gouverne par lui-même, wo Ludwig bei Beginn der Alleinherrschaft (1661) Francia im eigentlichen Sinn des Wortes in den Schatten stellt. Wenn der König abgebildet wurde, war er immer herausgehoben, zentral und über die anderen Figuren erhaben, die er nicht berührte; auch nicht Francia. ${ }^{135}$ In Ludwigs Jugend war das noch anders gewesen: Als Le Sueur kurz nach dem Sieg über die Fronde im Louvre unter anderem das Zimmer des Königs mit - nur noch als Skizzen erhaltenen - Deckengemälden der Francia mit Obelisk (dauerhafte Souveränität) und Lilienstrauss (fleurs de lys, für die Dynastie) schmückte, fehlte der König noch. ${ }^{136}$ Allerdings trat Francia auch

133 Bar, Peinture allégorique, 60.

134 Le royal et magnificque preparatif du sacre et couronnement du roy en l'année de sa maiorité, 1654; BNF Estampes, 74 B 65496. Für das Verhältnis von König und Francia auch Milovanovic, Du Louvre à Versailles, $207 \mathrm{f}$.

135 Sabatier, Versailles, 291-302, 425f; Milovanovic, Du Louvre à Versailles, 207-210, Abb. 13.

136 Mérot, Décors, 115f., Abb. 3 und 4; Milovanovic, Du Louvre à Versailles, 205f. Auch die dort erwähnte Rotunde im Louvre (Abb. 16), mit dem König und der personifizierten «Monarchie française», zeigt noch die ursprüngliche Nähe der beiden Figuren. An- 
in Versailles allein auf, als handelnde Figur, nämlich in Auseinandersetzung mit weiblichen Personifikationen konkurrierender, aber unterlegener Länder (Hollandia, Hispania, Germania, Roma für den Kirchenstaat) oder - wohl auf der protokollarisch noch tieferen Ebene - mit den männlichen Gesandten der Eidgenossen, Türken oder anderer nichtchristlicher Länder. ${ }^{137}$ Hiermit wurde Frankreichs Dominanz über alle Mächte der Welt ausgedrückt; keineswegs aber eine Vorrangstellung Francias gegenüber dem König. Die Allegorien repräsentierten jeweils «génie et fortune de la nation»: Ehrgeiz, Stolz, Anmassung der Landesfeinde gegenüber der kraftvollen Überlegenheit und dem weisen Gestaltungswillen der Francia. ${ }^{138}$

Das zeigte sich auch im Salon de la Paix, vor allem aber im Salon de la Guerre, wo die besiegten Landespersonifikationen Germania, Hispania und Hollandia die blitzeschleudernde Francia im Deckentondo umgeben. Vor ihren Körper hält sie einen Schild, den ein Brustbild Ludwigs XIV. schmückt. «Cette monarchie est représentée dans le milieu du plafond [...] Son bouclier est orné du portrait de Louis le Grand coloré pour signifier que c'est par lui qu'elle a vaincu ses ennemis, d'autant que ne pouvant pas être en tous lieux à la tête de ses armées, sa conduite et son bonheur ont toujours donné du centre à la circonférence de l'État les moyens [...] de vaincre ses ennemis et de rendre cette monarchie invincible.»1 ${ }^{139}$ Die Kraft und die Tugend des fürstlichen Schilds machen Francia unüberwindlich, beschützen sie vor allen feindlichen Schlägen und tragen ihr die militärischen Siege ihrer Generäle ein. ${ }^{140}$ Ludwigs Porträt als imago clipeata war eine ursprünglich heidnisch-römische Form, die dazu diente, der verstorbenen Vorfahren zu gedenken. In Byzanz wurden die Kaiserikone und das Bild Christi in dieser Form ganz ähnlich verehrt: das Haupt des Imperiums und das Haupt der Kirche in seiner menschlichen Natur. ${ }^{141}$ Analog wird hier Ludwig XIV. in eine Mittelstellung zwischen Menschen und Gottheit emporgehoben: Die Unvergänglichkeit kam nicht ihm, sondern Francia zu, die in den Farben seiner Dynastie gewandet ist. Ohne dass Francia deswegen einen Vorrang erhält, erscheint sie als ewig, ihr souveräner Beschützer da-

ders als Milovanovic vermutet, liess sich Francia problemlos als Minerva darstellen, vgl. auch unten, Anm. 267.

137 Sabatier, Versailles, 307-336.

138 Das Zitat von François Charpentier nach Sabatier, Versailles, $298 \mathrm{f}$.

139 Claude Nivelon, zitiert bei Sabatier, Versailles, 428.

140 Nach dem Mercure galant bei Sabatier, Versailles, 387.

141 Sabatier, Versailles, 387-392; Belting, Bild und Kult, 119-125; Milovanovic, Du Louvre à Versailles, 228f. (Abb. 62). 
gegen als Sterblicher. Während ihr génie eine zeitlose Bestimmung zum Ausdruck bringt, war das Porträt auf dem Schild potenziell ersetzbar. ${ }^{142}$

Derselbe Gedanke wurde in Ludwigs Grande chambre im 1871 zerstörten Tuilerienpalast deutlich, wo eine gekrönte Francia mit der Linken ein Zepter hielt, mit der Rechten dagegen eine Bordüre, an der das Porträt des jeweiligen Königs hängen sollte. ${ }^{143}$ Auch Nicolas Coustous goldene France triomphante veillant sur le sommeil du Roi, die seit 1701 in Versailles über dem Lit d'état wachte, gehorchte dieser Logik, zumal sie nicht über ein privates Bett für den Schlaf wachte. Der Lit d'état mit seinem Baldachin war der Sitz der königlichen Macht und Teil des höfischen und diplomatischen Zeremoniells, mit dem der Herrscher hier Staatsgeschäfte wie Diplomatenempfänge durchführte. Die ewige Francia wachte, auch wenn der König als Mensch schlafen musste. Das implizierte keine Überlegenheit oder Selbständigkeit der Personifikation, sondern ihre treue Verbindung mit dem König, dem sie ihre Triumphe verdankte. Entsprechend bekennt France, wenn sie einmal allein dargestellt wird, dass sie ihm gehört: «Le Prince a qui je suis, est le plus grand des Rois.. ${ }^{144}$ Seinerseits verkündete Ludwig XIV., dass die Nation vollständig in ihm selbst ruhe: «La nation réside tout entière

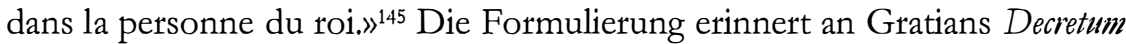
und Luca da Penne. Doch das «tout entière» macht deutlich, dass es sich, anders als bei ihnen, nicht um ein wechselseitiges Ineinander-Aufgehen von Bischof und Ecclesia, Fürst und Respublica handelt. Die Nation - wohl die frühere Respublica - ist dem absoluten Herrscher ein- und untergeordnet in dem Sinn, dass die unterworfenen Glieder des politischen Körpers ihre Identität allein im Namen und im Bild des Königs erhielten. ${ }^{146}$ Bossuet impfte Ludwig XIV. genau dieses Selbstverständnis ein: «La majesté est l'image de la grandeur de Dieu dans le prince. Dieu est infini, Dieu est tout. Le prince, en tant que prince, n'est pas regardé comme un homme particulier : c'est un personnage public, tout l'Etat est en lui, la volonté de tout le peuple est renfermée dans la sienne. Comme en Dieu est réunie toute per-

142 Für eine republikanische Variante dieser Konzeption vgl. das Frontispiz zu Philipp von Zesens Leo Belgicus (1660) in Gamboni u. a., Zeichen der Freiheit, 81.

143 Bar, Peinture allégorique, 68. Diese Francia wurde oft mit Religio verwechselt, weil sie von ungewohnten religiösen Attributen begleitet war (Oriflamme, heilige Ampulle), die allerdings auf Chlodwigs Bekehrung und damit die Gründung der Dynastie verwiesen.

144 N. Bonnard, La France, Paris 1680, 45; BNF Estampes, Hennin 5161.

145 Zitiert bei De Pange, Le Roi très chrétien, 383; vgl. zur Ehemetaphorik bei Ludwig XIV.: Zanger, Mariage.

146 Marin, Porträt, 338f,; vgl. auch 23f., 339-346. 
fection et toute vertu, ainsi toute la puissance des particuliers est réunie en la personne du prince. Quelle grandeur qu'un seul homme en contienne tant! $\rangle^{147}$ Mit Identitätsrepräsentation stellte der Sonnenkönig allein die Nation vollumfänglich, ohne jede Dualität dar, was analog durch das apokryphe «L'état c'est moj» ausgedrückt wurde. ${ }^{148}$

Im Heiligen Römischen Reich erschien schon früh der Kaiser als Schutzherr: Ulrich von Hutten liess «Italia» von Maximilian I. eine Intervention erflehen, was Matteo da Milano ähnlich im Bild erfasste: «Supplex Italia ad Maximilianum confugib». ${ }^{149}$ Die «Romisch Fraw» oder das «Reich» schien vorübergehend fast mit Maximilian zusammenzufallen. ${ }^{150}$ Auf Enea Vicos Kupferstich von Karl V. hält Germania mit Mauerkrone eine Tafel, die sie - nach dem Schmalkaldischen Krieg - auffordert, sich über ihren Untertanenstatus zu freuen. ${ }^{151}$ Abraham Aubry zeichnete 1663/64 ein Flugblatt, auf dem Germania mit dem Reichsapfel in der Hand zu Füssen des thronenden Kaisers Ferdinand III. sitzt und von den Kurfürsten eingerahmt wird. Das dazugehörige Gedicht nimmt die organologische Sprache auf, sieht allerdings im geliebten Haupt nicht Gatten, sondern Vater: «Seht wie die Glieder sich mit ihrem Haupt verstehen, Wie freundlich dass das Haupt Wie lieblich Deutschland sich In ihres Herrschers Schoss erquickt. Es küsset dich, O Vater Ferdinand dein Land vor deine Liebe.»1 ${ }^{152}$ Constantino Roncaglia liess 1696 eine stehende, hermelingewandete Germania mit dem Finger auf Kaiser Leopold I. weisen, der mit einem Reichsadler zusammen die Feinde des Reichs durch Blitze niederschlägt. ${ }^{153}$ Daniel Grans malte Karl VI. in der Kuppel der Wiener Hofbibliothek, gefeiert von Austria, Germania und Vienna in untergeordneter Stellung. ${ }^{154}$ Auf Elias

147 Bossuet, La Politique, 384 (lib. 5, art. 4).

148 Vgl. Giesey, Two Bodies, 314f. (237f.). Giesey verweist auch auf Kantorowicz bzw. Saint-Simon, wonach Ludwig XIV. die Prinzen von Geblüt als «enfants de l'Etat et de la couronne» ansah, die Bastarde dagegen als «enfants de ses amours». Vgl. auch Marin, Porträt, 24f., 67-194, 351.

149 Ulrich von Hutten, Briefe, 105-113; dazu auch Eickmeyer, Heroidenbrief.

150 Trzinski, Ikonographie, 175-187; vgl. auch Müller, Das Heilige Römische Reich.

151 Gall, Germania, 40, Anm. 14 und Abb. 3; vgl. von Hagenow, Bildniskommentare.

152 Harms, Deutsche Illustrierte Flugblätter, Bd. 2, 578f. (II, 331); vgl. Brandt, Germania, 47f. sowie Abb. 3.

153 Roncaglia, Admirables efectos; vgl. Kocher, Zeichen und Symbole, 88, Abb. 125.

154 Krasa-Florian, Allegorie, 38. 
Baecks Kupferstich von 1742 zeigte eine demütige Germania dem neu erwählten Karl VII. auf einer Karte den Krönungsort Frankfurt. ${ }^{155}$

Solche Kompositionen entsprachen auch dem Programm, das der Reichserzkanzler Lothar Franz Graf Schönborn und der Reichsvizekanzler Friedrich Karl Graf Schönborn für Johann Rudolf Byss festlegten, der in den 1720er Jahren die Reichhofkanzlei in der Wiener Hofburg mit nicht mehr erhaltenen Bildern ausschmückte. Den thronenden Karl VI. sollten Personifikationen von Italia, Lombardia und «Teutschland» umgeben, welch Letztere ihm ihre, die vornehmste Krone darreichte. «Dise drei provinzien müssen alle stehend vorgebildet werden, weilen es sich sowohl aus der staatskunst oder politique nicht bewürken lasset, dass man einen regenten in eine paralel oder gleichformigkeit mit einer provinz ziehre, zweitens auch in dem alterthum auf münzen und anderstwo die provinzien entweder kniend oder stehend vor dem regenten, niemahlen aber sitzend angetroffen werden.» Ebenso diente der Schild mit einem Reichsadler, den ein Genius dem Kaiser präsentierte, «zum zeichen der unterwürfigkeit oder anhangs, so bemelte drei das Römische reich ausmachende provinzien oder figuren gegen dem kaiser hegen [...] weilen der staatscörper unsers Teutschen reichs in denen chur- und fürsten, praelathen und grafen, reichsstädt und der ritterschaft besteht.. ${ }^{156}$

Die Gegner eines starken - habsburgischen - Kaisertums betonten dagegen nicht die Unterwürfigkeit der Stände, sondern die in ihnen wurzelnde, ja autonome maiestas realis, was sich ebenfalls bildlich niederschlug. Als sich 1616 die süddeutschen Führer des Protestantismus in Stuttgart trafen, feierten sie nicht nur die Taufe des württembergischen Herzogssohns, sondern beschlossen auch gleich die Verlängerung der Union, der sie angehörten. Den Einzug der Fürsten begleiteten Allegorien vor allem aus der antiken Mythologie, die Matthäus Merian auf Kupferstichen verewigte. Im Aufzug des Markgrafen Georg Friedrich von Baden ritt auch die «Herztliebste Land-Mutter und Allergnädigste Herrscherin Germania» mit Krone, Zepter und Reichsapfel, begleitet von Jungfrauen als Repräsentantinnen der Reichskreise und von der Concordia invicta, einer Tante («Muhme») der Germania. Mit ihren acht Armen hielt Concordia den Schild mit ihrem Namen, einen Spiess zur Abwehr der Glaubensfeinde, das Schwert der Justitia sowie das Zepter als «Keyserliches Cammandement» [sic, für Com-

155 Vgl. Brandt, Germania, 48f. und Abb. 4. Die Betonung von Frankfurt richtet sich wohl gegen das habsburgische Wien.

156 Tietze, Programme und Entwürfe, $26 f$. 
mandement] und den Reichsapfel als «Majestet dess Römischen Reichs». Während dem Kaiser, der ansonsten beim Einzug nicht auftauchte, (nur) der Oberbefehl zustand, ruhte im Reichsapfel die ständische Souveränität des Reichs im Sinn eben der maiestas realis. ${ }^{157}$

Wer dieser Logik folgte, zeigte die Landespersonifikation als selbständige Frau. Germania, die 1620 im Namen der «Teutschen Nation» über den von dem päpstlichen Antichristen verursachten Krieg klagt, trägt selbst Krone, Zepter und Reichsapfel; kein Kaiser ist auf dem Bild zu sehen. ${ }^{158}$ Mit denselben Insignien zeigte das Titelblatt von Hermann Conrings De Germanici Imperii Republica 1654 allein Germania auf dem Kaiserthron. ${ }^{159}$ Eine protestantische Flugschrift feierte 1635 den Prager Frieden, in dem Ferdinand II. sich mit der lutherischen Vormacht Sachsen einigte und auf die Umsetzung des gegenreformatorischen Restitutionsedikts von 1629 verzichtete. Die Repräsentation des «Teutschen Reiches», auf dem Bild bezeichnet als «Resp[ublica] Rom[ana]», sitzt zentral auf einem Thron, gekrönt und leicht erhöht, während der Kaiser und der sächsische Kurfürst Johann Georg II. an ihren Seiten sich und ihr die Hand zum Frieden reichen. Als «Reichs-Mutter» vermittelt sie zwischen den beiden Vertragspartnern. Diese sind ihr gleichrangig untergeordnet, der Kaiser nicht ihr Herr wie 30 Jahre danach auf dem erwähnten Stich von Aubry. ${ }^{160}$

Wie für die Befürworter von starken Reichsständen, so war auch im venezianischen Governo misto die Kontrolle des monarchischen Elements durch die Aristokratie von zentraler Bedeutung. Das zeigte sich 1570 in einem Gedicht nach der Wahl eines neuen Dogen, das ihn sowohl «sposo», nämlich Bräutigam der Republik, als auch «capo» nannte, also das Haupt von Venedig. ${ }^{161}$ Zwar brauchte der politische Körper eine effiziente Spitze,

157 Van Hulsen/Merian, Repraesentatio, 80-86; vgl. auch Brandt, Germania, 45f.

158 Harms, Deutsche Illustrierte Flugblätter, Bd. 2, 292f. (II, 165).

159 Conring, De Germanici Imperii Republica; vgl. Müller, Heilige Römische Reich, 1997, 417, Abb. 1; Müller deutet allerdings Germania auf S. 401 zu Unrecht als Kaiser.

160 Brandt, Germania, 46f. und Abb. 1, sowie Burkhardt, Bildkultur, 95f. und Abb. 4. Bezeichnenderweise zeigte Johann Schlüters De Imperio Romano-Germanico adversus Hippolitbum de Lapide, eine Polemik von 1653 gegen die ständische Streitschrift des Bogislav von Chemnitz, den Kaiser wiederum als erfolgreichen Beschützer einer bedrohten Germania gegen die Türken.

161 Luigi Grotto, Oratione, Venedig 1570, zitiert bei De Mattei, Idea democratica, 39, Anm. 3. Möglicherweise ist die - sehr seltene - Darstellung eines Dogen auf einer Medaille ähnlich zu deuten, wenn auf der Rückseite Venetia mit ihren Attributen dargestellt ist, vgl. Wolters, Bilderschmuck, 78 (Abb. 50). Vgl. auch 240, wonach auch San Marco als Bräutigam der Venetia angesehen werden konnte. 
aber diese musste eingebunden bleiben in die Mitsprache der Standesangehörigen, die für die Freiheit garantierte. Die berühmte Vermählung Venedigs mit dem Meer (sposalizio del mare) gehorchte einer etwas anderen Logik, zumal il mare anders als la repubblica männlich ist. Der Doge warf jeweils an Christi Himmelfahrt vom Staatsschiff Bucintoro einen Ring in die Wogen und sprach als Bräutigam: «Desponsamus te, mare. In signum veri perpetuique dominii.» Das Meer war nicht ein partnerschaftlicher Körper, sondern beherrschtes Element, das zugleich in seiner Unberechenbarkeit versöhnlich gestimmt werden musste. ${ }^{162}$

Die Symbolik des Rings, der wie erwähnt die bischöfliche Ehe mit der Diözese besiegelte, wurde allerdings auch sonst in die politische Sphäre übertragen. Seit der karolingischen Zeit liessen sich Fürsten und so auch der Kaiser bei der Krönung einen Ring reichen. Ähnlichkeiten und Unterschiede zum Bischof wurden bereits von den Zeitgenossen insbesondere im Umfeld des Investiturstreits intensiv diskutiert. ${ }^{163}$ Im französischen Krönungsordo wurde festgehalten, dass der König durch die Ringübergabe feierlich das Königreich oder die Krone heirate - also nicht Francia. ${ }^{164}$ Bei Heinrich IV. wurde die Partnerin dieser «reciproque conjonction» noch deutlicher benannt: Es konnte die couronne selbst sein oder der royaume, worunter die Untertanen (subjects) verstanden wurden. ${ }^{165}$ Ludwig XIV. erhielt für seine Krönung nicht nur einen Diamanten "pour épouser la France», sondern auch eine Erklärung für den Ring, den die französischen Könige als Symbol trugen für die «étroite alliance qu'ils contractent avec l'Etaむ». Wie der Gatte in Leidenschaft für seine Frau glühe, so beschütze er liebevoll seine Untertanen. ${ }^{166}$ Die Identifikation von Francia mit dem Etat, ja ihre Verdrängung durch diesen hatte schon im 16. Jahrhundert eingesetzt, als der König als Ergebnis der «mariage politique» zum «mari de l'Etat» erklärt wurde. ${ }^{167}$ Das lag nicht nur daran, dass republique in einem generischen Sinn eben durch état abgelöst und zusehends auf den Freistaat beschränkt wurde. ${ }^{168}$ Etat meinte auch nicht ein Gemeinwesen, das poten-

162 Muir, Civic Ritual, 122.

163 Kantorowicz, Zwei Körper, 205, 222f. (mit Verweis auf Eichmann, Kaiserkrönung im Abendland, Bd. 2, 94ff.).

164 Descimon, Fonction, 1135.

165 Kantorowicz, Zwei Körper, 232; vgl. Descimon, Fonction, 1131.

166 Ohne weitere Quellenangaben zitiert von De Mattei, Idea democratica, 39, Anm. 2.

167 Der französische Jurist des 16. Jahrhunderts wird zitiert nach De Mattei, Idea democratica, 39 (ohne weitere Quellenangabe).

168 Maissen, Geburt, 74f., 88f. 
ziell selbständig agieren konnte, sondern einen Herrschaftsapparat, der allein vom König abhing und geführt wurde.

Die Situation in England war im 16. Jahrhundert insofern eine besondere, als mit Elisabeth eine Frau herrschte. Zudem heiratete sie trotz verschiedener Heiratspläne mit katholischen Prinzen aus Spanien und Frankreich nie. Gerade um entsprechenden Erwartungen entgegenzutreten, erklärte sie 1561, dass sie bereits verheiratet sei und ihr Ring die Ehe mit ihrem (protestantischen) Königreich symbolisiere: «I was once marryed to this realme at my coronatione, in token wherof I weare this ring. ${ }^{169}$ Auch Elisabeths Konkurrentin Maria Stuart bezeichnete sich als Gattin des Königreichs, und ihr Sohn, Elisabeths Nachfolger Jakob I. erklärte 1604: «I am the husband, and all the whole Isle is my lawful wife. I am the Head, and it is my Body.» Jakob wollte durch seine Thronrede die Personalunion legitimieren, die unter ihm die bis dahin selbständigen Reiche England und Schottland verband. Die Betonung lag also weniger auf der Ehe selbst als darauf, dass es sich bei der Gattin um eine Einheit handle ("the whole Isle»), so dass Jakob empört erklären konnte, er sei doch kein Polygamist und habe, als Haupt, auch keinen geteilten und monströsen Körper. ${ }^{170}$ Die organologische Metaphorik erwies sich dann allerdings für seinen Sohn und Nachfolger Karl I. als gefährlich. Das neu einberufene, «kurze» Parlament gestand ihm zwar 1640 die Bezeichnung «head of the commonwealth» zu. Doch John Pym beanspruchte für das Parlament, dessen Seele zu sein. Damit war es auch Sitz der Souveränität und Vermittler zwischen Haupt und Gliedern: «the parliament is as the soul of the commonwealth, that only is able to apprehend and understand the symptoms of all such diseases which threaten the body politic». ${ }^{171}$

169 Zitiert bei Valerius, Weibliche Herrschaft 268; vgl, auch 262.

170 King James VI and I, Political Writings, 136; ähnlich 162. Vgl, auch Valerius, Weibliche Herrschaft, 263; Kantorowicz, Zwei Körper, 233; zu Jakob I. auch McLaren, Monogamy, Polygamy, 446-480.

171 Cope/Coates, Proceedings, 149, zitiert nach Wende, Herrscherbild, 65f. 


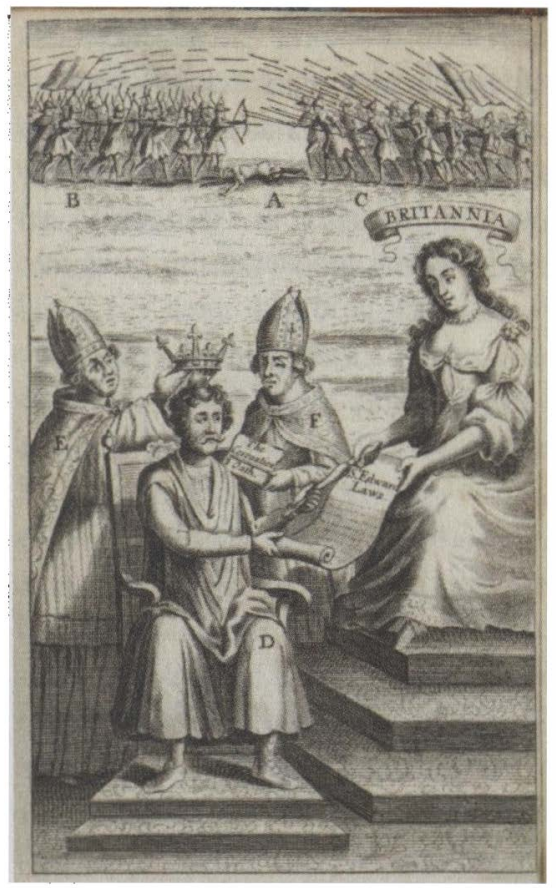

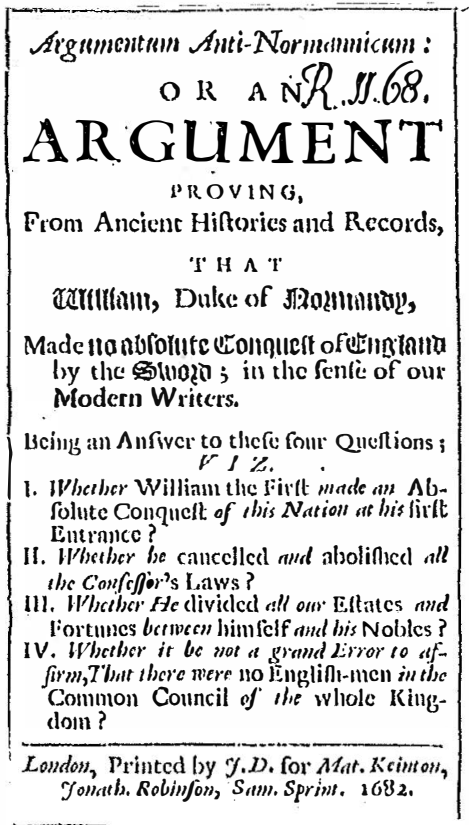

Abb. 3.: Edward Cook (?), Argumentum Anti-Normannicum, 1682.

Die parlamentarische Position, wie sie sich - nach den Erfahrungen von Bürgerkrieg und Commonwealth - im Vorfeld der Glorions Revolution crgab, führte 1682 wohl Edward Cook im anonym gedruckten Argumentum Antinormannicum vor, in dem er mit sciner Variante in die zeitgenössische Klage über das Norman yoke einstimmtc. Demnach waren dic ursprünglichen angelsächsischen Frciheiten der Inselbewohner durch die Normannen aufgehoben worden. Das sei die Wurzel der Konflikte des 17. Jahrhunderts, in denen der absolutistische König in normannischer 'I'radition stehe. Wie die Levellers mit ihrer sozialkritischen Leseweise, die den zeitgenössischen Adel ebenfalls als Teil des normannischen Jochs angriffen, übcrnahm auch die parlamentarische Opposition das Motiv. Cooks Interpretation schlug sich in seinem Frontispiz nieder. (Abb. 3). Nicht Wilhelm der Eroberer habe eine absolutc Herrschaft errichtet, sondern erst seine späteren Nachfolger. Im Hintergrund erkennt man die Kämpfe bei Hastings, mit dem toten Angelsachsenkönig Harald in der Mitte. Der Schlachtensieg war für Cook ein legitimer Erwerb der Krone. Doch Wilhelm erhält sie von den zwei Erzbischöfen auf dem Stich nur unter klaren Bedingungen. Im Krönungs- 
eid, dessen Text ihm der eine darbietet, gelobt Wilhelm, die Gesetze des Heiligen Eduard des Bekenners - des zweitletzten angelsächsischen Königs und damit die hergebrachten Freiheiten zu achten. Hingehalten werden ihm diese Gesetze auf dem Bild durch Britannia, die im 17. Jahrhundert eher selten und zumeist - wie auf Rubens Darstellung Karls I. mit Britannia und Scotia in Whitehall - in der untergeordneten, demütigen Haltung erschien, wie dies dem absolutistischen Streben entsprach. ${ }^{172}$ Ganz anders Cooks Britannia: Sie sitzt auf drei hohen Stufen deutlich über dem Normannenherrscher, der auf bloss zwei flachen Stufen thront. Mit dem Gesetzbuch zusammen reicht sie ihm das Zepter, und Wilhelm spricht sie als «Fairest Queen» und «Sacred Queen» an. Er werde gerecht über die Engländer herrschen und nicht, unter Berufung auf die Prärogative, willkürlich; also keine «Absolute, or Despotical Power over their Lives, Liberties and Estates» erstreben oder die Grundgesetze («Fundamental Rights») des Königreichs brechen, um wie ein Tyrann über Sklaven zu herrschen. ${ }^{173} \mathrm{Im}$ gleichen Geist präsentierten nach der Glorious Revolution einige Frontispize als Beleg für The Nezy State of England eine geharnischte oder thronende Britannia, die wohl auf Schwert und Hilfe Wilhelms III. zählen konnte, aber selbständig die Reichsinsignien (Verfassungstexte, Zepter, Wappen, Baldachin) hütete. ${ }^{174}$

\section{Ehebruch}

Ein Kupferstich aus derselben Zeit zeigt Wilhelm III., der den Papst davon abhält, die in Ketten gelegte Britannia zu erdolchen. Die Bildlegende präsentiert den Oranier als «the Rescuer Albions Gen'rous Friend», der die ebenfalls abgebildete, siebenköpfige Hure Babylon zerstöre und seine Gat-

172 Britannia erschien vergleichsweise spät, auf Medaillen erst unter Karl II., so 1667 auf der Rückseite, während auf dem Avers Karl II. zu sehen war; vgl. John Rocttiers Medaille im British Museum, Reg. Nr. G3, EM.4; auch G3, EM.113.

173 [Edward Cook], Argumentum Anti-normannicum, An Explanation of the Frontispiece s.l. 1682; vgl. auch Foucault, Verteidigung, 127-129.

174 Mic̀ge, The New State of England, 1691; Britannia oppressa per Arausionensium principem liberata et restaurata, 1688; beide in Major, Madam Britannia, 2f. (Abb. 1, 2), auch 26f.; Neü-geharnischtes Gros-Britannien, 1689. 1714 liess John Croker Britannia George I. zum König krönen, British Museum Reg. Nr. 1978,1002.402 und M.8167; vgl. dagegen ihre unterwürfige Position auf den Medaillen der Deutschen Nikolaus Seelander, Reg. Nr. 1928,0514.15, und Ehrenreich Hannibal, Reg. Nr. 1906,1103.355. 
tin befreie: «The Harlot \& the Beast destroy'd ye Spouse set free». ${ }^{175} 1691$ gestand Britannia in einem Gedicht ihre Eifersucht, weil ihr Verlobter Wilhelm seine Aufmerksamkeit seiner Mutter Belgia sowie Bellona und Gallia widme - also auf dem Kontinent den Krieg gegen Frankreich führte. ${ }^{176} \mathrm{Wie}$ die Metaphorik der Ehe, so waren auch politische Analogien zu Ehebruch und Hurerei durch die Bibel nahegelegt. Hosea war der erste Prophet, der Israel für seine Hurerei, also den Bundes- beziehungsweise Ehebruch und die Verehrung falscher Götter, schwere Strafen ankündigte. ${ }^{177}$ Wie bereits erwähnt, taucht auch sonst das Motiv der treulosen und deswegen verstossenen oder schwer bestraften Gattin im Alten Testament wiederholt auf. ${ }^{178}$ Es ist ein Thema, das auch die Kirchenrechtler lange beschäftigte, wenn etwa ein Bischof seine Diözese verliess. ${ }^{179}$ Angesichts von Schismen und anderen Streitigkeiten gab es genügend Fälle, in denen auch Dichter denen Ehebruch vorwarfen, die Ecclesia im Stich gelassen hätten. ${ }^{180}$

Auch in der Auseinandersetzung um die französische Krone nach der Ermordung Heinrichs III. griffen Anhänger des - gemäss der Thronfolgeordnung legitimen - Nachfolgers, des Hugenotten Heinrich von BourbonNavarra, auf das Bild der Ehe zurück. Ein Flugblatt (Abb. 4) präsentierte ihn als Verlobten einer ihm versprochenen Gallia, die aber verwirrt ist offenbar weil der "Adulter Ligista» sie in Versuchung gebracht hat. ${ }^{181}$ Repräsentiert wird die katholische ligue als Ehebrecher durch einen Mönch mit Teufelsschwanz, der Gallias Lilienkleid noch zu greifen sucht, aber vom König zu Boden gestossen wird. Dabei zerbricht dem Adulter das Schwert, die Maske der Verstellung und der Rosenkranz entfallen ihm. Mit den Symbolen von Gewalt, List und Bigotterie wird offensichtlich auf den Dominikaner Jacques Clément angespielt, den Mörder Heinrichs III. Die Bildlegende ist deutsch und warnt die Frau vor den Folgen ihrer Versuchung: «Dein konig Heinrich von Bourbon, dem du mit recht bist zuge-

175 In Memory of ye Deliverance from Popery \& Slavery by King William III in MICLXXXVIII; British Museum, Reg. Nr.: 1850,1109.46; auch Major, Madam Britannia, 53f., Abb.' 16 (allerdings falsche Identifikation als «Church»); vgl. auch ebd. 32f. zur Hure Babylon im Book of Common Prayer von 1662.

176 Alicia d'Anvers, A Poem Upon His Sacred Majesty, 1691, nach Major, Madam Britannia, $25 \mathrm{f}$.

177 Hosca 1,$2 ; 2,2-8 ; 3,1 ; 6,7 ; 8,1 ; 9,1$.

178 Jesaja 1,21; 50, 1; Jeremia 2,1 f.; 3,20; 13,27; Hesekiel 23; vgl. oben, Anm. 57 und 58.

179 Trummer, Mystisches, 62-75; Gaudemet, Symbolique, 110-123.

180 Hierzu Blumenfeld, Dramatic Troubles, 185-98.

181 BNF, Hennin, Bd. IX, 920. 
thon, solch schwacheit möchte rechen.» Ihr rechtmässiger Gatte schmeichelt aber auch: «Franckreich ô Rosengarten schon, du zartc Braut, und königskron, Wielang volgst dem Ehbrecher?» Die Metaphorik erinnert an den Bildtyp der gekrönten «Madonna im Rosenhag», also Maria in einem von Rosen umrankten Paradiesgarten, wie sie etwa Stefan Lochner, Martin Schongauer oder Sandro Botticelli dargestellt hatten.

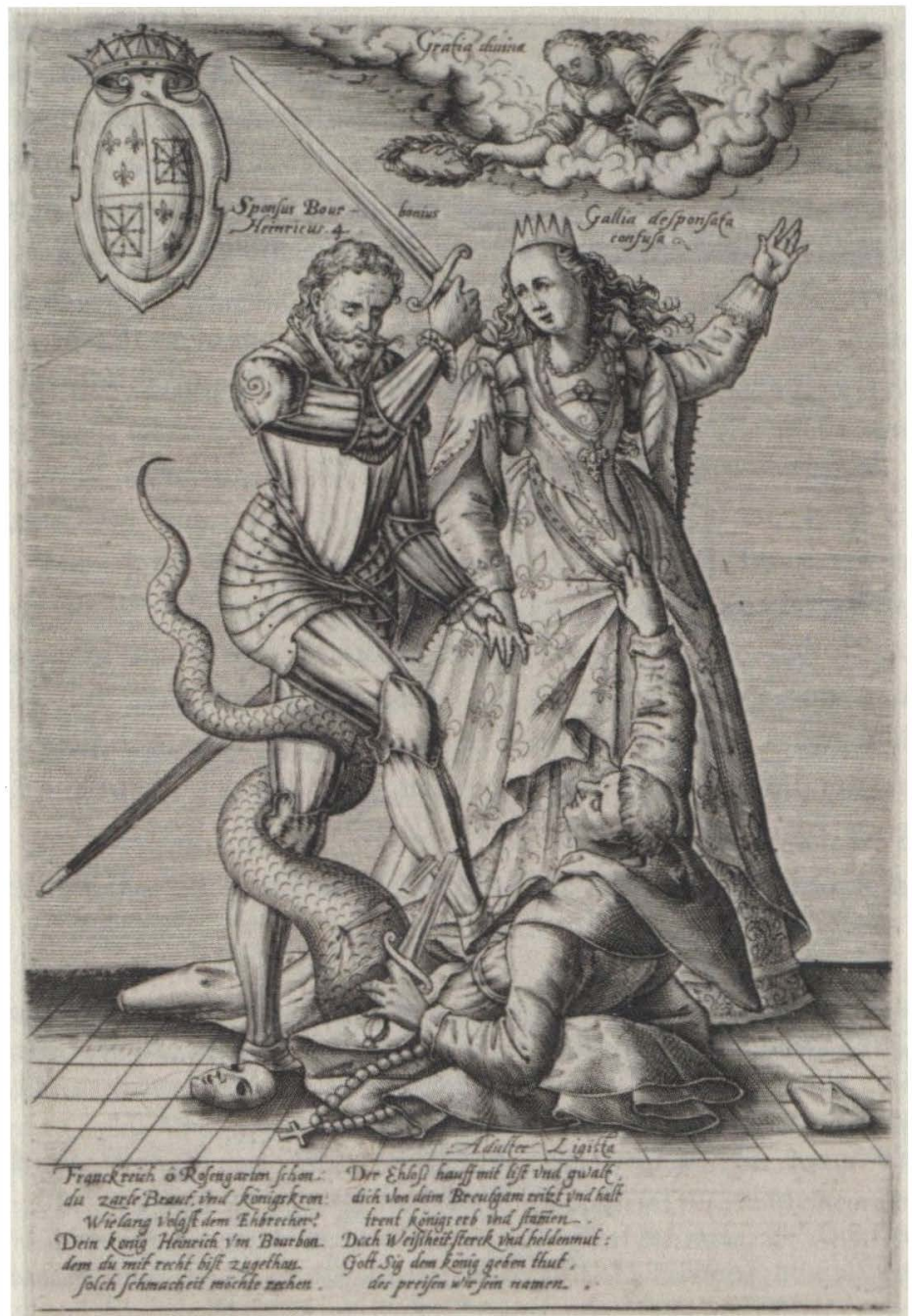

Abb. 4: Heinrich IV. mit Francia und dem ligistischen Ehebrecher, Flugblatt 1589. 


\section{Jungfräulichkeit}

Die theologische Parallele zur reinen Gottesmutter und zugleich jungfräulichen Braut Maria/Ecclesia war eine Voraussetzung dafür, dass die weibliche Partnerin Respublica in der mystischen politischen Ehe ebenfalls als Jungfrau verstanden werden konnte, wozu Ansätze bereits auf das Hochmittelalter zurückgehen. ${ }^{182}$ Doch auch abgesehen von Maria thematisiert die Bibel Jungfrauen, wobei im Hinblick auf Personifikationen vor allem Klagen, Anschuldigungen und Heilsversprechen wichtig sind, die etwa beim Propheten Jesaia an die jungfräuliche Tochter Zion («virgo filia Sion»)) oder Israel («virgo Israel») gerichtet werden. ${ }^{183}$ Amos 5,2 stimmt gar eine Totenklage an: "Gefallen ist sie und steht nicht mehr auf, die Jungfrau Israel; sie liegt zerschmettert am Boden in ihrem Land und niemand richtet sie auf.» Die alttestamentlichen Jungfrauen wurden so in ihrer ganzen Verletzlichkeit vorgeführt, aber in der christlichen Leseweise manchmal auch schon als typologische Ankündigung Mariä gedeutet. ${ }^{184}$ Jungfräulichkeit und Ehe liessen sich nach kanonischem Recht (can. 604 \$1) im ordo virginum insofern kombinieren, als Jungfrauen geweiht und damit «Christus, dem Sohn Gottes, mystisch anverlobt» werden konnten. Es handelte sich ebenfalls um ein unauflösbares Band auf Lebenszeit. Dabei wurde die «virgo» zur "sponsa Christì - so, wie die Kirche selbst, der sie mit der Weihe gehörte. ${ }^{185}$

Maria selbst bewies ebenfalls, dass eine Jungfrau einen Gatten haben konnte. Wie hier noch darzulegen ist, sollte die Madonna gerade in ihrer Jungfräulichkeit zum Modell für die Darstellung der Landespersonifikationen werden. Um die Thronbesteigung Ludwigs XI. im Jahr 1461 zu feiern, orientierte sich Georges Chastellain in L'Entrée du roy en nouveau règne an der Weihnachtsgeschichte, wobei er Francia in Analogie zu Maria als keusche und unversehrte Jungfrau zeichnete. ${ }^{186}$ Gut bekannt ist die Darstellung Elisabeths I. als virgin queen und Glorianna. 1582 vereinte Thomas Bentley in einem Sammelwerk religiöse Texte für Frauen unter dem Titel Lamps of Virginitie, um Elisabeth zu ehren, der das Werk gewidmet war, zu dem sie

182 Vgl. etwa oben, Anm. 68, Rupert von Deutz. Siena bezeichnete sich als «civitas virginis», Pisa als «virginis ancilla», vgl. Wolters, Bilderschmuck, 237, Anm. 4.

183 2. Könige 19,21; Jesaia 23,12; 37,22 und 47,1.

184 So die erwähnte Stelle Jeremia 31,21: «femina circumdabit virum», die Frau wird einen Mann umgeben.

185 Vgl. Johannes Paul II., Vita consecrata.

186 Beaune, Naissance, 316. 
auch beigetragen hatte. Auf Bèzes Paraphrasen der Psalmen baute das Stück «God's familiar Speech to the Queen» auf: «I have begotten thee, and espoused thee to thy king Christ, my Son; crowned thee with my gifts, and appointed thee Queen, to reign upon my Holy Mount Zion.» Als Gattin Christi sei Elisabeth die Mutter und Amme seines neuen Volkes Israel, England, mit dem Gott in einem Bund (covenant) vereint sei. Ein Stich nimmt die Apotheose der Königin schon vorweg, deren leiblicher Körper unter den Toten betend das Jüngste Gericht erwartet, während Christus im Himmel ihrem geistigen Körper eine Krone aufsetzt - in der Art einer Marienkrönung. ${ }^{187}$ Auf dem sogenannten «Ditchley-Porträt» von etwa 1592 wurde sie ähnlich wie eine Schutzmantelmadonna dargestellt. Elisabeths Kleid und die Karte Englands unter ihren Füssen gehen ineinander über, wodurch die «imperial virgin» als sterbliche Vertreterin des unsterblichen body politic erscheint - ihre «Ehe» mit dem Königreich ist bereits erwähnt worden. Die Jungfräulichkeit stand dazu ebenso wenig im Widerspruch wie bei der Madonna und wurde durch das mariologische Symbol der Perlenkette verstärkt. Auf anderen Bildern dient dazu das Sieb der Vestalin Tuscia oder, so bei Crispijn van der Passe d. Ä. auf einem Stich von 1596, neben den Perlen auch Rosen, Monde, der makellose Hermelin, ein korinthisches Kapitell und Phönix. ${ }^{188}$ Der Phönix war nicht nur ein Sinnbild der Auferstehung Christi und entsprang ebenso wenig wie der Heiland sexueller Fortpflanzung; er ist zudem unsterblich, ein Symbol der perpetuitas. Damit symbolisiert er ebenso wie die korinthische, jungfräuliche Säule die staatliche Souveränität. ${ }^{189}$ In Elisabeths Staatsporträts fallen so die körperliche Integrität der Frau und die politische Unabhängigkeit des Landes zusammen. Mit etwas anderen Implikationen sprach später Ben Johnson in einer «obsession with married chastity») die (katholische) Gattin Karls I., Henrietta Maria, mit «Haile Mary, full of honours» an. Ebenso wie die Mutterschaft der «first Mary» die Menschheit beglückt habe, erfreue «the womb divine» der Henrietta Maria die «whole Nation» durch die Geburt des künftigen Karl II. ${ }^{190}$

187 Bentley, Monument; der Stich gegenüber von 862; dazu King, Thomas Bentley's Monument. Den Hinweis verdanke ich Merio Scattola.

188 King, Queen Elizabeth I.; Montrose, Elizabeth; Hackett, Virgin Mother; Scholz, Körper; dies., Body Narratives; allgemein Strong, Cult of Elizabeth; sowie Yates, Astraea; zur Perle: Ohly, Perle des Wortes, bes. Abb. 70.

189 Kantorowicz, Zwei Körper, 1990, 383-398, 409-411, Abb. 22-24; Yates, Astrea; Maissen, Geburt, 323f. (Phönix), 388-390 (Corinthica); Marin, Porträt, 165-168.

190 Zitiert von Baynes Coiro, Ball of Strife, 32f.; vgl. auch Corns, Duke, Prince and King, insbes. 17-21. 


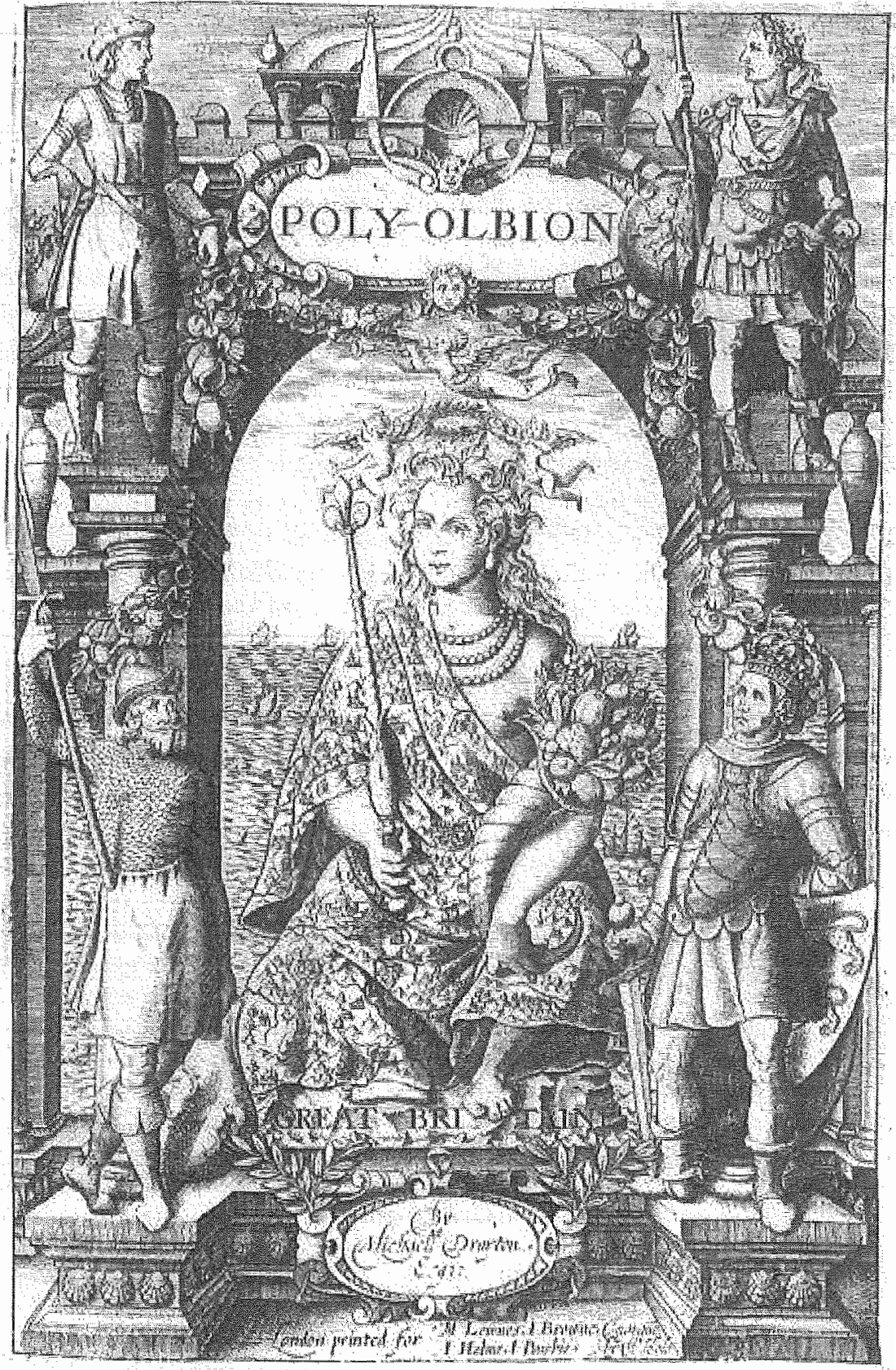

Abb. 5: Michael Drayton, Poly-Olbion, 1612. 


\section{Brautwerbung}

Der elisabethanischen Ikonografie auffallend ähnlich ist die Bildsprache auf dem Frontispiz (Abb. 5) zu Michael Draytons Poly-Olbion von 1612, einer Beschreibung von ganz England (Albion) in Alexandrinern. Die Personifikation Great Britain trägt ein Gewand in Form einer Landkarte sowie Zepter und Füllhorn - und Perlen als Zeichen der Jungfräulichkeit. Das widerspricht scheinbar der Tatsache, dass vier erfolgreiche Bewerber um ihre Gunst sie auf einem Triumphbogen umgeben, "what Princes Time hath seene Ambitios of her»: oben der legendäre Brutus und Julius Caesar, dem sie lange widerstand; nach der Scheidung von Caesar («Divors't from him») gewann der mythische Sachse Hengist ihre Gunst, doch wandte sie später ihre Liebe dem Normannen Wilhelm zu, der unten rechts Hengist gegenübersteht. ${ }^{191}$ Die Metaphorik der erotischen Eroberung wird also gebraucht, um die reale, militärische Unterwerfung darzustellen. ${ }^{192}$ Unter männlichen Herrschern übernahm somit allmählich Britannia die Stellung, die vorher Elisabeth als Jungfrau beansprucht hatte: «Britannia, then, had become an acceptably Protestant version of the Virgin Mary. ${ }^{193}$ In Anthony Mundays Re-United Britania von 1605 machte Britannia im Gespräch mit Brutus entsprechend deutlich, dass erotische Eroberung und Jungfräulichkeit kein Widerspruch waren: «But that my conquest, first by thee begun, Hath in fames Chronicle such honor woon, That thy first setting from Albania, Crowned me thy virgin Queene Britania.»1 ${ }^{194}$

191 Drayton, Poly-Olbion; vgl. Dresser, Britannia, 30f. und Major, Madam Britannia, 47-53. 192 Ebenso Jakob I. zum englischen Parlament, King James VI and I, Political Writings, 164: «You are to be the husband, they [die Schotten] the wife: you conquerours, they as conquered, though not by the sword, but by the sweet and sure bond of love.». Vgl. auch Harms, Illustrierte Flugblätter, Bd. 4, 212f. (IV, 162): Crispijn van der Passe d. J. stellte die Eroberung von Herzogenbusch durch Friedrich Heinrich von Oranien als Nachgeben der städtischen Jungfrau gegenüber den Werbungen des Statthalters dar. Auch die Eroberung Pilsens durch den Grafen von Mansfeld wurde dichterisch als Verlust der (religiösen) «Jungfrawschaf»» beschrieben, vgl. Emich, Bilder einer Hochzeit, 212, Anm. 25. Vgl. für dieses auch in anderen Kulturen gebräuchliche Motiv Duerr, Obszönität, 220-241 («Rammbock und Festungstor»); für Köln im 17. Jahrhundert: ebd., $222 f$.

193 Dresser, Britannia, 34. Vgl. auch das Frontispiz für John Nalsons Impartial Collection of the Great Affairs of State von 1682, wo Britannia als Mater dolorosa vom göttlichen Licht bestrahlt wird und sich im Vertrauen auf die anglikanische Kirche von einem nahenden Werber abwendet, der halb Puritaner, halb Jesuit ist.

194 Anthony Munday, The Triumphes of Re-United Britania, 1605, zitiert nach Major, Madam Britannia, 23. 
Ähnliche Kompositionen gab es auch anderswo: Germania umgeben von den sagenhaften zwölf ersten deutschen Königen; ${ }^{195}$ oder Hollandia im Kreis ausländischer Eroberer und cinheimischer Befreier. ${ }^{196}$ Sie brachten zum Ausdruck, dass die abstrakte weibliche Jungfräulichkeit, sollte sie erhalten blciben, ganz im Sinn der mystischen Ehe den konkreten schützenden Mann brauchte. ${ }^{197}$ Die Parrbeziehung war die Regel für die politische Ordnung: hier die Respublica mit ihrer Mitgift, ihren materiellen Gütern, dort der Fürst mit seinen Waffen. Dicses Grundmotiv liess sich aber unterschiedlich komponieren. So rettcte Wilhelm von Oranien als «Nassauscher Perseus» in Jacob Duyms gleichnamigem Stück die Andromeda, nämlich eine nackt angekettete niederländische Magd, vor dem spanischen Drachen. ${ }^{198}$ Auf Hessel Gerritsz' Stich Afbeeldingbe van't Nederlandts Bestandt, ciner Allegorie auf den niederländisch-spanischen Waffenstillstand von 1609, thront eine «Belgica libera» im Sonnenlicht, umgeben von Moritz von Oranien und zwci bürgerlichen niederländischen Ständevertretern («ordines»), während ihr gegenüber die ebenfalls thronende «Belgica Archiducibus subdita» von Philipp III. und Spinola im Schatten gehalten wird. ${ }^{199}$

Jan 'T'engnagel malte um 1618 eine Allegorie auf die Herrschaft des Prinzen Moritz von Oranien. ${ }^{200}$ (Abb. 6) Eine thronende Hollandia hält mit ihrer Linken eine Lanze, auf der oben der Freiheitshut steckte. Moritz von Oranien stützt die Lanze daneben stehend mit seiner Rechten. Zwischen ihnen erkennt man Justitia, mit einer Waage, als Allegorie der politischen Grundtugend Gerechtigkeit, und links neben Hollandia Fides mit der Bibel in der Hand als Personifikation von Kirche und Glaube, während zu ihren

195 Vgl. Jonas Silbers Nürnberger sogenannte «Weltallschale» für Rudolf II in Trzinski, Ikonographie, 204-225, Abb. 69.

196 Vgl. die 'Titelblätter der Werke von Arnoldus Montanus und Philipp von Zesen (1660) in Gamboni u. a., Zeichen der Freiheit, 81.

197 Eine offenbar singuläre Ausnahme unter diesen Paarbeziehungen stellt Adriaen van de Vennes Waffenstillstandsallegorie von 1616 dar, heute im Louvre (Dlugaiczyk, Waffenstillstand, 84-86, 341, Kat. 27; vgl. auch 81f.), insofern die Hochzeitsfeier der weiblich personifizierten nördlichen Niederlande mit einer männlichen Personifikation der südlichen Provinzen stattfindet, nicht mit einem konkreten Mann. Üblicherweise wäre das der Oranier, was hier aber nicht passt.

198 Atlas van Stolk, 461; vgl. Duits, Vryheid, 106-109.

199 Dlugaiczyk, Waffenstillstand, 55-58, 81-83, 329f. (Kat. 3, 7); vgl. ebenfalls 338 (Kat. 20/1), den Stich von Pieter Serwoutrs von 1608, der die beiden Personifikationen ebenfalls in Licht und Schatten taucht.

200 Grijzenhout, Verbeelding, 259 (Abb. 8); Bussmann/Schilling, Krieg und Frieden in Europa, 30f., Nr. 20. 


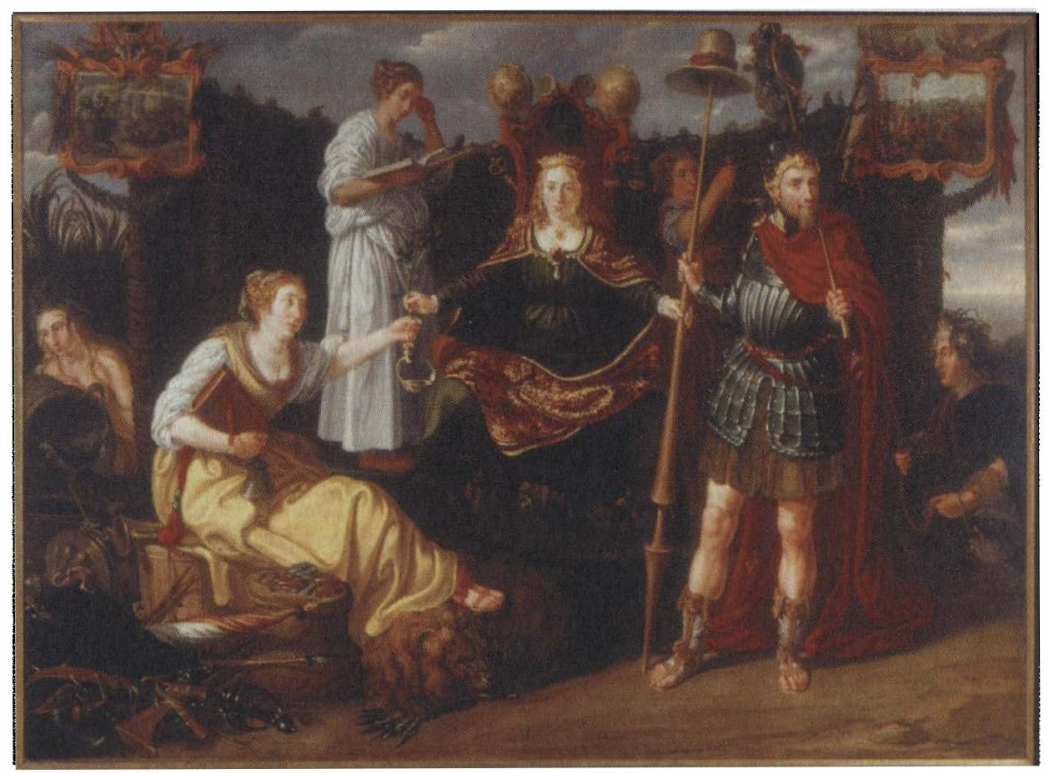

Abb. 6: Jan Tengnagel, Allegorie auf die Blüte der Republik unter Moritz von Oranien, ca. 1618, Gemälde, Museum Het Prinsenhof Delft.

Füssen eine Abundantia sitzt, welche Hollandia die Schätze des Landes darreicht. Die drci Allegoricn bringen zugleich die ständische Gesellschaftsstruktur zum Ausdruck, die den politischen Körper strukturicrt: Klerus als Betstand (Fides), Adel als Wehrstand (Moritz) und Herrschaftsträger (strafende und belohnende Gerechtigkeit) sovvie der Dritte Stand als Nährstand (Abundantia). Schon damit ist der Statthalter als integraler Teil der Ordnung erfasst, nicht als ihr. Dominator. Das schlägt sich auch bildlich nicder, wic der Vergleich mit Lucas de Heeres Philipp II. (Abb. 2) zeigt. Dort thront der König; hier die Respublica. Sie trägt dic Kronc, nicht - vie bei de Heere der Mann. Ihr Kopf ist glcich weit oben wic derjenige von Moritz, während Philipp bei de Heere herabschaut. Die Personifikationen der Provinzen bringen ihm Güter dar, während sie hier solche bckommt (von Abundantia) und gemeinsam mit dem Oranicr die Lanze hält, also für äussere Sicherheit sorgt, wozu ja die finanzicllen Ressourcen insbesondere der Städtc ebenso unabdingbar waren wic die adligen Schwerter. Tengnagel präsentierte das Eheparr in einer gleichrangigen Partnerschaft, was sie von Lucas de Heeres respektvoller Hierarchie unterscheidet und erst recht von den zahlreichen Landespersonifikationen, die demütig zu ihrem (absoluten) Monarchen cmporschauen. 
Diese Gleichrangigkeit ergab sich durch die Verfassung. Der Ständepcrsonifikation von 1559 war ihr Gatte, der König Philipp II., gegeben; die Landespersonifikation von 1623 konnte ihren Statthalter Moritz von Oranien als Ehemann auswählen. Erst in dieser Konstellation, nicht zuletzt mit ausländischen Implikationen, machte Brautwerbung als Bildmotiv Sinn. In einer Scric von 13 Zeichnungen stellte Joachim Wtewael um 1620 die Geschichte des niederländischen Aufstands als Allegorie dar: Belgica wird von spanischen Adligen (darunter wohl Alba und Spinola) umworben, belästigt und geschändet, doch von galanten Niederländern (unter anderem Wilhelm und Moritz von Oranien) gerettet und in ihrer Blüte wiederhergestellt. ${ }^{201}$ Auf eincm Kupferstich Crispijn van de Passes d.J. der während der westfälischen Friedensverhandlungen entstand, wird dic gekrönte und thrononde Jungfrau Hollandia von einem spanischen Granden und eincm französischen Edelmann mit Geschenken umworben. Doch ein einheimischer Bürger umfasst ihre Brust, um sie vor den adligen Repräsentanten der Nationalmonarchien zu bewahren, die ihre eigennützigen Pläne verfolgen und ihre Freiheit nicht achten würden. Diescm ihrem Freund wendet sie sich mit den Worten zu, welche die anderen Freier zurückweisen: «Sein Blut ist noch jung und warm, das ist das Beste für einc Jungfrau wie mich.» Das Wappentier der Niederlande ist dieser Liebe gewogen: ein Löwe mit sicben Pfeilen, für jede Provinz einc. ${ }^{202}$

Das Motiv war schon früher aufgetaucht, auf dem Flugblatt Dans om de Hollandtsche Brint von 1615. (Abb. 7). Es warnte dic holländische Braut vor den beiden Habsburgern, die sie während des zwölfjährigen Waffenstillstands (1609-1621) im Achtzigjährigen Kricg mit Spanicn tanzend umwerben: Kaiser Matthias und Philipp III., der König von Spanien, gefolgt von Erzherzog Albrẹcht VII. und Isabella Clara Eugenia (den Statthaltern in den südlichen, Spanischen Niederlanden), während im Hintergrund der Papst zum 'Tanz spielt. Hollandia beobachtet die Szene mit einem Fernrohr aus einer Gartenlaube heraus, auf deren Dach der holländische Löwe wacht. Neben ihr tut das auch der Statthalter, derselbe Moritz von Oranien,

201 McGrath, Netherlandish History, sowic Lowenthal, Netherlandish history, und Dlugaiczyk, Waffenstillstand, 324-327.

202 Harms, Illustrierte Flugblätter, Bd. 4, 332f. (Nr. 251). Fast zeitgleich wurde eine ähnliche Konstellation auf einer niederländischen Medaille von 1655 deutlich deftiger dargestellt: Oliver Cromwell war abgebildet, der Britannia den Kopf in den Schoss legt und den Hintern entblösst hat. Ein Franzose und ein Spanier streiten sich im Hintergrund darum, wessen König zuerst ehrerbietig den Hintern küssen darf; vgl. British Museum, Coins and Medals, Nr. MB1p420.60, und Morrill, History, 252. 
und der Kranich auf Hollandias linker Hand symbolisiert Prrdentia: kluge Vorsicht im Umgang mit den fremden Verführern. ${ }^{203}$ Die Gartenlaube erinnert in der Form an einen baldachinartigen Tabernakel, wie etwa Madernos Baldachin in St. Peter - nur dass hier der Löwe den Platz des Kruzifixes einnimmt. In der katholischen Kirche steht der Tabernakel als Aufbewahrungsort für die Hostie als Leib Christi auf dem Hauptaltar. Der Baldachin überragt ihn und repräsentiert das Himmelszelt: Wer sich darunter befindet, steht also unmittelbar unter Gott - nicht nur der weltliche Leib Christi, sondern auch der Souverän, dem cin solches Ehrendach im höfischen Zeremoniell vorbehalten war, wie es nicht nur in Versailles über dem Lit d'état hing.

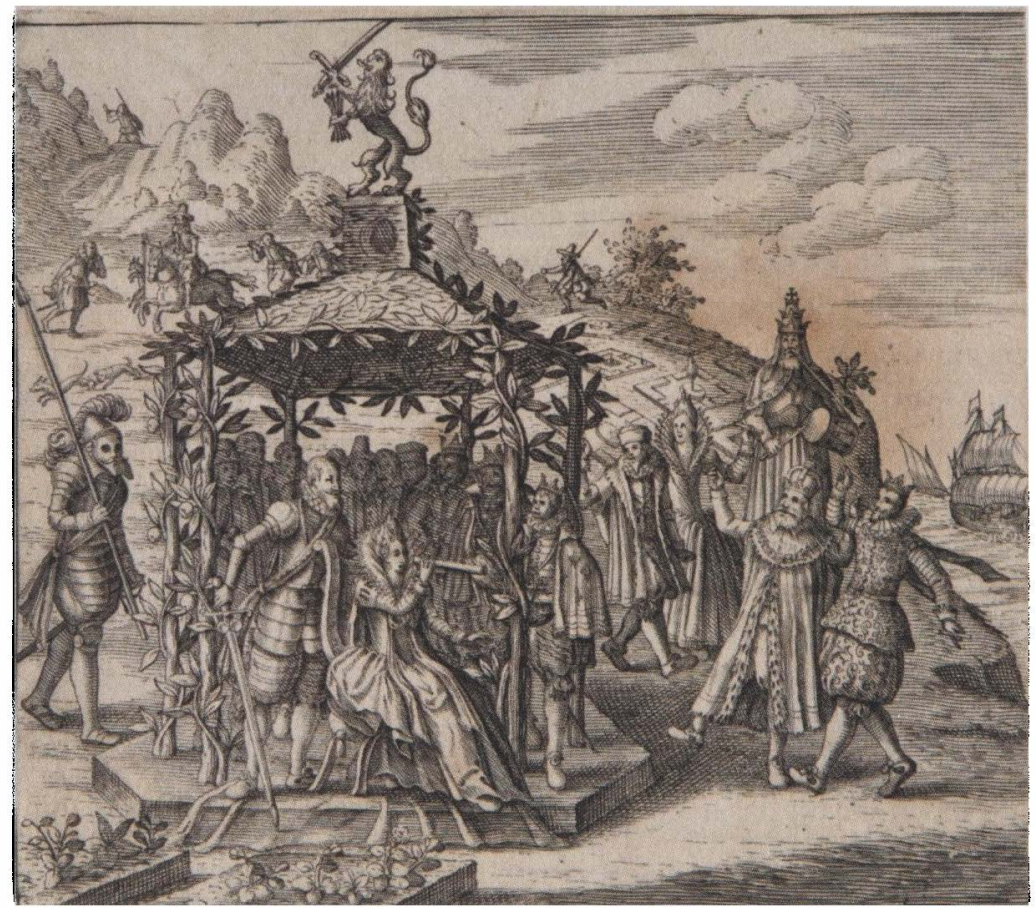

Abb. 7: Ghy Patriotten thans «kijck uyt, kijck uuy, Sict wat een vreemden Dans» om de Hollandtsche Bruut, Flugblatt, 1615, Atlas van Stolk, Nr. 1308.

203 Atlas van Stolk, 1308, Ghy Patriotten t'hans «kijck uyt, kijck uuy, Sict wat een vreemden Dans» om de Hollandtsche Bruut, 1615; vgl. auch Dlugaiczyk, Waffenstillstand, 86f., 342 (Kat. 28). 


\section{Hortus conclusus}

Gerade im niederländischen Kontext weckte der Gartenbaldachin aber auch noch andere Assoziationen. ${ }^{204}$ Ein anderes Flugblatt von 1617 (Abb. 8) warnt im selben Geist vor den betrügerischen Friedensplänen der Spanier, die ein junger Höfling scheinbar ehrerbietend überbringt. Sein Hinterkopf verrät jedoch, dass dies nur eine Maske ist, hinter der sich ein räuberischer Wolf verbirgt. ${ }^{205}$ Hollandia, die niederländische Magd, thront in einem Garten mit Orangenbäumen, in dem Moritz von Oranien (Orange) Unkraut jätet: Als adliger Anführer der aussenpolitischen Kriegspartei und der reformierten Orthodoxie (Gomaristen) bekämpft er also die bürgerliche Friedenspartei der holländischen Städte und die ihnen nahestehende gemässigtarminianische Variante des Calvinismus. Der Konflikt sollte 1619 mit der Hinrichtung Johan van Oldenbarnevelts enden, des Anführers der Friedenspartei.

Der Garten, in dem Moritz, Hollandia und ihr beschützender Löwe weilen, ist umzäunt, das Eingangstor verschlossen. Der Ursprung dieses bortus conclusus lag bereits in der spätmittelalterlichen Marienikonografie. Dic Madonna sitzt oder steht in einem (Paradies-)Garten (bortuls), der von einem Zaun umschlossen (conclusus) ist. Das Motiv geht wiederum auf die Auslegung des Hohelieds $(4,12)$ zurück: «Ein verschlossener Garten ist meine Schwester, [meine] Braut, ein verschlossener Born, eine versiegelte Quelle.» Im Einklang mit der dortigen Liebesmetaphorik kann Maria erneut als Ecclesia verstanden werden, die als keusche Braut (Maria sponsa) dem Bräutigam Christus in symbolischer Ehe verbunden ist. So wurden sie auch gemeinsam im Garten abgebildet oder aber im Gespräch über den 'Zaun hinweg, dessen 'Tor dann allerdings weit geöffnet war. Ein niederländisches Blockbuch von etwa 1465 erzählte die Geschichte Marias in Form einer Hoheliedauslegung und kombinierte eine solche Gegenüberstellung des Paars mit den bereits behandelten Liebesversen. ${ }^{206}$

204 Der Zusammenhang wird darin sehr deutlich, dass ein weiteres Flugblatt von 1615 mit dem 'Titel «Den wackeren Leew» eine ähnliche Konstellation von Hollandia mit Fiernrohr, Kranich und Oranier zeigt, diesmal aber in einem umzäunten Garten. Dieser Stich ist wiederum in der restlichen Komposition (Prälaten, spanische Soldaten) eine Vorform des unten, Abb. 9, behandelten Testaments des Friedens aus demselben Jahr.

205 Atlas van Stolk, 1329, Maechts Antwoort tegen op en aen de aenspraek van een courtisaen, 1617.

206 http://daten.digitale-sammlungen.de/bsb00038199/image_13 (6.1.2012); dazu Delen/ Meertens, Canticum Canticorum. Ich danke Marilyn Lavin für gründliche Diskussionen 


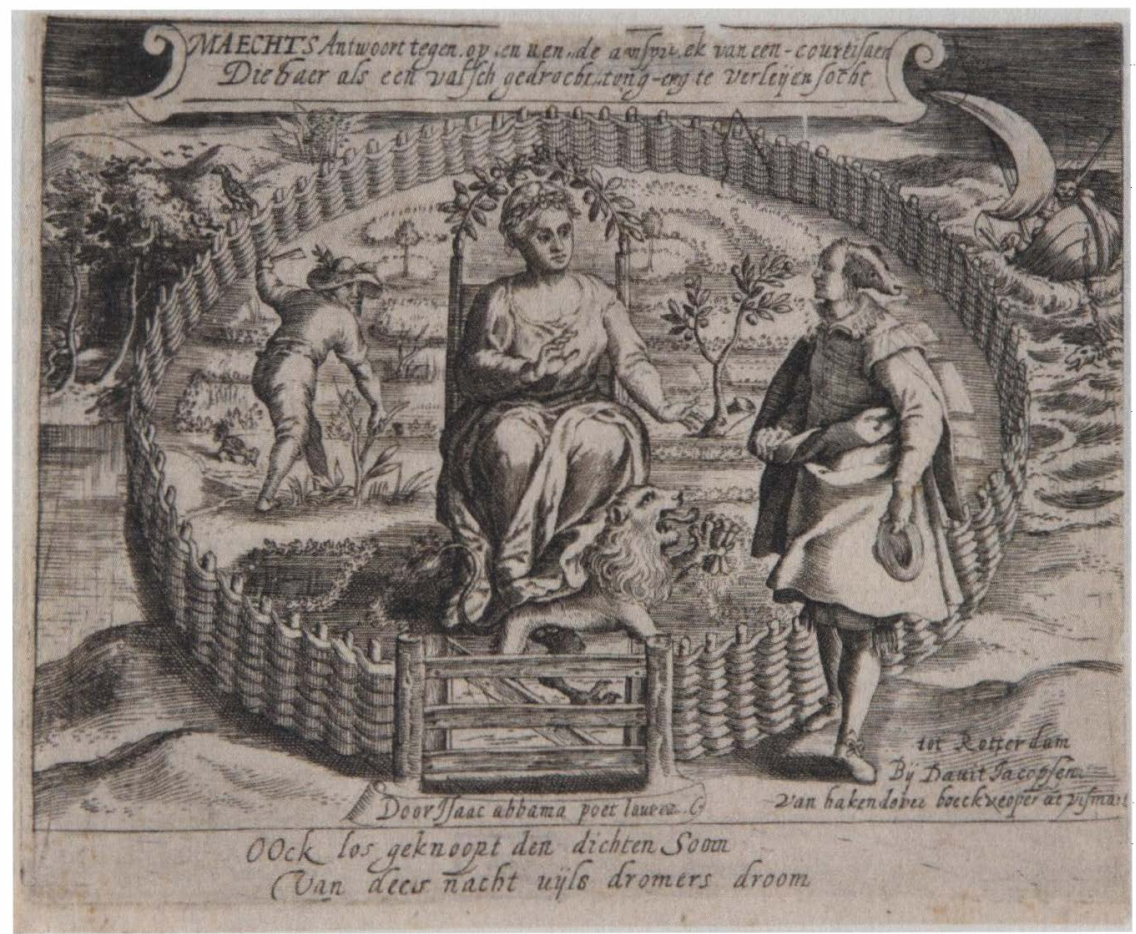

Abb. 8: Macchts Antwoort tegen op en aen de aenspraek van cen courtisaen, Flugblatt 1617, aus: Frederik Muller, De Nederlandsche geschiedenis in platen.

Die Vorstellung des bortus conclusus war dem Motiv des Rosengartens verwandt, der auch bei Heinrichs IV. Verteidigung der Francia gegen den ligistischen Ehebrecher begegnet. Die Madonna im Rosengarten war ein sehr populäres Bildmotiv und konnte, in einem Brüsseler Kodex von etwa 1450, auch mit einem vor ihr knienden Herrscher kombiniert werden, nämlich Karl dem Grossen. ${ }^{207}$ Die Rose stand als marianisches Symbol schlechthin für die unbefleckte Empfängnis, also die Jungfräulichkeit. ${ }^{208}$ So vvurde der Rosengarten als unmittelbares Werk des Allmächtigen auch Gegenstand von Dichtungen:

über das Blockbuch und den Einblick in ihr Arbcitsmanuskript (Mä̀z 2010) zu diesem Thema.

207 Cod. 9213, Bibliothèque royale, Brüsscl; abgebildet bei Vetter, Maria, Abb. 21. 208 Schumacher-Wolfgarten, Art. Rose, 563-568; Vetter, Maria. 
«Maria, die viel zarte, sie sass im Rosengarten, den got selber gezieret hat mit seiner götlichen majestat.,209

Auf ein Land übertragen wurde die Gartenvorstellung zuerst in Frankreich, wo man seit dem 14. Jahrhundert das Königreich als «jardin de douce France» besang und seit der Mitte des 15. Jahrhunderts so darstellte. Jean Gerson entwickelte theologisch die Gemeinsamkeiten des himmlischen (Paradies-)Gartens und des Gartens Frankreich. Die gerechten Gesetze bildeten einen Zaun, der die irdischen oder spirituellen Feinde von den Schafen und ihrem Hirten fernhielt. Das verwies mit den Symbolen der Jungfräulichkeit (Rose, Lilie) bereits auf die Idee des bortus conclusus. Doch die bildlichen Darstellungen des «jardin de France» zeigen zwar einen Zaun mit offenem Tor, aber keine Jungfrau, sondern einen Lilienwappenbaum, der von einem Baldachin überwölbt ist, und den König selbst, der den Garten pflegt und hütet wie der göttliche Hirte seine Herde. ${ }^{210}$

In den Niederlanden dagegen, wo der bortus conclusus als religiöses Motiv schon im Mittelalter oft aufgegriffen worden war, nahm im Unabhängigkeitskrieg Belgica/Hollandia, die niederländische Magd, die Position der Jungfrau im Hollandse tuin, dem holländischen Garten, ein. ${ }^{211}$ Das Motiv wurde in den 1570er Jahren populär und sehr oft dargestellt.. ${ }^{212} \mathrm{Da}$ es sich bei den Darstellungen oft um Flugblätter handelte und damit um Massenprodukte patriotischer Propaganda, erreichte diese Symbolik ein breites Publikum; ebenso durch Medaillen oder Ofenkacheln. Der bortus conclusus als Ort der jungfräulichen Reinheit stellte die Generalstaaten dar, die ihre territoriale Integrität bewahren wollten. Spanien belagerte sie, weil es ihre Souveränität niçht anerkannte. Diese Warnung wiederholte 1615, während

209 Das undatierte Gedicht aus dem 15. Jahrhundert zitiert nach Hoffmann von Fallersleben, Geschichte, 172; vgl. auch Vetter, Maria, 15.

210 Beaune, Naissance, 318-320, Abb. 8; Kıynen, Idéal, $255 f$.

211 Dazu van Winter, De hollandse Tuin, 29-121, und Dlugaiczyk, Waffenstillstand, 102-106.

212 Ein frühes Beispiel mit Magd und Löwenwappen, von Philips Galle, stammt möglicherweise aus den 1560er Jahren, vgl. http://www.geheugenvannederland.nl/?/nl/items/ BVB01:MB1563DIPK (6.1.2012). Datiert ist eine Medaille von 1573, vgl. Grijzenhout, Verbeelding, 254-256 (Abb. 1), Gamboni u. a., Zeichen der Zeit, 329f., und Dlugaiczyk, Waffenstillstand, 342 (Abb. 8); der Löwe in einem verschlossenen Garten als Gegenspieler der «Spaensche tiranni» ist auf einer Medaille von $1575 \mathrm{zu}$ sehen, vgl. Le Clerc, Explication historique, 38 (Abb. LXI); auch Harms, Illustrierte Flugblätter Bd. 4, 94f. (IV, 68); Sawyer, Medium and Message, 167f. (Abb. 9.1.); und Schama, Schöner Schein, 87. 
des Jülich-Klevischen Erbfolgestreits, auch Willem Buytewech, der Hollandia im Garten zeigte, umgeben von «des vaderlants vereenicht gemeent»der vaterländischen Gemeinschaft, also der Respublica. Eine Pyramide mit der Inschrift «privilegie», die wie der Obelisk die Ewigkeit und damit die Souveränität darstellt, wird von einem eher kümmerlichen, also wohl innenpolitisch gelähmten Orangenbäumchen beschützt, so dass die Abwehr vor allem beim Löwen liegt, der das Tor und den Zaun der Standhaftigkeit (Trouvicheyt) bewacht. ${ }^{213}$ Aussen nähert sich die Statthalterin der südlichen Niederlande Isabella Clara Eugenia, auch sie janusköpfig: nach vorn das Lächeln des Friedens, nach hinten - zu den nachfolgenden Soldaten - die Fratze des Krieges. ${ }^{214}$ An der Leine führt sie den Leoparden, vor dem der Titel warnt; möglicherweise ist auch das ein Bezug zum Hohelied, das ja die Grundlage des Gartenmotivs bildet. ${ }^{215}$ Jedenfalls näherten sich in den ursprünglichen, religiösen Varianten des Bildes ebenfalls Tiere dem bortus conclusus und den jungfräulichen Symbolen, nämlich vier Hunde, die den vier apokalyptischen Reitern entsprechen: Misericordia, Pax, Justitia, und Veritas, alle vom Erzengel Gabriel geführt. ${ }^{216}$

213 Für Pyramide/Obelisk als Symbol ewiger Majestät vgl. Roeck, Titelkupfer, 343-349; Henkel, Emblemata, 1222: «Pyramides Pharium monumenta perennia Regum» und auch den Entwurf des Abbé de Lubersac für ein Montment à la gloire du roi Lonis XVI et de la France, woran das Medaillon des Königs aufgehängt ist und von der Tugend der Zeit überreicht wird, während zu Füssen der Säule Francia die Reichsinsignien bereithält, vgl. Sabatier, Versailles, 578-581, ferner Milovanovic, Du Louvre à Versailles, 212 (Abb. 64); vgl, auch Dlugaiczyk, Waffenstillstand, 157-179.

214 Zu Buytewech: Mörke, Bataver, 208f.; Schama, Schöner Schein, 87-89; Dlugaiczyk, Waffenstillstand, 102f., 341 (Kat. 26).

215 Vgl. Hohelied, 4, 8: «Komm mit mir, meine Braut, vom Libanon, komm mit mir vom Libanon, tritt her von der Höhe Amana, von der Höhe Senir und Hermon, von den Wohnungen der Löwen, von den Bergen der Leoparden!»

216 Vgl, etwa den Flügelalter von Maria-Gail, Villach, um 1500, oder das Antependium von Lachen, um 1480, heute im Schweizerischen Nationalmuseum; zu den mariologischen Symbolen gehört dort ausser dem Einhorn auch Phönix. Siehe Daley, Late Medieval Iconocraphy, 255-258; Frauenfelder, Symbolik, 133-136; Wyss, Hortus-Conclusus, 113-124. Wyss zeigt auch (119), dass das Motiv im reformierten Umfeld weiter gepflegt und sogar von Bullinger gerechtfertigt wurde. 


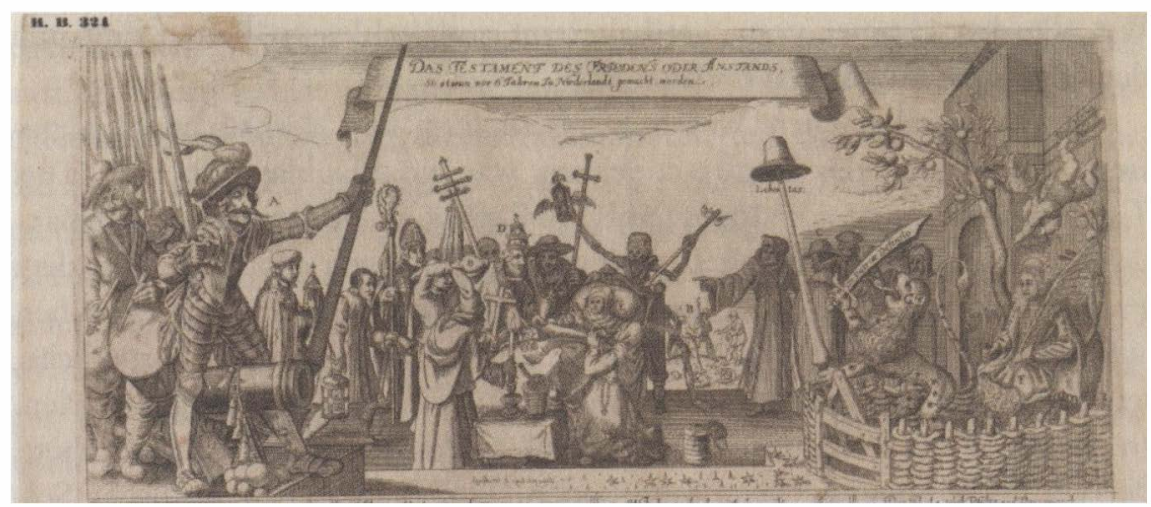

Abb. 9: Das 'Testament des Friedens oder Anstands, 1615.

Im 16. Jahrhundert veränderte sich aber diese anfangs positive Deutung des Gartenumfelds: Der bortus wurde zu einer Festung der Keuschheit, die durch Begicrden belagert wird. ${ }^{217}$ Wie das Zauntor nun - anders als gegenüber Christus - verschlossen ist, so verwandeln sich dic Hunde: Auf den mittelalterlichen religiösen Bildern sind sic als Tugenden wie spiclende Welpen frcudig auf den Zaun gesprungen. Nun sind es ein bedrohlicher Lcopard oder, in einer schwcizcrischen Variante, ein spanischer Wolf und ein bayerischer Eber, die in den Zaun einbrechen - cine allegorische Darstellung der Veltliner Wirren im Dreissigjährigen Krieg, mit eidgenössischen Akteuren im Inneren des Zaunes und den kriegführenden Parteien aussen. ${ }^{218}$ Schon beinahe ganz abgetragen ist der Zaun auf einem niederländischen Stich von 1672, dem Katastrophenjahr des Überfalls durch Ludwig XIV. Hollandia hält verzwcifelt den Stab mit dem Freiheitshut fest, den französische Soldaten mit Scilen schon weit heruntergezogen haben. Der Löwe mit dem Hosenbandorden (Wilhelm III. von Oranicn) will ihr mit dem Schwert helfen, ist aber am Obelisken festgekettet - erneut das Symbol der Souveränität, die über Krieg und Frieden entscheidet, wie der Januskopf auf der Spitze zeigt. Ein Wachhund schläft, und auch dic nicderländischen Soldaten im Hintergrund greifen nicht ein. Der Künstler protestierte so gegen die Friedenspolitik der Regentenrepublikaner um Jan de

217 Scholz, Body Narratives, 90-93; vgl. auch die männlichen Bedrohungen ausserhalb des Gartens auf Claes Jansz. Visschers Allegorie auf den Waffenstillstand von 1615, Atlas van Stolk, 1312, und Dlugaiczyk, Waffenstillstand, 347 (Kat. 40).

$218 \mathrm{Zu}$ den «Spanischen Muggen» Maissen, Eidgenossen, 273f. 
Wit, die den Oranier vom Statthalteramt ausgeschlossen hatten und nun den Invasoren zu erliegen drohten. ${ }^{219}$

Die in verschiedenen Varianten überlieferte und deshalb wohl populärste Umsetzung des hortus conclusus war ein Flugblatt mit dem Titel Testament des Friedens von 1615. (Abb. 9). Rechts im Bild sitzt die niederländische Magd im umzäunten Garten, mit dem Löwen an ihrer Seite, dem Freiheitshut auf der Lanze und einem Orangenbaum. Ihnen gegenüber, ausserhalb des Zauns, sieht man die Angreifer, welche die - körperliche, territoriale - Integrität der holländischen Jungfrau beeinträchtigen wollen. In der Mitte steht eine Gruppe katholischer Prälaten um ein Krankenbett: der Waffenstillstand auf dem Sterbelager. Ganz links stehen spanische Soldaten, an ihrer Spitze der Feldherr Ambrogio Spinola mit unzweideutiger erotischer Metaphorik: Wie einen Phallus richtet er eine Kanone zwischen den gespreizten Beinen auf das geschlossene Zauntor, gleichsam den Hymen, dessen Schutz den Niederländern obliegt. ${ }^{220}$ Auf einer Variante des Flugblatts, ebenfalls von 1615, ist statt des Soldaten der thronende Papst einer ganz ähnlich abgebildeten «holändischen Jungfraıv» gegenübergestellt, die verkündet, dass "Gottes heilig Wort [...] unser höchster hort» sei. ${ }^{221}$

Das säkularisierte Motiv des bortus conclusıs vereint viele der skizzierten Elemente: die spätmittelalterliche Bildtradition, auch der Maria im Rosenhag; die christliche Exegese der Liebesbeziehung im Hohelied als keusche Partnerschaft mit einer Jungfrau, der Schutz der Frau durch den Mann in der mystischen Ehe und damit der Schutz der territorialen Integrität und Souveränität gegen aussen. Letzteres betonte dann Heinrich Ludwig Gude, als er um 1700 die Hollandse Maaghd beschrieb, die er mit dem niederländischen Löwen in einem Zaun abbildete und seinem Werk übcr den Staat der Vereinigten Niederländer voranstellte. «Eine Dame welche, von gütigen Himcl mit allen Gcmüths- und Leibes-Vollkommenheiten, von dem gewogenen Glücke mit seinen kostbarsten Schätzen begnadigt worden, findet bald mehr als einen Liebhaber, die umb die Wette sich ihrer Gunst zu bemäch-

219 De worstelende Maagd tot Bescherming van hare Vryheyt, 1672, in: Cillessen, Krieg der Bilder, 124f. (B.IV.3).

220 Das Testament des Friedens oder Anstands, 1615, in: Harms, Illustrierte Flugblätter 182f. (II, 104); auch Dlugaiczyk, Waffenstillstand, 335f. (Kat. 16). Auf das Tor gerichtete Kanonen zeigt auch Adrian van der Vennes Stich der Pacificatie van Gent, 1625; http://upload.wikimedia.org/wikipedia/commons/b/b5/Allegorie_Pacificatie_van_Ge nt.jpg (01.08.2012). Zum Kanonenrohr als Phallus allgemein Duerr, Obszönität, 226f.

221 Der kram des Romischen Papst, 1615, in: Harms, Illustricrte Flugblätter, Bd. 2, 180f. (II, 103). 
tigen suchen. [...] Das Original des Frauenzimmers, so dem geneigten Leser auff dem Kupfferblat vorgestellt, hat das Glück gehabt, von solchen Monarchen angebetet zu werden, die sich rühmen dürffen, dass in ihrem Gebiethe die Sonne niemahls untergehe; da die Güte nicht helffen wollte, fand sich mehr als ein Paris, der diese Helenam mit Gewalt zu entführen gedacht. Allein der durch die Fürsichtigkeit aus lauter Eintracht zusammen geflochtene Zaun, samt den dabey wachenden Löwen hat bishero glücklich verwehret, dass niemand ihr den purpurfarbenen Hut der Freyheit, welchen sie par une noble fierte von ihrem Haupt auff kein fremdes Haupt setzen wollen, par force entreissen können.»122

\section{Vergewaltigung}

Was es für die Niederländer zu verhindern galt, war in der erotischen Metaphorik klar: Belästigung und Vergewaltigung. Sie waren entsprechend häufige Motive der niederländischen Bildpropaganda. Auf Jan Collaerts Stich vergewaltigen um 1570 spanische Soldaten Belgia. Auf Peter Bors Beschreibung des Aufstands (1603) bedrohen sie ihren Bauch mit der Inquisitionsfackel, weil sie mit Kämpfern für die Freiheit («Libertas») schwanger geht. ${ }^{223}$ Auf Wtewaels erwähnten Zeichnungen wird die Landespersonifikation um 1620 von zwei Männern belästigt, den Repräsentanten der katholischen Kirche und des spanischen Heeres. Die niederländischen Beschützer dagegen treten nach geleisteter Arbeit zurück, sind also eben nicht Monarchen, sondern überlassen es zuletzt einer allein thronenden Belgia, die Tribute der exotischen Länder entgegenzunehmen. ${ }^{224}$ Die gewaltsame Inbesitznahme des weiblichen Körpers ist jenseits der Eroberungsmetaphorik eine «dramatische Chiffre für den Übergriff auf Leib und Eigentum der Untertanen, der den Herrscher als Tyrannen kompromit-

222 Staat der Vereinigten Niederländer, s.l., s.a., Vorrede. Urte Weeber, der ich für den Hinweis auf das Buch sehr dankbar bin, schreibt es nach dem Vergleich mit anderen Werken Heinrich Ludwig Gude zu und datiert es vor 1708.

223 Jan Collaert d.Ä. Belgicae delaceratae lamentatio, um 1570 (nach Ambrosius Franken), Atlas van Stolk, Nr. 411; auch in: Israel, Dutch Republic, Abb. 4, und Dlugaiczyk, Waffenstillstand, 78; ebenso mit weiteren Bildern der nackten Belgica bei McGrath, Netherlandish History, 186f. und Abb. 32a)-d), worunter (Abb. 32b) auch die frühe Variante von A. van Leest, Declaratie, 133 = Atlas van Stolk, Nr. 641 (16); bei McGrath auch (Abb. 35a) Bor, Oorspronck = Atlas van Stolk, Nr. 410.

224 Lowenthal, Netherlandish history, $222 \mathrm{f}$. 
tiertı. ${ }^{225}$ Auch hierfür gibt es etliche alttestamentliche Referenzen, wenn etwa Jesaja $(23,12)$ zum zerstörten Sidon spricht: «Nie mehr sollst Du fröhlich sein, Tochter Sidon, du vergewaltigte Jungfrau. $\rangle^{226}$ Lucretia und Verginia sind berühmte römische Beispiele dafür, dass die tyrannische Nötigung der Frau schwere politische Konsequenzen haben konnte. ${ }^{227}$ Im Investiturstreit sahen Vertreter des Reformpapsttums in der Laieninvestitur eine Vergewaltigung, weil die betroffene Kirche einen anderen Priester und damit Gatten erhielt, als rechtmässig war. ${ }^{228}$

Besonders häufig wurde das Bild im Dreissigjährigen Krieg aufgegriffen, als etwa in Johan Rists Drama das geschundene Teutschland, umgeben von männlichen Personifikationen der kriegführenden Mächte, «Friede, Friede, Friede» schrie. ${ }^{229}$ Naheliegend war der Bezug zur Ehe mit einer Jungfrau im Fall der «Magdeburger Hochzeib, welche die beiden Kriegsparteien mit derselben Metaphorik beschrieben, auch wenn sie unterschiedliche Akzente setzten und voneinander abweichende Wertungen vornahmen. Die Elbestadt führte die Madonna im Wappenschild und hatte daran auch nach der Reformation festgehalten, ja als «Herr Gotts Kanzlei» ihren erfolgreichen Widerstand gegen das Augsburger Interim und die kaiserliche Rekatholisierungspolitik im Zeichen der Jungfräulichkeit zelebriert. Dieser Stolz widerspiegelt sich noch in Martin Opitz' ambivalenten Versen nach der Eroberung der Stadt: «Die stets alleine schlief, die alte keusche Magd, von Tausenden gehofft und Tausenden versagt [...] weil [...] keine Jungfrau nicht ein fremdes Bett erkiest, kriegt Tilly..$\rangle^{230}$

Entsprechend sahen die Protestanten die aufsehenerregende Zerstörung der lutherischen Hochburg nach der Eroberung durch Tillys Truppen als Vergewaltigung der "Magdeburgischen Jungfrau», die sich den Schwedenkönig Gustav Adolf als Bräutigam gewünscht hätte. ${ }^{231}$ Stattdessen verlor sie ihr Jungfernkränzlein und steckte sich darauf selbst in Brand, um wie die

225 So Koschorke, Staat, 173-176, am Beispiel von Daniel Caspar von Lohensteins Ibrahim Sultan.

226 Etwa Jeremia 6, 23-26; Klagelieder 1 und 2 sowie 5,11; auch Jesaja 13,16.

227 Koschorke, Staat, 36-46.

228 Humbertus a Silva Candida, Adversus simoniacos, 211f. $(3,11)$ : «sacerdotis uxor ab aliis violatur, quandocumque ecclesia a laicis, quibus non pertinet, administratur vel ordinatur.»

229 Rist, Das Friedewünschende Teutschland, 1649; auch in ders., Sämtliche Werke, Bd. 2.

230 Vgl. hierzu Lenz, Jungfrau, 193-203.

231 Klägliches Beylager der Magdeburgischen Dame, in: Paas, German Political Broadsheet, Nr.1367. 
geschändete Lucretia Selbstmord zu begehen. ${ }^{232}$ Jedenfalls könne die Magd, wie sie im Kläglichen Beylager der Magdeburgischen Dame [...] mit ibrem Blutdiirstigen Gemabl (1631) zu Tilly klagte, «dein liebster Schatz nicht sein, In dem du mit gewalt mir nimmst mein Kräntzelein». Leiblich habe er sie wohl geschändet, doch «ist die Jungfrawschafft der Seelen noch vorhanden». ${ }^{233}$ In hoffnungsvolleren Varianten wie dem Tröstlichen Gespräch wurde Magdeburg Gustav Adolf als rettender Bräutigam verheissen. Er sollte es laut dem Mitternacht Stern auch sein, der die entführte Stadt befreien würde, um sie wieder ihrem Gatten Christus zuzuführen. ${ }^{234}$ Tatsächlich wendete sich das Kriegsglück bei Breitenfeld. Das konnte als verdiente Strafe für denjenigen gelten, der «Jungfrauen schändt»; und so galt Tillys Tod wenig später den Protestanten hämisch als Heimfiibrung dess Magdeburgischen Hochzeitters. ${ }^{235}$

Auf der anderen Seite triumphierten hingegen die Katholiken, nachdem die Hoffart der Stadt und (mit den Worten des Siegers Pappenheim) «ihre jungfrawschafft hinwech» und der «keuschen Dame Scham gebrochen» war. ${ }^{236}$ Das Flugblatt Capitulationes kommt stilistisch als Ehevertrag (Notel) daher und hält die Rolle der protestantischen Verbündeten Magdeburgs fest: Ulm sollte das Heiratsgut geben, Strassburg die Morgengabe und Nürnberg die Hochzeitskosten übernehmen; Augsburg und Regensburg walteten als Brautführer, während Gustav Adolf als Brautvater seine Tochter Magdeburg dem siegreichen Eroberer Tilly übergeben musste, was der Stich auch festhält (Abb. 10). ${ }^{237}$ Die katholische Publizistik sprach auch von einer Reinigung: Aus Magdeburg sollte «Marienburg» werden, die Stadt der wahrhaften, nicht durch die lutherische Lehre besudelten Jungfrau. ${ }^{238}$ Diese Umbenennung erfolgte dann jedoch nicht, und die Metaphorik überlebte selbst die zerstörerische Vergewaltigung. Als die Stadt 1680 an Brandenburg fiel, befürchtete man, die «adelige Jungfrau» werde zur «elenden Dienstmagd» erniedrigt, doch verkündete 1702 ein anderer Autor, die Magdeburger Jungfrau könne unter dem Schutz des Preussischen Adlers nun sicher ruhen. ${ }^{239}$

232 Saguntina Prospopeia, bei Medick, Historisches Ereignis, 389-394; Emich, Hochzeit in Trümmern, 21.

233 Emich, Hochzeit in Trümmern, 16, 21; dies., Bilder einer Hochzeit, 208-210.

234 Tschopp, Deutungsmuster, 164, 327; vgl. auch dies., Rhetorik des Bildes.

235 Emich, Hochzeit in Trümmern, 23-25; dies., Bilder einer Hochzeit, 215-217.

236 Emich, Hochzeit in Trümmern, 19; Burckhardt, Dreissigjährige Krieg, $228 \mathrm{f}$.

237 Harms, Illustrierte Flugblätter, Bd. 2, 400f. (II, 227).

238 Emich, Hochzeit in Trümmern, 18, 26f.; dies., Bilder einer Hochzeit, 206-208.

239 Schmidt, Vorstellungswelt, 511; Kittsteiner, Stabilisierungsmoderne, 61. 


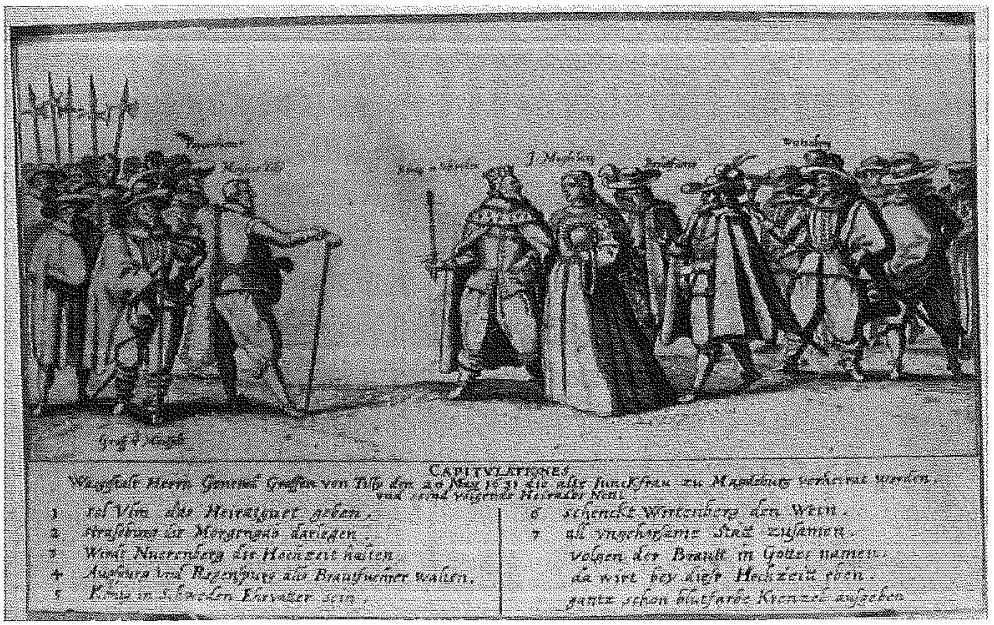

Abb. 10: Capitulationes, wasgestalt Herrn General Graffen Tilly die alte Junckfrau zu Magdeburg verheiratet worden, 1631.

\section{Scheidung}

Die Verpflichtung des Herrschers, als Gatte und Rechtsvertreter die Freiheit oder Mitgift seiner Angetrauten, des Gemeinwesens, zu wahren, ist der Schlüssel, um eine weitere Gruppe von Bildern und Texten zu deuten. Ausgangspunkt ist erneut die Begegnung von Salomo/Philipp II. mit der Königin von Saba beziehungsweise der Personifikation der niederländischen Stände, wie sie Lucas de Heere malte. (oben, Abb. 2). Ähnliche Begegnungen waren auf Stichen von Dirck Volkertszoon Coornhert zu sehen: einmal die Königin von Saba, ein anderes $\mathrm{Mal}$ aber die Unterwerfung der deutschen Städte unter Karl V., nachdem dieser den Schmalkaldischen Krieg gewonnen hatte. ${ }^{240}$ In der Grundkonstellation nahmen diese Darstellungen einen Bildtyp vorweg, der in den Anfängen des niederländischen Aufstands gegen Spanien entstand, 1569 erstmals als Stich gedruckt wurde und in über 20 verschiedenen Varianten als Gemälde oder Druckgrafik überliefert ist. ${ }^{241}$

240 Sawyer, Tyranny of Alva, 186-188 (Abb. 3 und 4).

241 Das Original ist Atlas van Stolk, Nr. 409; andere Varianten sind z. B. Utrecht, Centraal Museum, Inv. 2354, und Dirck van Delens Gemälde von 1630. Vgl. den Katalog bei Sawyer, Tyranny of Alva; auch Pieken, Ehrsame; ebenfalls unter http://www.dhm.de/ magazine/niederlande/Kapitel03.htm (3.4. 2010). 
(Abb. 11). Wie auf de Heeres Gemälde König Philipp II., so thront hier der Herzog von $\Lambda$ lba, der seit 1567 als Statthalter des spanischen Königs in den Niederlanden herrschte. Doch die 17 niederländischen Provinzen stehen ihm nicht - wie bei De Heere - erhobenen Haupts gegenüber, sondern knien gedemütigt und in Ketten gefesselt. Zwischen ihnen und dem Herzog liegen die zerrissenen Privilegien und Freiheitsrechte. Im Hintergrund kann man neben anderen Gräueltaten die Hinrichtung der Grafen Egmont und Hoorn erkennen. Die Bildlegende benennt die Gruppe um den Statthalter als «Die blutige mörderische Spanische inquisition Sampt der gantze rhat Und papistiche hauff». Hierzu zählt der Kardinal Granvelle, der mit einem Blasebalg $\Lambda$ lba Hass und Mordlust ins Ohr bläst, während ein Teufel ihm eine Tiara und dem Statthalter eine Krone über das Haupt hält. ${ }^{242}$

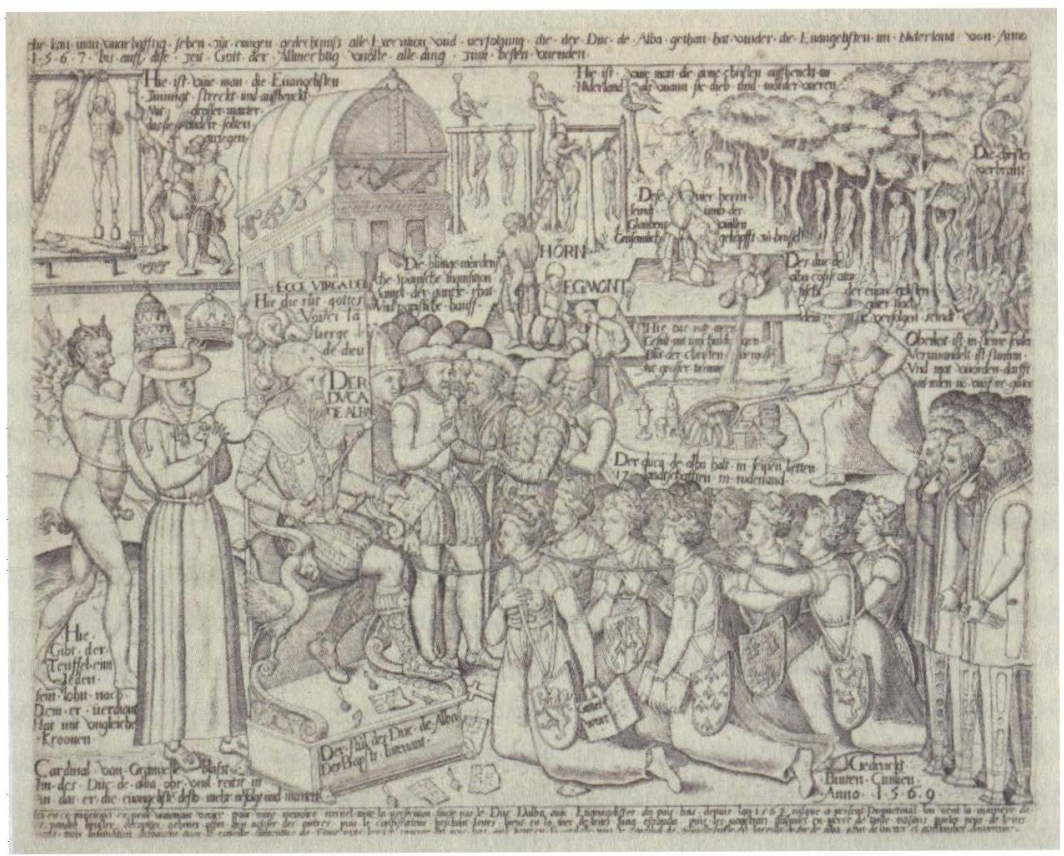

Abb. 11: Execution vnd verfolgung die der Duc de Alba gethan hat vuider die Euangelisten im Niderland, 1569, $\Lambda$ tlas van Stolk, Nr. 409.

242 Vgl. auch den Kupferstich ron 1570, auf dem $A$ lba eine nackte Jungfrau Belgica an Fesseln heranfühıt; Harms, Illustrierte Flugblätter, Bd. 2, 46 (II, 24) = Atlas van Stolk, Nr. 416; ebenso eine nackte Belgia vor Alba als spanischem Drachen, 1572, $A$ tlas van Stolk, Nr. 461. 


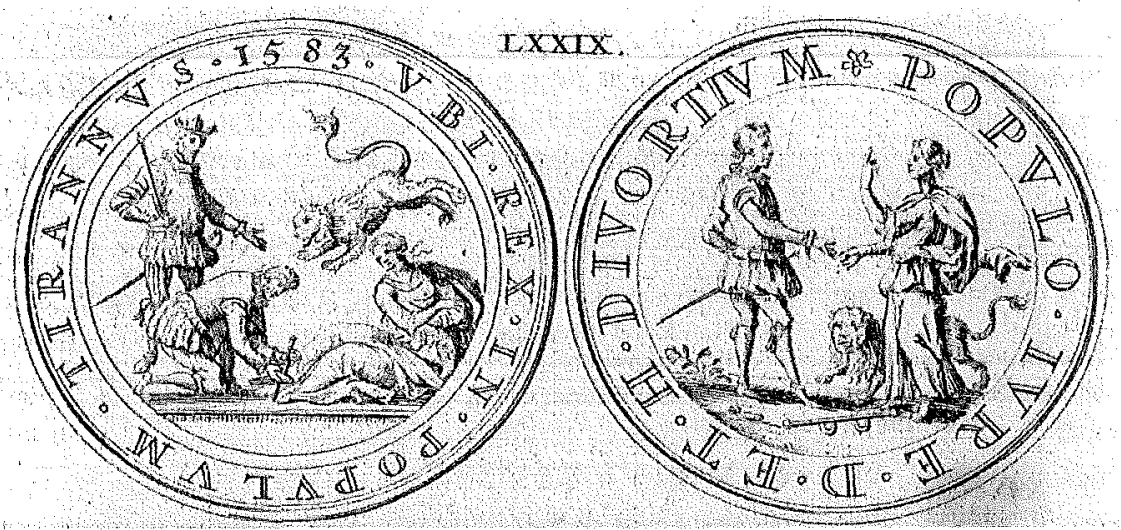

Abb. 12 : Niederländische Medaille, 1583, in: Explication historique des principales médailles frapées pour servir à l'histoire des Provinces-Unies des Pays-Bas, Amsterdam 21736, S. 48f., Nr. 79.

Eine Medaille von 1583 (Abb. 12) illustrierte die Reaktion der Niederländer auf diese Missachtung ihrer Freiheiten und damit des politischen Körpers. Es handelt sich um eine Allegorie auf die Absage an den pflichtvergessenen Philipp II. durch die Abschwörung im Plakkaat van Verlatinghe von 1581. Auf der Vorderseite der Medaille legt ein spanischer Soldat unter den Augen des Königs die holländische Magd in Ketten, als das niederländische Wappentier, der Iö̈ve, schützend hinzuspringt. Die Umschrift lautet: UBI REX IN POPULUM TIRANNUS; der Satz wird auf dem Revers fortgesetzt mit POPULO JURE D[IVINO] ET H[UMANO] DIVORTIUM: Wo sich der König als Tyrann gegen das Volk erweist, dort steht dem Volk nach göttlichem und menschlichem Recht die Scheidung zu. Die Logik war dieselbe wie bei Luca da Penne: Mit Tyrannen konnte es keine Gemeinschaft geben. ${ }^{243}$ Vom Lörven begleitet gibt die Frau, die auf der Rückseite nun wieder aufrecht neben dem König steht, diesem den Ehering zurück, nachdem ihre Fussfesseln zerbrochen am Boden liegen. ${ }^{244}$ Ähnliche Vorstellungen vvaren im Spiel, als im lutherischen Sachsen Christoph Otto Freiherr von Schönaich sein Epos Hermann oder das befreyte Deutschland (1751) verfasste. Der Held wirft dem römischen Gesandten seinen goldenen Bürgerring hin: «So empfang hier Ring, und Schmuck, die

243 Vgl. oben, Anm. 88, und Luca da Penne, c. 12, 63, 1, Nr. 74, zitiert bei Viroli, From

Politics, 67, Anm. 193: «Nulla est societas cum tyrannis».

244 Le Clerc, Explication historique, 48f., Nr. 79. 
mich nur an Rom gebunden; Ich zerreisse keck das Band, was man mir zur Schmach gewunden.» Stattdessen erhält er von einer Priesterin ein bescheideneres Symbol wechselseitiger Treue zum Vaterland: «Nimm hier diesen Ring von Eisen [...] sey dadurch ewig an das Volk geschlossen». ${ }^{245}$

Das Motiv der Scheidung ergab sich aus den Verpflichtungen, die der Ehebund für beide Seiten mit sich brachte - gerade auch in der mystischen Ehe, die ja zumindest implizit auf einem Vertrag beruhte. Schon im Alten Testament hat Gott die Scheidung vom bundesbrüchigen Israel verfügt, diese dann aber rückgängig gemacht. ${ }^{246}$ Von einem Vertrag ging auch Paulus in den einschlägigen Passagen des Neuen Testaments aus, namentlich im 1. Korintherbrief, 7,2-4, der sich wiederum auf die zitierten Passagen aus dem Epheserbrief, Kapitel 5, bezieht «Wegen der Gefahr der Unzucht soll aber jeder seine Frau haben und jede soll ihren Mann haben. Der Mann soll seine Pflicht gegenüber der Frau erfüllen und ebenso die Frau gegenüber dem Mann. Nicht die Frau verfügt über ihren Leib, sondern der Mann. Ebenso verfügt nicht der Mann über seinen Leib, sondern die Frau.» Gerade weil Paulus die Ehe insofern abwertete, als sie seinem Ideal der Keuschheit nicht entsprach, machte er die Sexualität zu ihrem zentralen Element - denn sie war nur in der Ehe legitim. Die fleischliche Vereinigung begründete die vollständige «potestas corporis», die Verfügungsgewalt über den eigenen Körper, die damit an die Paarbeziehung gebunden war. Paulus bezog sich auch auf den erwähnten Willen des Schöpfers, dass Mann und Frau eins werden sollten: «erunt duo in carne una» (Genesis 2,24). Der Beischlaf war also notwendig, damit die Ehe gültig war; er konstituierte aber umgekehrt auch eo ipso die Ehe, selbst mit einer Hure, wie Paulus warnend ausführte. ${ }^{247}$ Die Kanonisten deuteten dann wie erwähnt den Beischlaf als bischöfliche. Verwaltung der Diözese. ${ }^{248}$ Dessen Verweigerung stellte, zumindest in den protestantischen Kirchen, auch einen Scheidungsgrund dar.

Tatsächlich wurde die Metapher der Scheidung nicht nur im calvinistischen Umfeld der Niederlande, sondern auch im anglikanischen England und im zwinglianischen Zürich aufgegriffen. Jakob I. hielt in der oben zitierten Thronrede ebenfalls fest, dass der Mensch nicht scheiden solle, was Gott vereint habe - eben seine eheliche Gemeinschaft mit der britischen

245 Schönaich, Hermann, 130; dazu Brandt, Germania, 91.

246 Jeremia 3,1-20.

247 Kor. 6,16f.

248 Vgl. oben, Anm. 63. 
Insel. ${ }^{249}$ In einer Flugschrift von 1643 rechtfertigte Britannia die Rebellion gegen Karl I. im Namen ihrer Freiheiten damit, dass er sie wieder an den tyrannischen Stuhl Petri fesseln wolle. ${ }^{250}$ Johann Rudolf Hess, ein Referent in einem frühaufklärerischen Zürcher Gelehrtenzirkel, meinte 1679, dass nach dem Eherecht das böswillige Verlassen des Partners («desertio malitiosa») einen ausreichenden Grund für die Scheidung darstelle. Dadurch werde die wechselseitig zugesagte Treue gebrochen und folglich die von der anderen Seite geschuldete Loyalität hinfällig. Denn durch die Ehe würden die beiden Partner zu einem einzigen Körper, der auch alle Gefahren und Herausforderungen notwendigerweise als gemeinsame angehen müsse, so dass auch beide Teile sich in dasselbe Schicksal teilen müssten. Die Ausführungen dienten dazu, die Ablösung der Eidgenossenschaft vom Heiligen Römischen Reich damit zu rechtfertigen, dass die habsburgischen Kaiser ihre Schutzverpflichtung nicht wahrgenommen und damit die Schicksalsgemeinschaft de facto aufgekündigt hätten. ${ }^{251}$

Überraschender als im durch monarchomachisches Gedankengut geprägten reformierten Kontext erscheint die Erörterung der Scheidungsmöglichkeit durch einen süditalienischen Kardinal. In der römischen Kirche galt auch im übertragenen Sinn etwa die Abdankung Papst Coelestins V., die als singulärer Akt von seinem Nachfolger Bonifaz VIII. erzwungen wurde, als unkanonische Scheidung. ${ }^{252}$ Kardinal Giovanni Battista de Luca sah das anders: Der Papst könne kraft der ihm direkt von Gott verliehenen Macht seine Ehe mit der Kirche auflösen. Bei einem weltlichen Herrscher hingegen müsse die Quelle seiner Macht, nämlich Volk und Republica, ihr Einverständnis zu einer Auflösung des Ehevertrags geben. Tatsächlich sei dies bei der Königin der Fall gewesen, in deren Auftrag er sein Werk Il Principe cristiano pratico 1680 schrieb: Kristina von Schweden hatte sich nach ihrer Abdankung und Konversion zum Katholizismus in Rom niedergelassen. ${ }^{253}$ Kristina weigerte sich zeitlebens, zu heiraten und sich dadurch einem Mann unterzuordnen. Solche Vorbehalte prägten auch De Lucas Traktat, in dem er das Bild der mystischen Ehe («mistico e politico matrimonio») als wechselseitigen Ehevertrag («reciproco contratto matrimoniale») präsen-

249 Kantorowicz, Zwei Körper, 233.

250 Britannia, passionately and historically (1643); vgl. auch Major, Madam Britannia, 14, $24 \mathrm{f}$.

251 Collegium Insulanum, Zürich, 5. August 1679; Zentralbibliothek Zürich, Ms. P 6224,

149; dargelegt in Kempe/Maissen, Collegia, 208.

252 Kantorowicz, Zwei Körper, 225, Anm. 61.

253 De Luca, Principe cristiano, 677-679 (Kap. 48). 
tierte. Die Republica als Gattin bringe als ursprüngliche, unmittelbare und gewohnheitsmässige Eigentümerin ("padrona originaria, diretta e abituale») die Rechtsprechung, Machtmittel und Erträge ("giurisdizione e podestà», «regali e rendite et emolumenti publici») als Mitgift in die Ehe ein. Darüber habe der Fürst als Gatte nur das untergeordnete Niessrecht («il dominio utile e subalterno»). Die Unterscheidung entstammte dem Lehnsrecht, wonach der Grundherr aufgrund seines Obereigentums («dominium directum») dem Vasallen oder Bauern das «dominium utile» als Untereigentum verleiht. Der Fürst müsse dieses Untereigentum bewahren und als Bevollmächtigter gut verwalten gemäss der Vorrangstellung, die dem Mann in der Ehe zukomme. Deshalb könne er den Gehorsam der Frau einfordern und sie bestrafen, wenn sie sich ungebührlich verhalte, insbesondere bei Ehebruch, also politisch bei unerlaubten und ungerechten Rebellionen und Revolutionen, mit denen das Volk eine Republik zu errichten suche («ingiuste rivoluzioni e ribellioni generali e popolari a forma di Republica»). ${ }^{254}$

Seinerseits sei aber auch der fürstliche Gatte verpflichtet, alle Vorsorge für ein glückliches und würdiges Leben («vita felice e civile») von Frau und Kindern (die Untertanen) zu treffen, was das Hauptziel einer solchen Ehe sei. Er müsse also diese Vertragsbestimmungen beachten und sich um die auferlegten Aufgaben kümmern, die Machtkompetenz massvoll einsetzen, die das Gesetz ihm zugestehe, also etwa den expliziten oder zumindest impliziten Konsens des Volkes bei der Gesetzgebung suchen. Noch konkreter dürfe er nicht als Ketzer oder Apostat der katholischen Konfession zuwiderhandeln, die seine Gattin bekenne; sich ehebrecherisch mit einer anderen Frau - einem anderen Territorium - einlassen; oder als Tyrann der Gattin den Unterhalt verweigern oder sie im Stich lassen, wenn barbarische oder häretische Nationen drohten. Wenn er auf diese Art seine Angetraute und Kinder misshandle, dann könne die Ehefrau sich gemäss Zivilrecht («legge civile») durch Scheidung aus der Ehefessel lösen («liberarsi dal vincolo di quel matrimonio»), ihre Mitgift wieder zurücknehmen und sich damit einem anderen Mann vermählen oder sich gar als Republik («nello

254 Ebd., 14 (cap. 1): «[...] il Regno[...] risiede in potere della Republica de' popoli, la quale paragonata alla sposa, è la padrona diretta e abituale così della giurisdizione e podestà [...]; e che il Principe [...] paragonato allo Sposo, ha il dominio utile e subalterno, con la piena amministrazione in quel modo che il concedono le leggi al marito nella dote, con l'obbligo di portare i pesi di questo mistico e politico matrimonio, al quale più propriamente il Principato merita paragonarsi [...]»; sehr ähnlich ebd., 659-661 (cap. 48); vgl. auch De Mattei, Idea democratica, 1948, 40f. Für die Theorie des «dominium directum» Flügel, Art. Grundbesitz, 1154. 
stato di Republica») selbst regieren («acquista la libertà di maritarsi con un altro, o pure di governarsi da sè stessa»). ${ }^{255}$

Wer aber konnte darüber entscheiden, ob es angebracht war, den gegenseitigen Eid - treuer Gehorsam gegen gute Verwaltung - in einer bestimmten Situation aufzulösen? Der Kardinal gestand ein, dass die Praxis einer konkreten Scheidung schwieriger war als die Theorie und wollte sich auch nicht auf die - diskutierte - Lösung einlassen, dass der Papst als Richter wirke. Grundsätzlich wichtig sei jedenfalls, dass der Fürst sich nicht als Herr über Sklaven verstehe, sondern als Gatte, Vormund, Verwalter oder Familienvater, der wisse, dass er vom Volk abgesetzt und sogar streng bestraft werden könne. Hierbei sprach De Luca erstaunlich freimütig ein säkulares Ereignis an: die Absetzung und Verurteilung Karls I. durch das englische Parlament. Er wolle nicht urteilen, ob die Gründe dafür ausgereicht hätten und das Verfahren korrekt gewesen sei; sei dem aber so, dann könne man die Handlung als legitim bezeichnen. Denn die Position. des Königs, er kenne niemanden über sich ausser Gott, sei nicht haltbar. Das vereinte Gemeinwesen («tutta la Republica nell'universale») bleibe ihm übergeordnet, von dort stamme seine Macht. ${ }^{256}$

Die Entscheidung für einen anderen Gatten im Sinne De Lucas brachte ein Flugblatt (Abb. 13) zum Ausdruck, das Belgia als Personifikation der Niederlande zeigte, wie sie sich von Philipp II. und den ihn begleitenden Prälaten und Soldaten abwendet und zum Herzog von Anjou hindreht: Franz, der Bruder des französischen Königs Heinrich III. ${ }^{257}$ Der Stich stammt aus dem Jahr 1579, zu dessen Beginn sich die nördlichen sieben Provinzen in der Union von Utrecht als Defensivbündnis gegen ihren legitimen Herrn, den spanischen König, zusammenschlossen. Von diesem militärisch arg bedrängt, boten die Generalstände dem französischen Prin-

255 De Luca, Principe cristiano, 662-664, und sehr ähnlich ders., Il cavaliere, 380f. (Kap. 22): «E quindi segue che quando esso [il principe/lo sposo] non osservi bene le leggi di questo contratto, e che trascuri di portare i suddetti pesi, e che maltratti la moglie \& i figli, abusandosi di quell'autorità che la legge gli concede; In tal caso, con l'istessa proporzione del matrimonio carnale, si fa luogo al divorzio, sì che, conforma la donna può separarsi dal marito e ripigliarsi la sua dote, e con la medesima dote maritarsi ad un altro, così può la republica sottrarsi da quel Principe \& eleggersene un altro.» De Mattei, Idea democratica, 42, wiederholt hier interessanterweise die falsche Schreibweise «casuale» statt «carnale», vgl. Anm. 82.

256 De Luca, Principe cristiano, 676.

257 Le Duc d'Anjou offre son bouclier, casques et epée à la Belgique, 1579, BNF Estampes, Hennin 723. 
zen den 'Titel eines «Verteidigers der Freiheit» an, verweigerten ihm aber das Adjektiv «souverän» («seigneur souverain»), wie es der von Bodin persönlich beratene Fürst 1580 verlangte. Das doppeldeutige Wort könne als «puissance absolue» verstanden werden, was ein Land, das im Einklang mit Gesetzen, Gewohnheiten und Privilegien regiert werde, nicht gewähren könne. ${ }^{258}$ Während die Machtübertragung an einen neuen Fürsten aus dem Ausland an solchen Bedenken scheiterte, zeigt das Flugblatt noch die vorangehende Situation, in der Belgia gerade diejenige Angst zum Ausdruck bringt, die sie letztlich auch davon abhalten sollte, sich einem Ersatzherrscher zu überantworten. Sie wirft nämlich Philipp II. vor, er als 'Tyrann danke ihren Gehorsam mit Versklavung. 'Tatsächlich bietet er Belgia eine Mausefalle an, während der Herzog von Anjou ihr seinen Schild und die Waffen darreicht. Seine 'Truppen im Hintergrund durchziehen ein friedliches Land, während die spanischen Soldaten in der anderen Bildhälfte brennende Städte, Galgen und Sklavenfesseln mit sich bringen. So verwundere es nicht, meint Belgia, wenn sie Philipp den Rücken zuwende und einen anderen Prinzen als ihren Herrn empfange. ${ }^{259}$

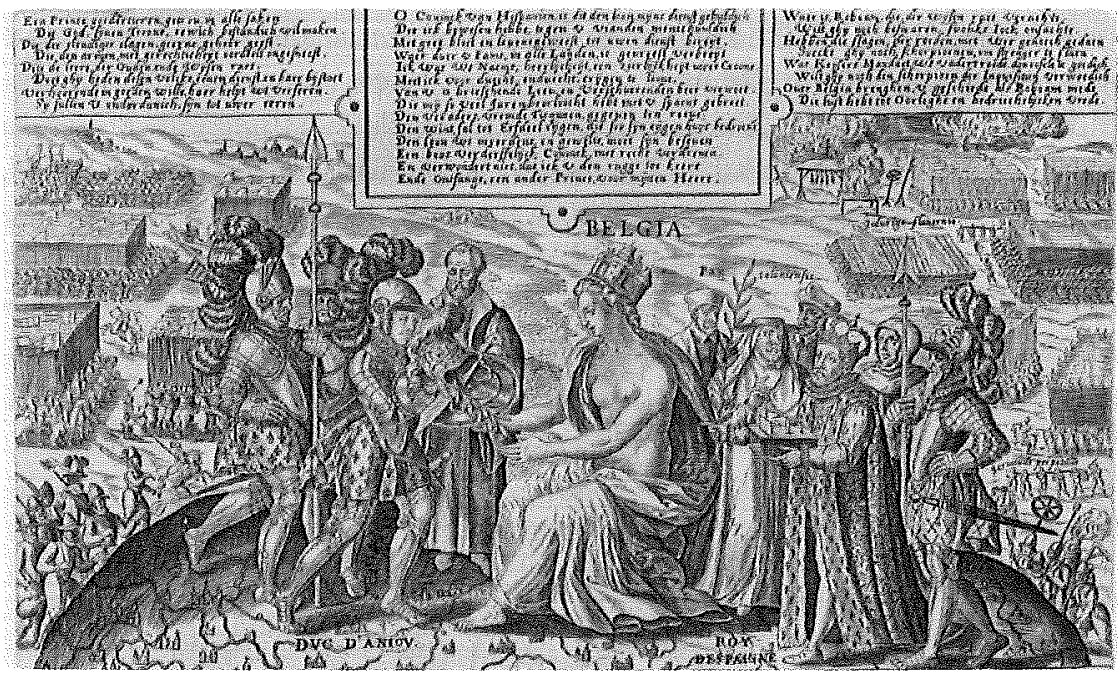

Abb. 13: Le Duc d'Anjou offre son bouclier, casques et epée à la Belgique, 1579.

258 Griffiths, Humanists, 73-77; Kossmann, Popular sovereignty, 144-146.

259 «En verwondert niet, dat ick den rugge toe keere Ende Ontfange, een ander Prince, voor mynen Heere.» 


\section{Die Emanzipation der Respublica}

Die Wahl der Belgia oder vielmehr, nach der faktischen Teilung der Niederlande, der Hollandia fiel schliesslich nicht auf den Herzog von Anjou, sondern auf das Haus Oranien, das regelmässig den Statthalter stellte. Daraus ergab sich eine Paarbeziehung, die oft die beiden Partner sich gleichrangig gegenüberstellte. ${ }^{260} \mathrm{Jan}$ Tengnagel malte 1623 Hollandia sogar thronend und damit in einer leicht überlegenen Position gegenüber Moritz von Oranien. (Abb. 6). Wie bei den erwähnten Anhängern einer aristokratischen Verfassung im Heiligen Römischen Reich wurde der republikanische Charakter erst recht darin greifbar, dass Hollandia mit den Herrschaftsinsignien selbständig auftreten konnte - ganz im Sinn von De Luca, bei dem ein Gemeinwesen sich nach der Scheidung «nello stato di Republica» selbst regieren konnte. ${ }^{261}$ Umgeben von Allegorien, thront Hollandia beispielsweise auf einer Zeichnung Theodor van Thuldens (um 1650) oder auf Bertrand Picarts Titelkupfer für Jean Le Clercs Histoire des Provinces-Unies des Pays Bas (1723). ${ }^{262}$ Auf einem Stich, der als Momumentum Pacis den Waffenstillstand von 1609 feierte, ist sie gar als «Regina Belgica» mit einem - als Souveränitätszeichen unmittelbar zu Gott in den Himmel reichenden - Obelisken im Rücken dargestellt. Über sich einen Lorbeerkranz, in den Händen Zepter und Palmzweig, thront sie über den 17 Provinzen der gesamten Niederlande. ${ }^{263}$

Ebenfalls triumphierend präsentierte Jakob Adrianszoon Backer 1644 Hollandia, aber nicht auf dem Thron, sondern in die Landesfarben gehüllt und stehend mit Helm, Lanze und dem Schild mit dem Löwenwappen. ${ }^{26+}$ Diese bewaffnete und behelmte Hollandia war keine Ausnahme. ${ }^{205}$ Sie entsprach der Beschreibung, die Cesare Ripas äusserst wirkungsmächtige und oft aufgelegte Iconologia (erstmals 1593) als Allegorie des "Governo della

260 Etwa auf Theodor van Thuldens Allegorie auf den Transfer des Erbrechts von Friedrich Heinrich auf Wilhelm II. von Oranien (ca. 1641).

261 De Luca, Principe cristiano, 662-664; vgl. oben, Anm. 255.

262 Bussmann/Schilling, Krieg und Frieden in Europa, 253, Nr. 737 (Theodor van 'Thulden); zu Picarts Titelbild: Maissen, Sovereign Republic, 141f. und Abb.3. Weitere Beispiele einer alleine thronenden Hollandia sind die Histoire générale des Pais-Bas, Brüssel 1720, oder Les délices de la Hollande, Amsterdam 1728.

263 Monument voor de vrede in de Nederlanden, 1609, Dlugaiczyk, Waffenstillstand, 356 (Kat. 58; vgl. auch Kat. 57).

264 Oranje boom. Katalog, 434f.

265 Vgl. etwa die oben, Anm. 260, erwähnte Allegorie 'Theodor van 'Thuldens. 
Republica» empfahl: eine «Donna simile a Minerva», mit friedlichem Olivenzweig in der Rechten und kriegsbereitem Schild samt Speer in der Linken, auf dem Kopf ein Helm als Zeichen der bewaffneten Abwehr äusserer Feinde. ${ }^{260}$ Wie die Madonna war Athene/Minerva eine Jungfrau, im Unterschied zu ihr aber in der ikonografischen Tradition bewaffnet, was sie dazu qualifizierte, ihre Unschuld - die territoriale Integrität eines freien Staates selbständig zu wahren. Genau dies war die Herausforderung an eine Republik: Sie musste ohne königliches Haupt den politischen Körper verteidigen, im Inneren gegen Anarchie, vor allem aber im militärischen Kampf gegen äussere Feinde. ${ }^{267}$ So lag es während des englischen Commonwealth nahe, dass James Harrington seinen idealisierten Freistaat Oceana in Sätzen, die aus dem Hohelied stammen, als «holy spouse of Jesus» ansprach - die Republik war nicht mit einem irdischen Haupt vermählt. ${ }^{268}$ Ebenfalls unter Cromwell wurde auf Ripa zurückgegriffen, als 1652, in der Auseinandersetzung mit den Niederländern, John Seldens Hauptwerk unter dem Titel $O f$ the Dominion, or Ownership of the Sea aus dem Lateinischen übersetzt wurde. Das Frontispiz zeigt eine «Angliae Respub.», der zwei Kronen zu Füssen liegen: die englische und schottische des hingerichteten Stuart-Königs. Mit dem englischen Schild, Speer und Helm bewehrt, hält die personifizierte Republik in der Linken eine Säule, auf der eine weibliche Figur ihr Lorbeerkranz und Palmzweig reicht, die Zeichen von Sieg und Frieden. ${ }^{209}$ Es ist praktisch dieselbe Darstellung, die 1709 für eine illustrierte englische Ausgabe von Ripas Iconologia als Illustration von «Commonwealth» gewählt wurde, wie der ursprüngliche Artikel «Governo della Repubblica» auf Englisch hiess. ${ }^{270}$ Auch im schweizerischen Umfeld begegnet Minerva als Personifikation namentlich der Stadtrepubliken Basel und Bern. Joseph Werners Allegorie des Regiments für das Berner Rathaus (1682) erinnert in der Komposition an Tengnagels Darstellung der Hollandia: Wie sie ist Berna umgeben von den Allegorien der drei Stände Geistlichkeit (Fides), Adel/ Patriziat (Fortitudo) und Volk (Gratitudo/Abundantia). ${ }^{271}$

266 Cesare Ripa, Iconologia, 194.

267 Insofern bot sich Minerva auch als Personifikation des britischen oder französischen Königreichs an, obwohl sie, wie in Versailles, Ludwig XIV. klar untergeordnet blieb.

268 Harrington, Oceana, 233.

269 Selden, Dominion. Auch die möglicherweise frühste Britannia überhaupt war ein MinervaTyp: Peacham, Minerva Britannia, 108.

270 Ripa, Iconologia, 80 (Nr. 321a).

271 Maissen, Geburt, 462-466, 485f. Auf die klassische Dreiständelehre verweisen auch Justitia, Fortitudo und Moderatio, die von Sapientia (Minerva) geführt werden und Venetia 
Gerade mit solchen umfassenden Programmen sollten Republiken in der Vielfalt dargestellt werden, die ihnen eigen war. Die Jungfrau personifizierte ihren akephalen politischen Körper, zu dem die verschiedenen Glieder oder Stände gehörten, ohne dass sie im zitierten Sinne Bossuets durch Identitätsrepräsentation im Fürsten aufgingen, der als Souverän für sich allein so der Staat war wie Gott das Universum. ${ }^{272}$ Während der absolutistische Herrscher die gesamte Kraft und den gesamten Willen aller Einzelbürger in sich zusammenfasste, musste die republikanische Obrigkeit die Vielfalt der Gewalten und Willen in ihrem politischen Körper mitberücksichtigen. Der französische Benediktiner Casimir Freschot erfasste diesen Unterschied bei seiner Beschreibung von Venedig : «Les Républiques sont filles, me disoit autrefois un Noble de fort bon sens dans Venise, \& les Royaumes sons mâles. Or comme pour garder l'honneur d'une fille il faut employer des soins beaucoup plus exacts, que pour garder un jeune homme, de même pour maintenir l'honneur \& la liberté d'une Rép. il faut d'autres \& de plus sévères maximes que pour maintenir l'autorité du Prince, à qui les sujets doivent obeïr, quelques commandement qu'il leur fasse, les y ayant déjà disposés.»273 Königreiche seien männlich, und deshalb einfacher zu handhaben: Der Befehl des Königs reiche aus, Gehorsam sei ihm gewiss. Die Republik hingegen müsse man umsichtig wie eine Tochter erziehen, und um ihre Ehre und Freiheit zu bewahren, brauche es strengere Regeln.

Das strenge Regelwerk der venezianischen Verfassung hatte genau den Zweck, in einem Gemeinwesen von freien Patriziern die Gleichheit zu bewahren, ohne dass Anarchie ausbrach - oder Klientelismus und Korruption regierten. Die Personifikation der Venetia war deshalb als politischer Körper und republikanische Ordnung allen Einzelbürgern übergeordnet und wurde in privaten Palazzi auch nicht dargestellt. Venetia war nicht nur, wie erwähnt, die Braut des Dogen, sondern sie krönte ihn auch; kniend dargestellt wurde sie nur selten. ${ }^{274}$ Dieser Vorrang wurde erst im 16. Jahrhundert ikonografisch deutlich ausgebildet, auch wenn es früher schon Personifikationen der Republik gegeben hatte: erstmals wohl 1341, «in forma

in der Sala del Collegio den Weg weisen, vgl. Wolters, Bilderschmuck, 262, Abb. 275, der mit der Identifikation Mühe hat.

$272 \mathrm{Zu}$ Bossuet oben, Anm. 147.

273 Freschot, Relation, 268f.

274 Vgl. Andreas Schiavones Zeichnung von 1521/23 und die Vedute des Meisters I. C. A. von 1565, Wolters, Bilderschmuck, 101-104, Abb. 79, 83; auch 106, Abb. 85 sowie 119, Anm. 1 (kniende Venetia). Für Grottos Ehemetaphorik oben, Anm. 161, für Britannia, die Georg I. krönt, Anm. 174 
di Justitia» an der Fassade des Dogenpalastes, und anderswo in der Ikonografie der Fortitudo oder Pax, die erst durch die Inschrift zur Venetia umgedeutet wurde. ${ }^{275} \mathrm{Um} 1500$ wurde die Jungfrau Astrea wohl mit Venetia identifiziert, und gleichzeitig zeigte Alessandro Leopardi auf einem Fahnensockel vor San Marco eine Venetia/Justitia, die Francesco Sansovino 1580 rückblickend als «franchigia e libertà, dipendente solo da Dio, e non da Principe alcuno» deutete - also mit der neuen staatsrechtlichen Terminologie als Freiheit, die unmittelbar zu Gott war. ${ }^{276}$

Das entsprach nicht nur bei Sansovino zugleich der bereits älteren Selbstdarstellung als «divina republica»: Der Weltenherrscher selbst hatte die Stadt und ihre Verfassung geschaffen. ${ }^{277}$ Das brachte im Dogenpalast auch Jacopo Tintorettos Mittelbild der Sala delle Quattro Porte zum Ausdruck: «Venetia [...] fu fatta per dispositione di Dio, aciochè vi si conservi la religione e la libertà christiana.. ${ }^{278}$ Als unmittelbares Geschöpf des Allmächtigen liess Tintoretto diese Venetia in einer etwas kühnen heidnischchristlichen Paarung mit einem Herrscherstab gleichrangig an der Seite des Göttervaters Jupiter aus dem Götterhimmel hinuntersteigen. Der grundlegende Gedankc war derselbe, wie bci Palma il Giovane, der den Heiligen Bischof Magnus unter den Augen von Madonna und Kind die Venetia selbst krönen liess, oder wie auf Francesco Vecellios Gemälde, auf dem Venetia neben San Marco und der höher thronenenden Maria mit dem Jesuskind die Huldigung des Cadore empfängt. ${ }^{279}$ Veroneses Allegoric auf den Sieg bei Lepanto führte die visuelle Hierarchie von - im ursprünglichen Entwurf - S. Marco, dann aber Christus über Venetia/Justina in einer Linie nach unten zum Dogen Sebastian Venier, der von der Personifikation den Palmwedel des Sieges und gemäss der ursprünglichen Skizze auch die Dogenmütze empfängt. Venetia, «una bellissima Regina coronata», erhält dort ihrerseits einen Rosenkranz, in Analogie zur Madonna del Rosario.280 Sie

275 Wolters, Bilderschmuck, 236-246, insbes. Abb. 243 (Filippo Calendario) und Abb. 246 (Justitia des Jacobello del Fiore, 1421); Letztere wird bereits als «virgo» angesprochen; vgl. auch Rosand, Venetia figurata, 179-183 (Abb. 1-5).

276 Wolters, Bilderschmuck, 241f., Abb. 249.

277 Vgl. die Belege bei Sinding-Larsen, Christ in the Council Hall, 140-147.

278 Sansovinos Erklärung zitiert nach Wolters, Bilderschmuck, 58.

279 Wolters, Bilderschmuck, 58, 109f., 280f, Abb. 35f., 90, 291.

280 Vgl. die Diskussionen der möglicherweise um 1600 erfolgten Änderung und auch der älteren Literatur bei Sinding-Larsen, Changes, 298-302, und ders., Christ in the Council Hall, 95-98, 259f.; sowie Wolters, Bilderschmuck, 126-128, Abb. 105f.; und Franzoi/ Pignatti/Wolters, Palazzo Ducale, 296. Danach ist die Frauenfigur links des Dogen nun 


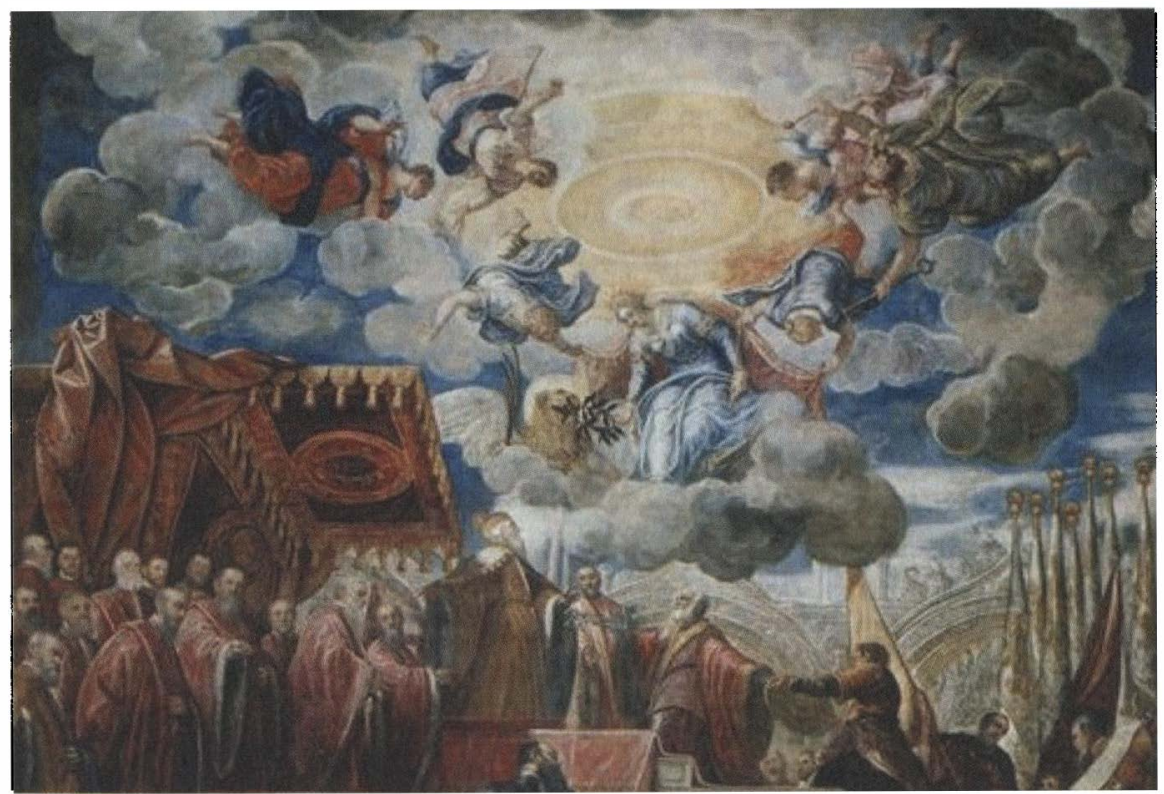

Abb. 14: Jacopo Tintoretto, Freiwillige Unterwerfung der Provinzen unter Venetia, Dogenpalast, Venedig, um 1580.

alle führten die venezianische Staatlichkeit als unmittelbare Wirkung der göttlichen Gnade vor Augen.

Nach den Brandkatastrophen von 1574/77 wurde Venetia im erneuerten Dogenpalast systematisch in einer neuartigen Bildsprache präsentiert, die dem ikonografischen Vorbild der Maria oder Ecclesia nachempfunden ist. So tritt sie auf Domenico Tintorettos Votivgemälde für die Sala dell'Avogaria de Commn in Begleitung eines Engels und der Libertas unmittelbar Christus gegenüber, der ihr die Eucharistie in den hingestreckten Kelch

Santa Giustina, deren Interzession der Sieg bei I.epanto zugeschricben wurde. Der Dolch ist in ihrer Hand, nicht wie üblich in der Brust; der Palmwedel ist das allgemeine Attribut der Närtyrer und auch der Giustina. Es überrascht, dass Venetia zu einer Randfigur, mit dem corro drreale in der Hand, rechts neben dem Dogen degradiert wurde. Sinding-Iarsen hält selbst fest, dass der Kleiderschmuck der zentralen Frauenfigur derjenige der Venetia ist; diese Identifikation entspricht auch der ursprünglichen bei Francesco Sansovino. Es ist also auch bei ihr an dic majestätische Venetia als unmittelbare Empfängerin göttlicher Gunst zu denken. 
spendet. ${ }^{281}$ Besonders imposant ist die Gestaltung der Sala del Maggior Consiglio. Für dessen Decke entstanden die zentralen grossen Gemälde, Veroneses «Apotheose der Venetia» (oder eher Pax V eneta) ${ }^{282}$ und Jacopo Tintorettos «Freiwillige Unterwerfung der Provinzen unter Venetia». Ebenfalls von Tintoretto stammt der «Triumph der Venetia als Königin der Meere» in der Sala del Senato, die er der marianischen Regina coeli nachbildete und auch sonst nach dem Bildtyp des «Paradiso» gestaltete. ${ }^{283}$ Eine gekrönte Venetia mit Herrscherstab thronte jeweils auf einer Himmelswolke, unmittelbar zu der Sonne, gar mit einer Aureole, und begleitet von Engeln, Göttern oder Allegorien. Auf der «Unterwerfung» reicht sie dem Dogen Nicolò da Ponte den Lorbeerkranz, den er mit ehrfürchtigem Blick nach oben empfängt. Hinter ihm und etwas weiter unten, aber unter dem Baldachin, stehen die Senatoren, während auf den Stufen, die vor dem Dogen hinunterführen, die Provinzen in Demut huldigen. (Abb. 14).

Dass Venetia hier Marias Rolle einnahm, war für die Initiierten offensichtlich, wie Luigi Detrico auch dichterisch festhielt: «Di Vinegia dirò adunque per somiglianza quel che con verità canta Santa Chiesa della Regina del Cielo» - er preise Venedig so wie die Kirche die Himmelskönigin. ${ }^{284}$ Wer aber mit der spezifischen lokalen Bildtradition nicht vertraut war, so der Engländer Thomas Coryate, der die Stadt 1608 besuchte, verwechselte Veroneses und Tintorettos Venetia mit der «Virgin Mary with a crowne on her heads, die oft als Himmelsherrscherin dargestellt wurde nicht zuletzt im Dogenpalast selbst, wo sich der ergebene Doge auf den zahlreichen Votivbildern auch der Madonna so unterordnen konnte, wie

281 Sinding-Larsen, Christ in the Council Hall, 218 (Abb. XCIXb); auch Rosand, Venetia figurata, 187, und ders., Myths of Venice, 39f. (Abb. 26). Das Bild kann als Distanzierung von der römischen Kirche verstanden werden und würde dann wohl in die Interdiktkrise von 1606/7 gehören. Vgl. auch in der Sala del Collegio Veroneses Venetia auf dem Erdball thronend, mit Justitia und Pax, Wolters, Bilderschmuck, 257f. (Abb. 268) und Franzoi/Pignatti/Wolters, Palazzo Ducale, 291 (Abb. 247); auch 295 (Abb. 254: Veronese, Venezia mit Ceres).

282 Für die Pax, wie die ganze Komposition «ad imitatione della Roma», Wolters, Bilderschmuck, 285f., und Rosand, Venetia figurata, 180.

283 Wolters, Bilderschmuck, 256-287 (mit Abb.); ebenfalls abgebildet bei Franzoi/Pignatti/ Wolters, Palazzo Ducale, 313 (Abb. 283), 320 (Abb. 292), 322 (Abb. 295), ähnlich 317 (Abb, 288: Palma il Giovane, Francesco Venier, Sala del Senato) und 324 (Abb. 297: Palma il Giovane, Trionfo di Venezia, Sala del Maggior Consiglio). Vgl. auch Gamboni u. a., Zeichen der Freiheit, 63, 65, Abb. 38f,; ferner Koenigsberger, Republicanism, 43-74.

284 Die Dichtung von 1587 zitiert von Wolters, Bilderschmuck, 280, und Sinding-Larsen, Christ in the Council Hall, 144. 
Nicolò da Ponte das vor Tintorettos Venetia tat. ${ }^{285}$ Auch in der restlichen Stadt war Maria omnipräsent, aber oft kaum zu unterscheiden von Venetia, Justitia, Libertas oder der Königin der Meere, so dass diese Personifikationen ineinander übergehen konnten. ${ }^{286}$ Diese Nähe war beabsichtigt, war doch die Lagunenstadt angeblich an Mariä Verkündigung 421 gegründet worden und sollte ewig bestehen. ${ }^{287}$ Auch sprach man von Venetia als der «immacolata pulzella». ${ }^{288}$ Wieder Coryate nannte die «most beautifull Queene» «a pure Virgin and incontamined mayde» und erklärte dies mit der erwähnten Metaphorik der Brautwerbung: «This noble citie hath [...] kept her virginity untouched these thousand two hundred and twelve years (for so long it is since the foundation thereof) though Emperours, Kings, Princes and mighty Potentates, being all allured with her glorious beauty, have attempted to deflowre her, every one receiving the repulse: a thing most wonderfull and strange. In which respect she hath beene ever priviledged above all other cities. ${ }^{289}$ Anders als etwa Magdeburg hatte Venetia ihre Keuschheit bewahrt, in der mystischen Ehe geschützt vom Dogen, der ihr Haupt war, aber sich zugleich ihr, dem Gemeinwesen, unterordnete. Das ging so weit, dass der Doge, ganz anders als die beschriebenen Könige, die gekrönte Venetia das Schwert sogar allein führen liess - so gegen die Liga von Cambrai auf Jacopo Palmas Allegorie in der Sala del Senato. ${ }^{290}$

285 Coryate, Crudities, 200; vgl. Wolters, Bilderschmuck, 92-136, 236-246, 270-272, 279 (Coryate) sowie 316 (Programmtext); vgl, aber auch 142 für den venezianischen Künstler Carlo Ridolfi, der 1648 eine Madonna als Venetia identifizierte; ferner Rosand, Venetia figurata, 187f.; ders., Myths of Venice, 44-46; Möbius, Frauenbilder, 61-66; für Beispiele Franzoi/Pignatti/Wolters, Palazzo Ducale, 261-264, 317.

286 Fenlon, Ceremonial City, 38-44. Siehe Wolters, Bilderschmuck, 59f., erneut für den einheimischen Künstler Ridolfi, der 1648 eine Allegorie als Venetia deutete, die von Tintoretto wohl als Libertà verstanden worden war.

287 Sinding-Larsen, Christ in the Council Hall, 53-55, 143f., 155; Rosand, Venetia figurata, 184f.; ders., Myths of Venice, 36-39.

288 Boccalini, Ragguagli 3, 147-151 (3, 49); für ähnliche Worte Sansovinos, des deutschen Reisenden Arnold von Harff (1497) oder James Howells (1651) vgl. Sinding-Larsen, Christ in the Council Hall, 242f. bzw. Rosand, Venetia figurata, 185f,; ders., Myths of Venice, $36 \mathrm{f}$.

289 Coryate, Crudities, 278.

290 Wolters, Bilderschmuck, 210 (Abb. 213); Franzoi/Pignatti/Wolters, Palazzo Ducale, 318 (Abb. 289). 
Der Doge war auch zugegen, als cine andere Republik zaghaft ihre ersten völkerrechtlichen Schritte in die Staatenwelt tat. Der Status der Eidgenossenschaft im Reich war noch unklar, als ein anonymer Künstler im Vorfeld des Dreissigjährigen Kriegs erstmals eine Landespersonifikation malte. ${ }^{291}$ (Abb. 15). Es handelt sich auch hier um eine Werbeszene: Von rechts nach links umstehen der Doge, die Könige von Frankreich und Spanien, der Herzog von Savoyen, der Erzherzog von Österreich und der Markgraf von Baden-Durlach die zentrale Frauenfigur. Der Text auf ihrer Schürze weist sie aus als «wunder Schweizerland, werthster Freyheit höchste Zier». Sie ist von «Malers Hand» in «alter Keüschheits'Trachø» unter «Frömbde Stände» platziert worden, wodurch ihre Macht «Königreichern glcich» gestellt sei. Die weibliche Personifikation des Schweizerlands tritt damit als gleichrangige Republik unter männliche Souveräne. Mit ihrer «Freiheitskron» erinnert sie an dic Regina coeli, doch enthält die Krone weltliche Hoheitszeichen: die Wappen der Kantone und der zugewandten Orte. Dic Landespersonifikation erzählt, wie sie durch «alte Stärcke, Treu unnd Bund» im Kampf gegen die habsburgischen Vögte einen Platz erlangt habe unter den Mächten, dic nun um die «Hülffe, Frid Und Rath, Ruhe, Stärcke, Treü und Thats der Jungfrau werben. Auch im barocken Schauspiel Ey dtgnossisch Contrafeth Aluff- und Abnemmender Jungfrawen Helvetiae, das der katholische Autor Johann Caspar Weissenbach 1673 veröffentlichte, hielten viele mächtige Freier um die «freche Jungfraw» an, zumindest solange sie jung und unverdorben ihre Freiheit bewahren wollte, wie Weissenbach anklägerisch formulierte. Damals habe sie an Freiheit, Macht und Herrlichkeit zugenommen und sei, wie das Titelblatt der dritten $\Lambda$ uflage des Werks verkündet, «in einen gantz sovrainen Stand und freye Republic erhebt worden» ${ }^{292}$ Die weịbliche Gestalt der Helvetia repräsentierte also den Status einer souveränen Republik, wie ihn die Eidgenossenschaft seit 1648 in der europäischen Staatenwelt beanspruchen durfte.

291 Der 'Text wird ziticrt nach Kreis, Helvetia, 28. Dic Datierung «um 1612», nämlich nach dem Bündnis von Zürich und Bern mit Baden-Durlach in dem Jahr, dürfte stimmen, vgl. Ruoss/Wüthrich, Katalog, 109-110. Die spätere Datierung auf 1665-1668, dic ich früher vertreten habe (Maissen, Geburt, 270f.), ist falsch, da sich die Wappen den genannten Mächten zuordnen lassen, die alle in den 1610er Jahren mit einzelnen Kantonen oder, im Falle Frankreichs nach dem Beitritt Zürichs zum Bündnis, mit der ganzen Eidgenossenschaft Bündnisse unterhielten. Bei Baden-Durlach war das sonst nie der Fall. Vgl. auch Lau, «Stiefbrüden», 398--401.

292 Weissenbach, Eydgnosssisches Contrafeth; ders., Auffnemmende Helvetia. 


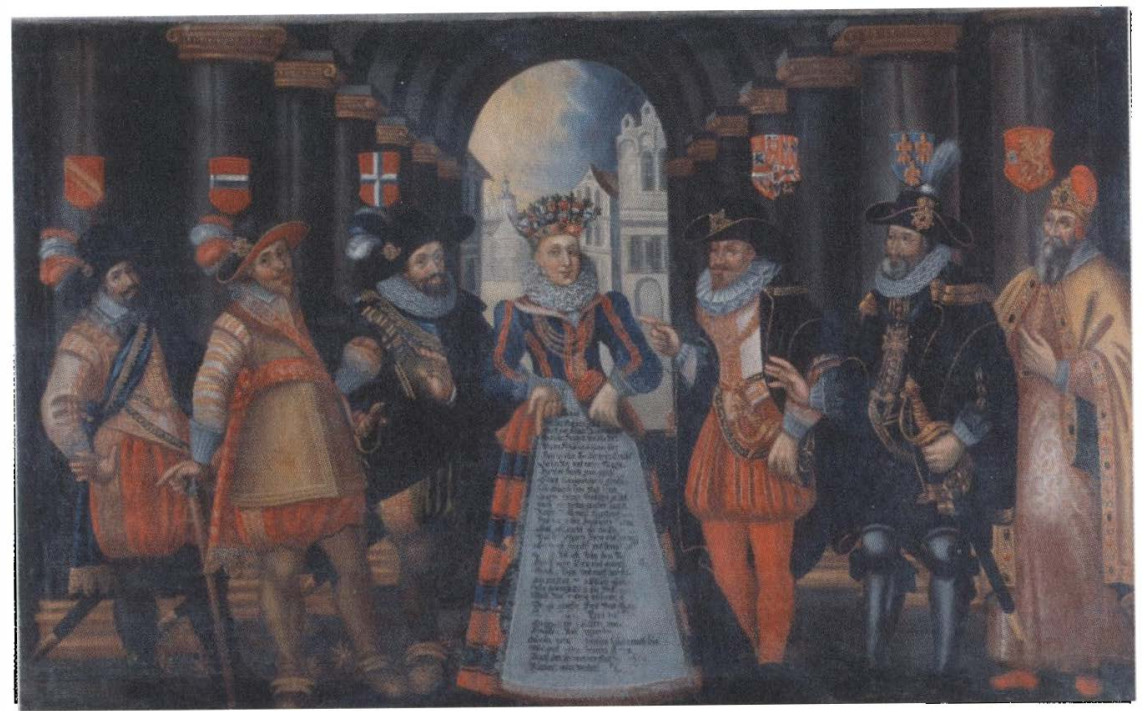

Abb. 15: Wunder Schweizerland, Öl auf Leinwand, Schweizerisches Nationalmuseum.

Fast zeitgleich erschien 1676 aus der Hand eines reformierten Magistraten eine bildliche und schriftliche Doppelbeschreibung der Helvetia, nämlich Jacob Wurmanns Bulschafft der sich representivenden Eidtgnössischen Dam, welche einer hochloblichen Eidgnoschaft ibre Herzensgedanken in trenen eröffnet, mit vermelden, dass sie Ihr verlobte tragende Jungfranschaft gegen allen ihven anssländischen Bulen rein bebalten, sich in Ebestand nit einlassen, sonder by ibrem bis dahin tragenden Kranz ihr Leib, Ehr; Gut und Blut anfsezen, darbei leben und sterben wolle. Dieser Blumenkranz auf ihrem Haupt var auf Conrad Meyers Frontispiz (Abb. 16) ein eidgenössischer Wappenkranz, wie er ähnlich bei Weissenbach aus Blumen in den Kantonsfarben zusammengesetzt war und als Krone das um 1612 gemalte «wunder Schveizerland» nobilitierte. Zugleich symbolisiertc der Kranz dic Keuschheit. Denn dic Dame habe ihre Jungfräulichkeit der Fidgenosscnschaft verlobt und verteidige sie nun gegen die Buhlen: «In der Ehe thet Ich grvüss kein Schick, Weil Ich besitz ein Republik, Ich erkenn kcinen Herren.» ${ }^{293}$ Als Jungfrau volle sie sterben, da sic schon vor langem mit eigenem Blut die «Freyheit», ihr «Reich und Gub»

293 Wurmann, Bulschafft, 6, 10; «kein Schick tun» hcisst «sich nicht einfügen können», Schweizerisches Idiotikon, Bd. 8, Sp. 494. 
erworben habe und jetzt «ein Land» besitze. Die Paarbeziehung der mystischen Ehe wurde hier als unbeflecktes Verlöbnis der Jungfrau mit den Eidgenossen aufgefasst, die trotz konfessionellen Differenzen einig bleiben müssten, um im Geist der Vorfahren Helvetias Keuschheit gegen fremde Freier zu verteidigen. Denn der Eheschluss mit einem von diesen würde das ewige Joch der «Dienstbarkeit» bedeuten: «Ich käme um mein Reich und Land, Und auch um mein den freyen Stand. ${ }^{294}$ Das von Conrad Meyer gestochene Frontispiz illustrierte diese Gefahr: Ein Mann in Rüstung greift der «Dam» nach dem Kranz und der Brust, doch diese entzieht sich und streckt die Hand nach Waffen aus, vor denen ein Schild mit einem weiteren eidgenössischen Wappenkranz steht. ${ }^{295}$ Nicht auf einen Mann, den Fürsten, muss sich die Republik verlassen; als Gemeinwesen, das auch ohne exklusives Haupt handlungsfähig ist, greift sie gut gerüstet selbst nach den Waffen. ${ }^{296}$ Der Garten als Umfeld verband wie beim bortus conclusus Wehrbereitschaft und Gottesunmittelbarkeit mit keuscher politischer Unschuld, Friedfertigkeit und Fertilität. Das entsprach der Maxime der Neutralität, wie sie die Eidgenossen in denselben Jahren erstmals für sich entdeckten und zur legitimen Position eines souveränen, aber defensiven Völkerrechtssubjekts entwickelten. ${ }^{297}$ Entsprechend begegnet Helvetia fortan in der Regel ohne beschützenden Mann, allein und erhöht auf einem Thron, mit republikanischen Symbolen in der Hand. Mit einem solchen Frontispiz schmückte David Herrliberger den Erstdruck von Aegidius Tschudis Cbronicon Helveticum (1734). Das Konzept verdankte er seinem Lehrer Bernard Picart, der die souveräne und deshalb gekrönte «République des Suisses» auf ihrem Thron in einer ähnlichen Grundkomposition mit Allegorien umgab wie seine «République de Hollande», das erwähnte Frontispiz für Le Clercs Histoire des Provinces-Unies von 1723. ${ }^{298}$

294 Wurmann, Bulschafft, Zitate auf 10, 13, 18, 24, 33, 55.

295 Er zeigt 14 statt 13 Wappen, weil der katholische und der reformierte Teil von Glarus einzeln gezeichnet werden.

296 Das unterscheidet die Komposition klar etwa von Funck, Helvetischer Bund, wo Helvetia zwvar unter einem Baldachin thront, aber einen Reichsadler umarmt und passiv zuschaut, wie ein Mann mit Schwert den gallischen Hahn vertreibt; vgl. auch Lau, «Stiefbrüder», Abb. 9.

297 Maissen, Weiser Fuchs.

298 Vgl. oben, Anm. 262, und Maissen, Geburt, 276f., Abb. 13; vgl. ebd., 591f., auch JeanMichel Moreaus Titelblatt für Beat Fidel Anton von Zurlauben, Tableaux de la Suisse ou Voyage pittoresque, Paris 1780. 


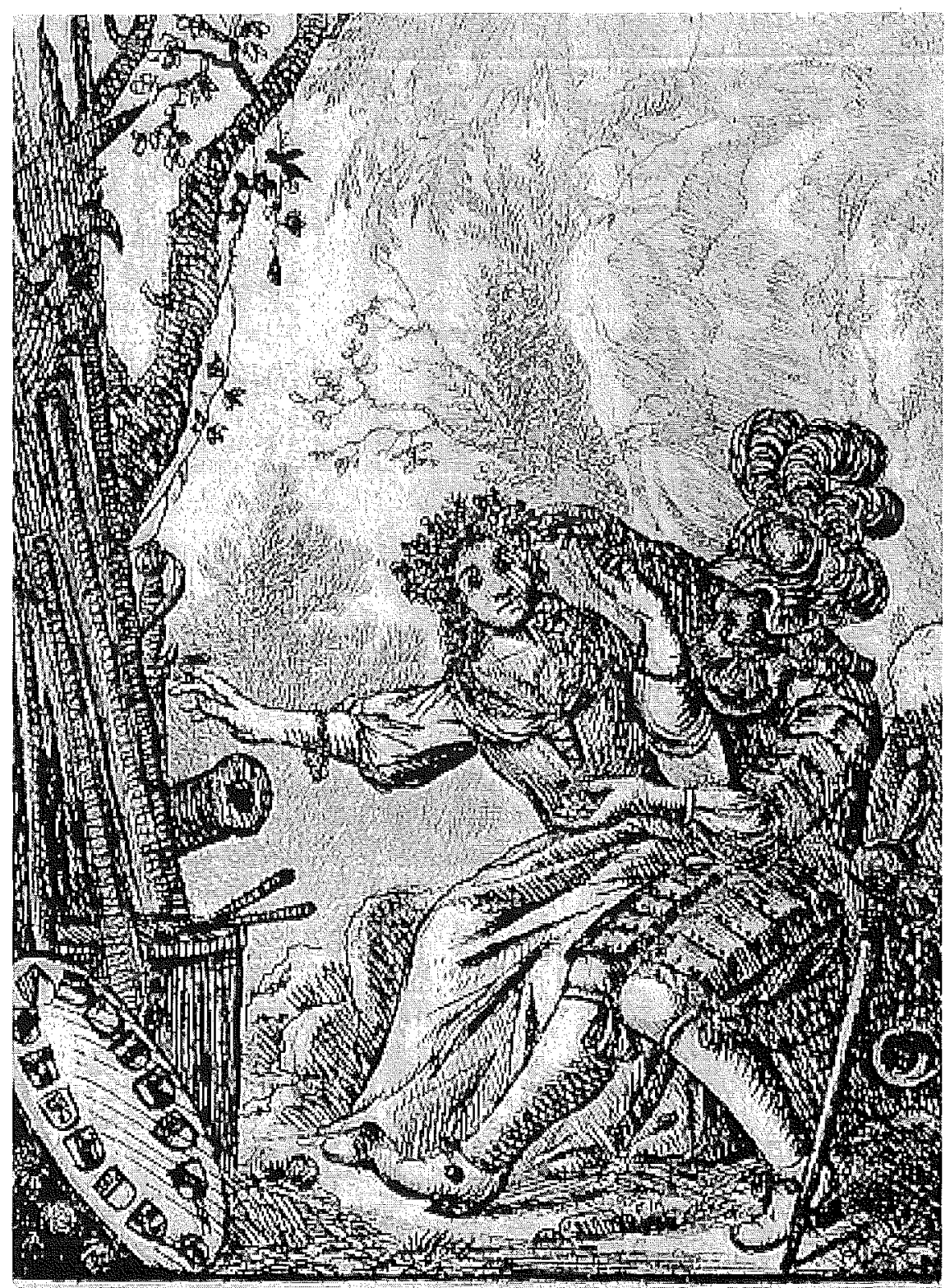

Abb. 16: Conrad Meyer, Titelblatt zu Jacob Wurmann, Bulschafft der sich representirenden Eidtgnössischen Dam, 1676. 
Obwohl Picarts Jungfrauen sich von der Vorlage der Maria oder Minerva lösten, blieb die Ikonografic der Madonna wic in Venedig auch anderswo für Personifikationen prägend. Das konnte an ihrer erwähnten Rolle als Stadtheiligen, die auch nach der Reformation weiter als offizielle Repräsentantin auftauchte, nicht nur in Magdeburg, sondern auch etwa in Hamburg oder Bascl. ${ }^{299}$ Erst recht geschah dics in katholischen Gefilden. Kurfürst Maximilian I. verstand sich sclbst als Statthalter Marias, der Patrona Boiariae und eigentlichen Herrscherin über Bayern. ${ }^{300}$ Die katholischen Schweizer Kantone beanspruchten Maria als Patrona Helvetiorum. ${ }^{301}$ Obwohl nicht sie, sondern Leodegar und Mauritius dic Schutzheiligen von Luzern waren, zeigte die Stadt die gekrönte Himmelskönigin auf einer Medaille von 1699, mit Jesuskind und nach unten, zur Stadt gerichtetem Zepter. Die Umschrift lautctc: «Luccrna pedibus meis», der Anfang von Psalm 119,105: «Dcin Wort ist einc Leuchte meinen Füssen und ein Licht auf meinem Pfade.» Ein Jahr zuvor schmückten Hans Georg Krauer und J. R. Morrini die Decke der Luzerner Kanzlei mit einer ähnlichen Figur: In einer Wolke sitzt, von der Sonne beleuchtet, eine gekrönte Frau auf einem goldenen Thron, das Zepter nach unten gerichtet und im anderen Arm kein Kind, sondern der Spiegel der Klugheit. (Abb. 17a). Die blau-weisse Kleidung, die Wappenfarben des im eigenen Selbstverständnis souveränen Kantons, macht sie zur Lucerna. Die Distichen unter der Szene leiten dies wortspielerisch von Lux, Virtus und Sapicntia her, die miteinander identifizicrt werden. 'Tatsächlich war das ikonografische Vorbild cindeutig Andrea Sacchis Divina Sapienza in der Sala del Mappamondo des Palazzo Barberini in Rom (Abb. 17b), Sinnbild für die W/cisheit, mit der das Haus Barberini den Kirchenstaat regiere. Dazu erwählt war cs, «sì come sì felice fameglia è nata ed clctta in luogo d'Iddio, per li primi govęrni della Chiesa»: Dicse Weisheit legitimierte gleichsam cine dynastische Herrschaft an Gottes Stelle. ${ }^{302}$ Die Barbcrini-Allegorie ist unter anderem von Justitia und Fides eingerahmt, wie in Luzern, wo sie Kirche und Regiment darstcllen. Mit ihren Attributen und dem scligen Blick nach oben erinnert Lucerna an die Regina coeli. Da die Weisheit im Buch der Sprüche (Salomos) in der ersten Pcrson als Frau auftritt und als weiblicher Aspekt der Gottheit gilt, lag ihre Identifikation mit Maria nahe. Neben

299 Reincke, Schutzpatrone; Hess, Rechtskontinuität, 347-349, Abb. 10.

300 Schreiner, Maria, $403 \mathrm{f}$.

301 Maissen, Geburt, 269, Abb. 10.

302 Für diesen Hinweis danke ich Marilyn Lavin. Für das Programm: Ost, Universitätskirche, 122. 
wiederholten Warnungen vor Ehebruch und Unzucht lehrt die Weisheit in genau dem Kapitel, in dem die erwähnten Tugenden als Begleiterinnen aufgezählt werden, eine politische Lektion (Spr. 8,15f.): «Durch mich herrschen die Könige und entscheiden die Machthaber gerecht. Durch mich regieren Fürsten und Edle, wer immer auf Erden Gewalt hat.» Lucerna als säkularisierte Maria/Sapientia war also der Ursprung der weltlichen Herrschaft, gleichsam die Quelle der. Souveränität im Sinne der maiestas realis. ${ }^{303}$

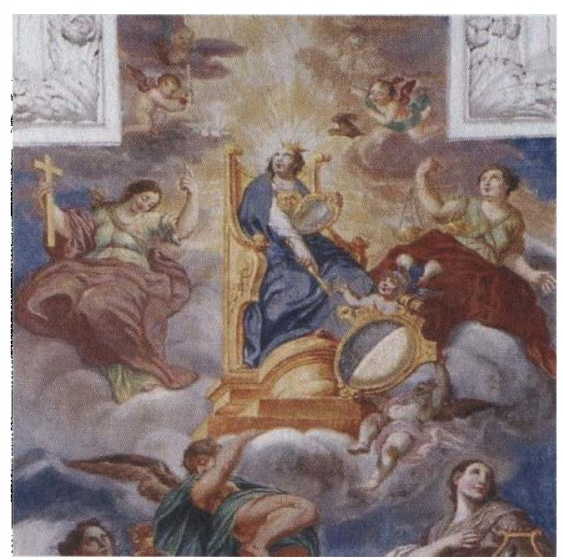

Abb. 17a: Hans Georg Krauer oder J. R. Morrini, Sapientia/Lucerna, Neue Kanzlei Luzern, 1698.

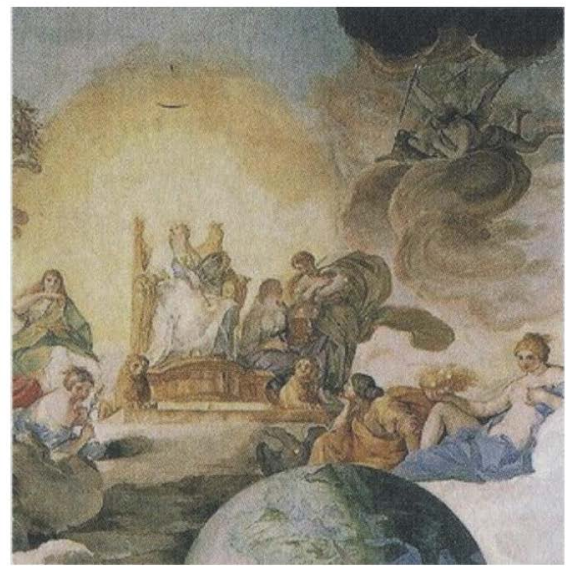

Abb. 17b: Andrea Sacchi, Divina Sapienza, Palazzo Barberini, 1633.

Diese Deutung wird bestärkt, wenn ein exakt gleichzeitiges Deckengemälde herangezogen wird, Johann Jacob Schärers Tondo im unteren Saal des Zürcher Rathauses, dessen Neubau 1698 fertig gestellt wurde. In diesem reformierten Kontext setztc Schärer eine sehr ähnliche Komposition um vie Krauer und Morrini im katholischen Luzern. Da die Wappenfarben dieselben sind, erscheint auch Tigurina blau-weiss gekleidet auf einer Wolke,

303 Vgl. auch bei Wolters, Bilderschmuck, 63, Anm. 1, Mutio Sforzas Frage von 1585, allerdings dort auf Venetia gemünzt: «et queste (Republica) non pare che stata sia dalla Divina Sapienza instituita?» 


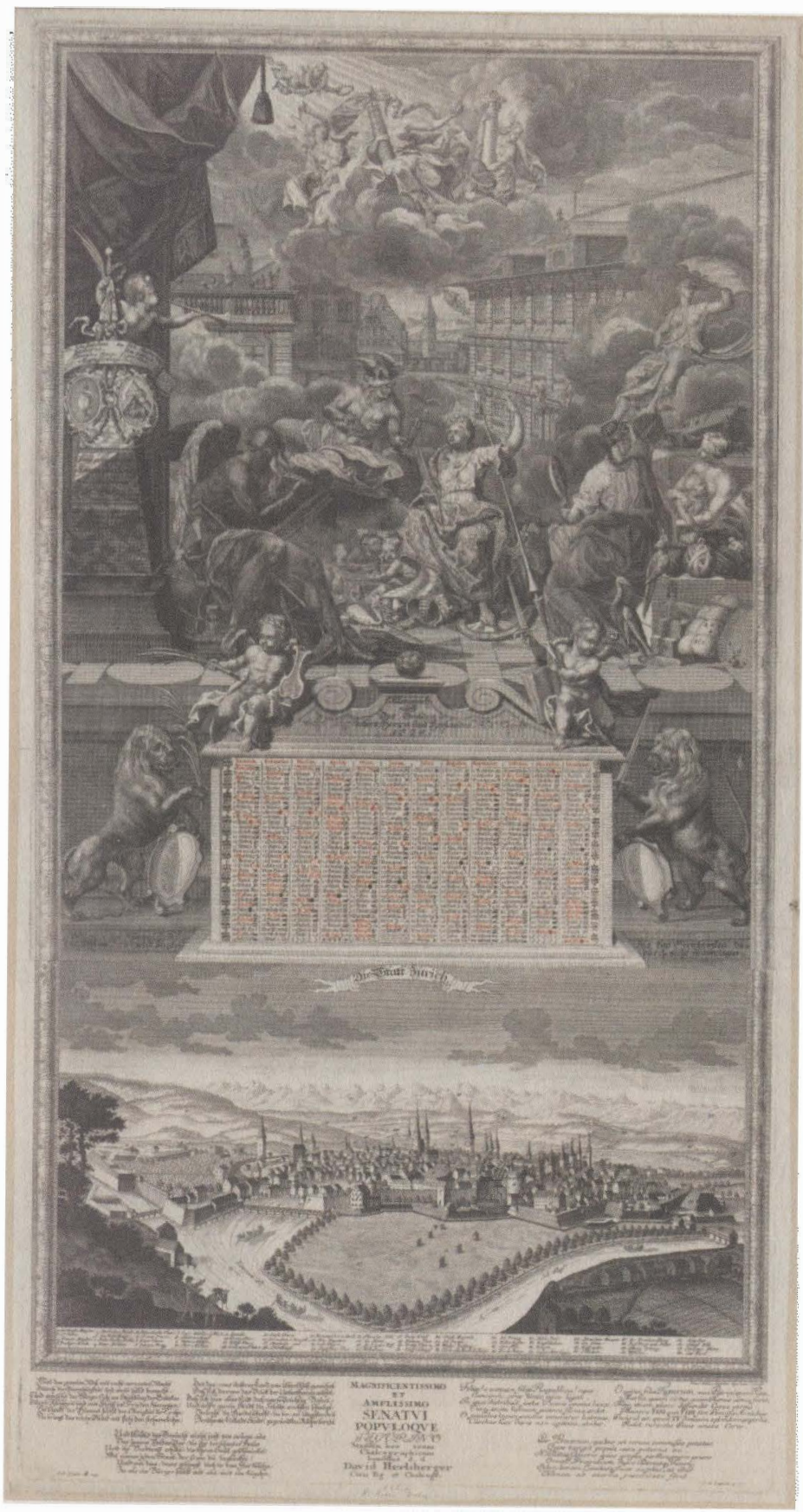

Mbb. 18: Johann Melchior Füssli/David Herrliberger, Zürcher Staatskalender, 1724. 
mit Justitia zur Linken und Abundantia zur Rechten. ${ }^{30+} 1724$ griff Johann Melchior Füssli dicselbc Gruppe für den oberen 'T'eil eines grossformatigen Almanachs auf. (Abb. 18). 'I'igurina sitzt über einer Szene mit Allegorien, rechts ist das Zürcher Rathaus zu erkennen, links cin Obclisk unter einem Baldachin, bcides Symbole der Souveränität. Am Obelisken hängen erleuchtet die Wappen der beiden aktuellen Bürgcrmeister, der vorübergehenden, da sterblichen 'T'räger dieser Souveränität. Da ihre Vorgänger gestorben sind, liegt der Rest der Pyramide im Schatten, den Chronos wirft, der Historiograf der vergänglichen Menschentaten. Evvig ist dagegen die Souveränität, weshalb die Obeliskenspitze und das Rathaus vom himmlischen, göttlichen Licht erleuchtet verden. Diesc Strahlen fallen auch auf die Gruppe, die Füssli von Schärers Rathausdecke übernahm, aber signifikant criveiterte: Neben 'Tigurina und Justitia (Regiment) folgen nun rechts ebenfalls eine betende Fides (Kirche) und neu eine Virtus mit einer korinthischen Säule, ebenfalls ein Symbol der jungfräulichen Souveränität. Wie bei 'T'engnagels Hollandia ( $\Lambda$ bb. 6 ) und Werners Berna ist die Staatspersonifikation von den drei Ständen umgeben, die sie umfasst. Dabei repräsentiert Virtus die Bürgerschaft, die im Gefolge der Zunftrevolte von 1713 «ein glied des ganzen burgerlichen leibs» geworden war, also in die Respublica aufgenommen worden war, um die mittelalterliche 'T'erminologic eincs Lucas de Penne zu verwenden. Neben den vornehmen regimentsfähigen Familien hatten die gewöhnlichen Bürger so zumindest formal Anteil an der von 'Tigurina versinnbildlichten Souveränität erlangt. ${ }^{305}$ Ihre ikonografischen Wurzeln lagen, auf katholischer wie reformierter Seite, in der Marienikonografie, die Füssli - selbst cin führendes Mitglied der Zunftopposition von 1713 - auf seinem Stich wiedergab.

30. Für die vollständige Interpretation und Einordnung in das Programm des Rathauses Maissen, Geburt, 383-400, insbes. 392-395 und Abb. 25.

305 Maissen, Geburt, 410-413. 


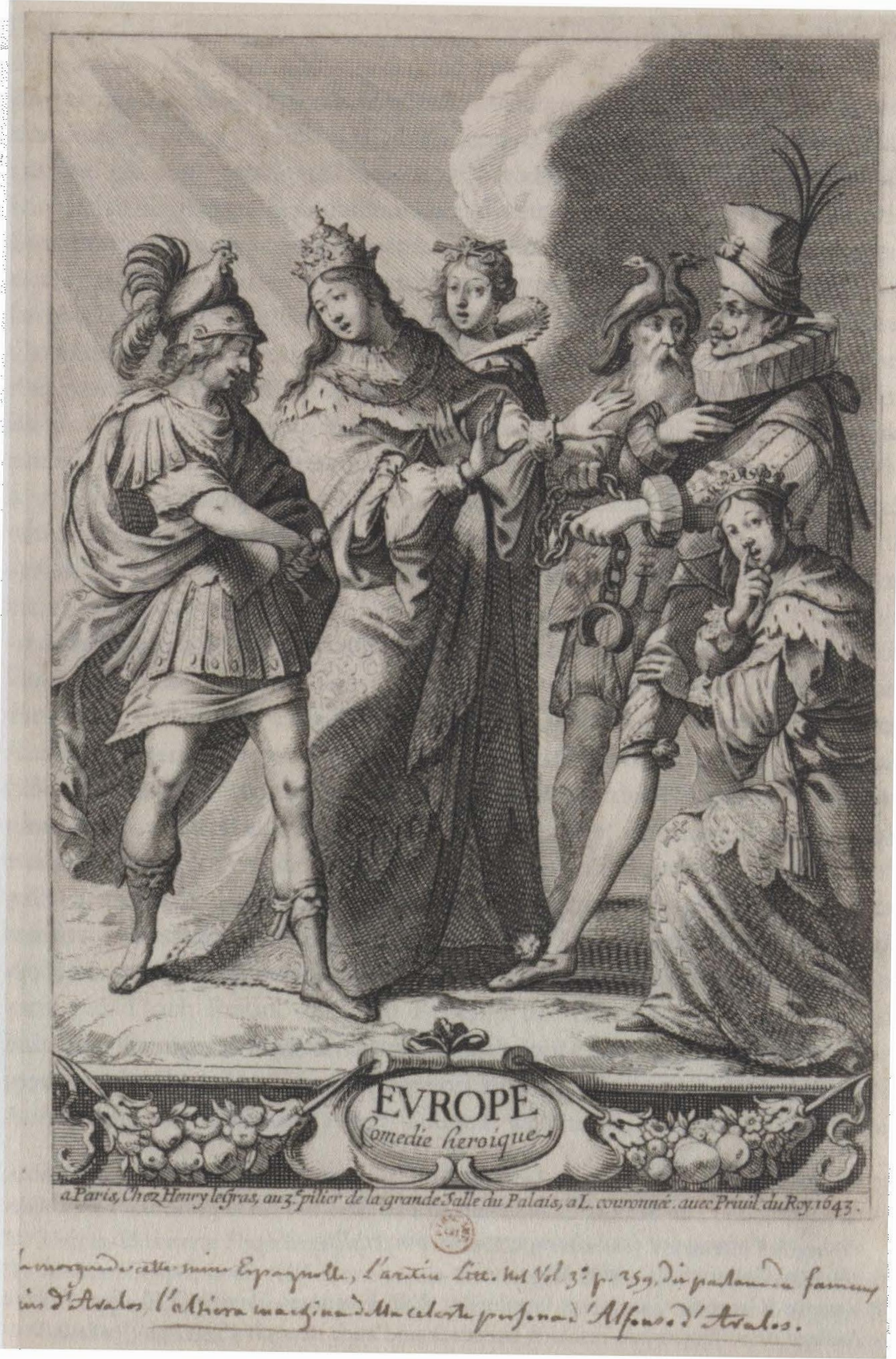

Abb. 19: Jean Desmarets de Saint-Sorlin, Europe. Comedie Heroique, 1643. 


\section{Die europäische Staatenwelt}

Die friedlichen oder gewaltsamen Werbungen um eine Respublica, etwa um das «wunder Schweizerland» (oben, Abb.15), haben gezeigt, dass die Kombination der mittelalterlichen Zwveikörpervorstellung und der auf ihr beruhenden mystischen Ehe mit der neuzeitlichen Souveränitätslehre nur dann Sinn ergab, wenn etwa mit der Unterscheidung von maiestas realis und maiestas personalis oder des corpus mysticum et civile vom corpus mysticum et politicum (Terre Rouge) Potenzial und Quelle der Souveränität von der konkreten Verfügungsmacht getrennt betrachtet wurden. Trotz ihren herrschaftlichen Attributen war eine Regina coeli kein Leviathan und eignete sich bloss bedingt für die Symbolisierung des Gewaltmonopols. Deshalb blieb es die Regel, dass ein streitbarer Mann die Landespersonifikation in einer Paarbeziehung beschützte. Doch der - in der Bildkomposition greifbare Grad der weiblichen «Emanzipation» eröffnete durchaus die ganze frühneuzeitliche Spannbreite von absolutistischer Despotie bis zu republikanischer Anarchie. Und die weiblichen Republiken konnten, wie «vunder Schweizerland» unter Männern zu selbständigen und gleichwertigen Akteuren der Aussenpolitik aufsteigen oder gar - vie Palmas Venetia oder Wurmanns Helvetia - selbständig das Schwert führen. ${ }^{306}$ Wohl der Luzerner Aufklärer Franz Urs von Balthasar liess dann eine republikanische Frauenrunde auf einem Deckenbild zusammenkommen: Roma lehrt die Freiheit, Venetia, Hollandia und Helvetia hören zu. ${ }^{307}$ Vermutlich war es auch kein Zufall, dass gerade ein Venezianer 1622 ein millenaristisches Flugblatt verfasste und die allesamt gekrönten Personifikationen Polonia, Gallia, Hispania, Germania, Anglia, Italia und Moscovia mit Schwertern aufeinander losgehen liess, um die «Discordia Christianorum Principum» zu illustrieren. ${ }^{308}$

Es gab aber auch die Möglichkeit, die erotische Metaphorik auf eine nächsthöhere Ebene zu tragen und Europa selbst zur Akteurin zu machen.

306 Die Darstellungen der kämpfenden Francia in Versailles sind damit nicht vergleichbar, da Ludwig XIV. im Schloss omnipräsent ist und dort, wo beide gemeinsam abgebildet sind, den Vorrang vor der Jandespersonifikation crhält.

307 Maissen, Geburt, 521f. (Abb. 38).

308 Venetus (Gregorio Giordano), Prophetiae; BNF Estampes, Hennin 2013. Eine frühere Auflage ohne Illustration erschien lateinisch und auch deutsch 1591, vgl. (Jordan), Propheceyung vnd Wcissagung. Von der Komposition her ähnlich ist Hendrik de Clercks Kampf der 17 niederländischen Provinzen untereinander, während Belgica um Frieden betet (1609); Dlugaiczyk, Waffenstillstand, 363f. (Kat. 70). 
Dies geschah zusehends im 17. Jahrhundert, als Europa die Rollen einnahm, die hier im nationalen Zusammenhang bereits skizziert worden sind: eine Europa querula et vulnerata, die 1631 ihre Kriegswunden beklagt und Schutz vor den Peinigern sucht, oder eine Verwirnte Europa, die Wilhelm III. 1677 aus den Fängen Ludwigs XIV. befreit. ${ }^{309}$ Umgekehrt liess sich der Sonnenkönig als Friedensgeber feiern, zu dem Europa emporschaut und den Frieden von Nimwegen von 1678 verdankt; oder er spaziert mit Europa einher, weil er dank seinen französischen Besitzungen der ruhmvollste Fürst sei. ${ }^{310}$ In Jean Desmarets de Saint-Sorlins Europe, einer von Richelieu angeregten Comedie Heroique von 1643, ist Europa eine vornehme Königin, die von Ibere, also Spanien, heiss begehrt wird. (Abb. 19). Auf dem Titelblatt hält er Ketten bereit, die er der gekrönten Europa anlegen will - ganz ähnlich wie auf der erwähnten niederländischen Medaille der Hollandia (oben Abb. 12). Die jungfräuliche Europa wehrt den aufdringlichen Ibere jedoch ab, «car ie veux demeurer vierge \& libre à iamais». Hilfe in ihrem Freiheitskampf findet sie nicht beim Greis Germanique, sondern bei Francio, der den Hahn auf dem Helm trägt und zum Schwert greift. ${ }^{311}$

Prägend für die allegorische Erfassung Europas ist die organologische Darstellung, wie sie erstmals 1537 bei Johannes Putsch greifbar war und dann vor allem über Sebastian Münsters Cosmograpbia universalis (seit der Ausgabe von 1588) und Heinrich Büntings Stich Europa in forma virginis (1582) wirkte. $^{312}$ Der edelste Teil dieser Jungfrau, das Haupt, liegt in Spanien, und auch Kaiserkrone, Reichsapfel und Zepter machen deutlich, dass es sich noch um die imperiale Variante von Europa handelt, wie sie Putsch wobl in direkter Absprache mit den Habsburgern entwarf. Noch ein Jahrhundert danach setzte auch Michael Prauns Relation von den Liebesneigungen der Allerscbönsten Princessin Europa (1660) mit der Beschreibung dieser Landkarte ein. Doch Praun, der «den Zustand der Allervortrefflichsten Fürstl. Fräul. Fr. Europa, und ihrer Hochfürstl. Jungen Herrn» zu beschreiben versprach, schilderte den Kontinent nicht mehr hierarchisch, sondern in einer Aufzählung von alten und neuen Staaten, welche die einzelnen Glieder der

309 Harms, Illustrierte Flugblätter Bd. 2, 392f. (II, 223); Valkenier, Verwirrtes Europa.

310 Antoine Coypel, Louis XIV donne la paix de Nimègue à l'Europe, Versailles; Fr. Mazot, L'Europe, BNF Estampes, Hennin 4021. Vgl. auch die Europa im Salon de la guerre bei Sabatier, Versailles, 394f.

311Desmarets, Europe; Desmarets de Saint-Sorlin, 841-944; vgl. auch Felbinger, Quellenautopsie «Jean Desmarets».

312 Schmale, Europa, 241-267. 
Jungfrau bilden. Diese erzählt dann ihre erotischen Erfahrungen. Jupiter und Alexander der Grosse waren ihre Liebhaber, ehe Julius Caesar sie schändete und Augustus sie mit Schmeicheleien gefügig machte. Danach ist Europa dem «vortrefflichen Teutschen Helden Carolo dem Grossen zu theil worden». Mit ihm zeugte sie «etliche junge Herrn (mit welchen Sie hernach alle Länder [...] besetzet)». Nach dieser erfolgreichen Ehe hat Europa beschlossen, «mit niemand anders mehr einige Ehliche Verbündniss einzugehen und alle ihre Herrschaft, länder und Gewalt keinen andern Eheherrn mehr zu vertrauen, sondern dieselbige ihren Fürstl. Kindern und Encklen zu überlassen.» Das waren die souveränen Fürsten des Kontinents, die sich allerdings lange Zeit im Ringen um die Hegemonie bekämpften - Praun dachte nicht zuletzt an den Dreissigjährigen Krieg. Erst seit dem Westfälischen Frieden bildeten sie die von Praun gewünschte christliche «allgemeine confoederatam Gentium Remp[ublicam]» - keine gemässigte oder gar "pura absoluta Monarchia», sondern eine Aristokratie von weitgehend gleichrangigen Brüdern unter dem Altersvorsitz des Kaisers. ${ }^{313}$

Prauns Darstellung der Europa mit Kindern war nicht singulär. In einem Flugblatt wandte sich Europa 1654 im Namen der hinter ihr stehenden Nationen an die europäischen Fürsten von Kaiser und Papst über die kontinentalen Könige bis zum Dogen, die Väter ihrer gemeinsamen Kinder: «Peres de ces enfans dont je me dis la mere». Indem sie das Elend der Nationen darlegte, bat sie die Herrscher um den Frieden. ${ }^{314}$ (Abb. 20). Aus den Jünglingen auf diesem Flugblatt wurden schliesslich wieder weibliche Staatspersonifikationen: Hans Assmann Freiherr von Abschatz liess in seinem Gedicht $Z u$ Römisch-Hungarisch = Königl. Vermählung Glückwünschendes Europa von 1699 nicht nur Europa auftreten, sondern ihre «Helden-Töchtet», die verschiedenen Länder von Portugal bis Polen, die dem Kaisersohn Huldigungen und Geschenke darbringen. ${ }^{315}$ Und wie sich die europäische Staatenwelt erweiterte, so fügten sich weitere weibliche Personifikationen in die Bilderwelt. Deshalb konnte Europa auf einem Medaillenentwurf zum Frieden von Belgrad 1739 den Palmzweig nicht nur der Allegorie Österreichs reichen, sondern auch den weiblichen Personifikationen des Osmanischen Reichs und Russlands. 


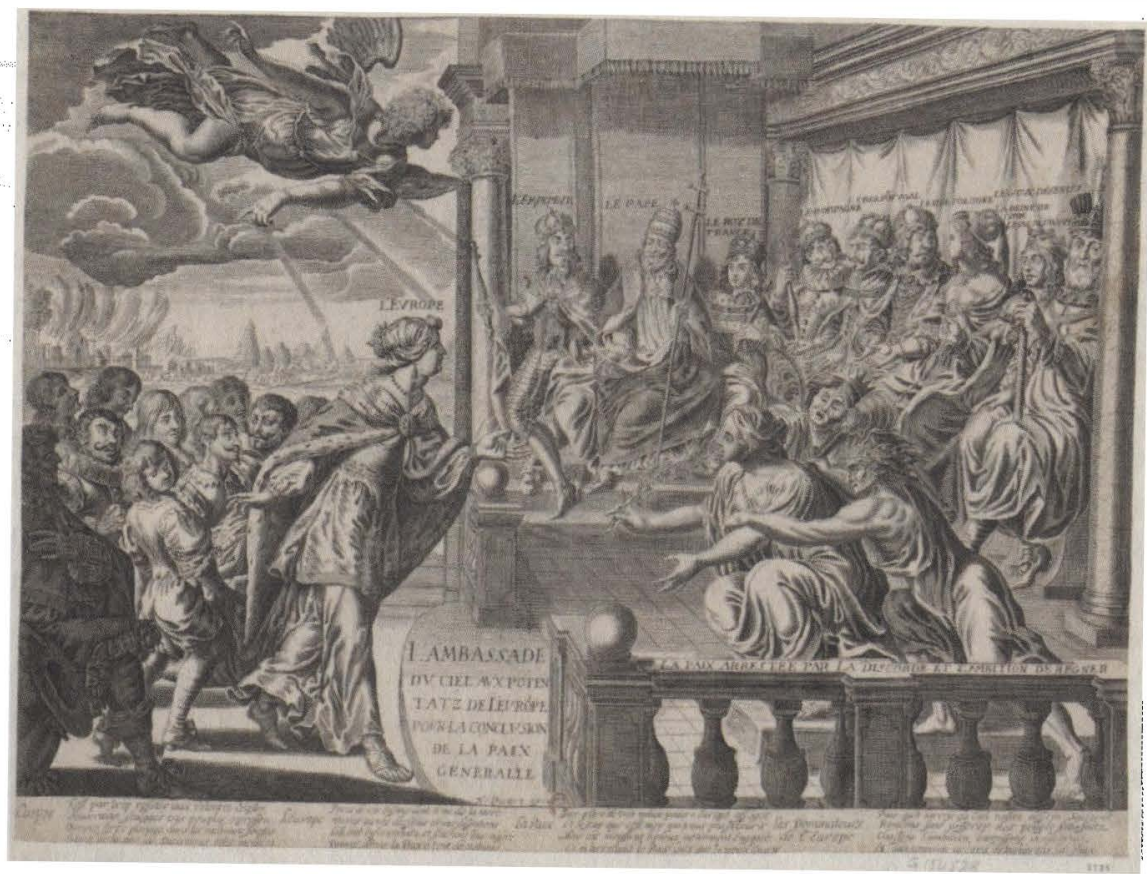

Abb. 20: L'Ambassade du ciel aux potentats d'Europe, 1654.

Die Repräsentation von Europa im Rahmen der Ehemetaphorik war nicht spannungsfrei. Europa musste polygam sein, wenn sie die Partnerin mehrerer Fürsten sein wollte. Dann waren ihre gemeinsamen Kinder Untertanen des Herrschers. ${ }^{316}$ Wenn aber die Kinder, wie bei Michacl Praun, sclbst Fürsten wurden, dann waren sie wiederum Souveräne. War Europa sclbst also bei Praun Trägerin eincr abendländischen maiestas realis als Grundlage einer föderativen Respublica Christiana, wie sie in Friedensplänen des 17. und 18. Jahrhunderts etwa Leibniz als Gegenkonzeption zu einer habsburgischen oder bourbonischen - Monarcbia universalis einbrachte? Dreux de Radicr zeigte 1755 Europa als thronende Minerva, mit der strahlenden Sonne unmittelbar hinter ihrem Kopf auf einem Baldachin, auf dem die Häupter von - sterblichen - Fürsten erschienen. ${ }^{317}$ Das war ein

316 Für die Kinder als Untertanen vgl. ausser die oben genannten Stellen (Anm. 53 und 255) auch Giulio Antonio Brancalasso, Philosophia Regia medulla politicorum, Neapel, 1609, 47, zitiert bei De Mattei, Idea democratica, 39, Anm. 4: «Sponsus si Princeps suae Reipublicae est, inde fit ut subditi a Republica procreati, filiorum sibi locum vindicent.»

317 Dreux de Radier, L'Europe illustre. 
ikonografisches Mittel, um Souveränität zu vermitteln. ${ }^{318}$ Dic Vorstellung einer gesamtcuropäischen Souvcränität var bestimmt unzeitgemäss; abcr es wird deutlich, welch langfristige Sprengkraft in den hier diskutierten Metaphern steckte.

Deutlich wurden jedenfalls bereits damals Ansprüche auf einc militärisch-kulturelle Hegemonie gegenüber der restlichen Wclt. Das cinigende Band bei Praun war der 'Türkenkrieg. Und der bereits erwähnte Heinrich Ludwvig Gudc erklärte 1708 das Frontispiz zu seiner Beschreibung der curopäischen Staaten (Abb. 21) durch den Verweis auf die modernen Künstler, die den Kontinent «als eine sitzcnde Jungfrau abbilden, welche Erfindung von dencn (das Frauenzimmer sonderlich hoch haltenden) Franzosen herkommet». Diese «unbefleckte königliche Princessin in Ansehung der andern Welt-'Theile [...], so unter dem Bilde eincr gekrönten Jungfrau vorgestellet werde, sey mit ihren volckreichen Staaten so mächtig, dass sie eine Beherscherin des Camcles, worunter Asia abgebildet wird, und eine Besitzerin des Hcrzens, unter welchen Bilde Africa zu verstchen, billich zu nennen, ja sic sey eine Erfindcrin und Königin der neucn Wclt geworden. Diese Hoheit von Europa, und dass sie eine Überwinderin der andern Welt'I'heile sey, will auch, das vor dicser Einleitung zu den Europacischen Staaten stehende Kupfferblat zuvcrstehen geben.»319 Auf dem Stich thront Europa im Hermelingewand mit Zepter unter cinem Baldachin, dic drei anderen Kontinentalpersonifikationen knien vor ihr. Der 'Text dazu verkündet: «Europa komt nichts gleich, wic ihre Staaten zcigen, Es muss die ganzc Welt vor ihrcr Macht sich neigen.» Das System souvcräner Staaten selbst machte die Überlegenheit Europas aus, das dadurch als vielfältiges Ganzes gleichsam Souveränität über die ganze Welt beanspruchtc.

318 Vgl. ausser dem oben crwähnten Stich von Füssli auch Sebastian Walchs Bürgermeisterporträts, Maissen, Geburt, 416-418, Abb. 29.

319 Gude, Europäischen Staaten. Für den Hinweis auf das Werk und die Identifikation des Autors danke ich Urte Weeber. 


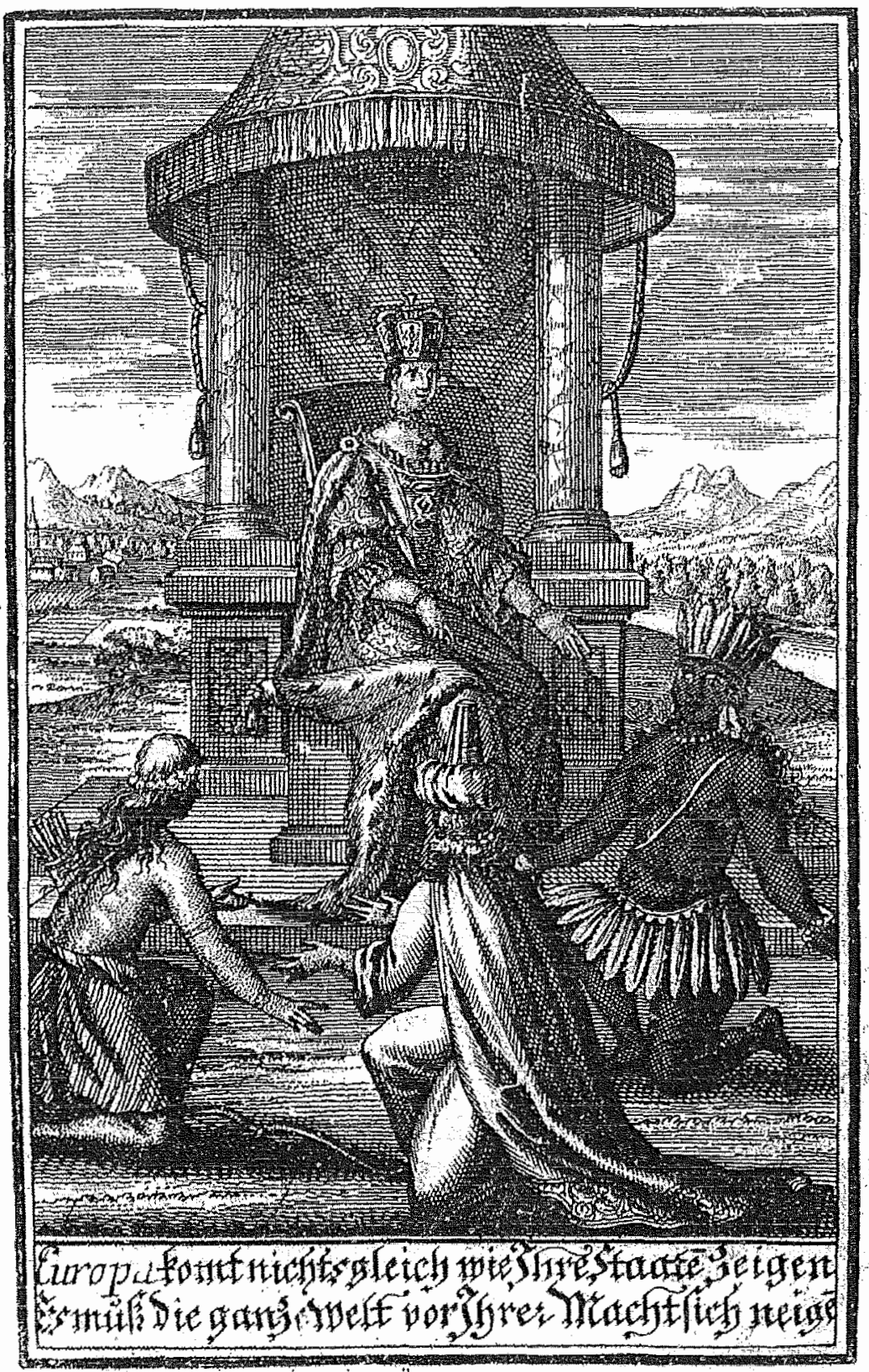

Abb. 21: Heinrich Ludwig Gude, Einleitung zu den europäischen Staaten und derselben Beschluss, s. 1. 1708, Frontispiz. 


\section{Resümierender Ausblick}

Nicht allein solche Konzeptionen der Europa waren entwicklungsfähig: in einem imperialistischen Sinn. Die aussenpolitische Emanzipation der Respublica zum Völkerrechtssubjekt hatte ebenfalls innenpolitische Implikationen, welche die Monarchien eher argwöhnisch beobachteten. Wohl war es Teil einer aussenpolitischen Strategie, wenn französische Diplomaten die Eidgenossenschaft seit den 1620er Jahren gelegentlich und im 18. Jahrhundert systematisch als corps belvétique oder corpus belveticum titulierten. ${ }^{320}$ Ein eigenständiger Körper war nicht länger dem kaiserlichen habsburgischen Haupt unterworfen. Das suggerierten die Franzosen in den Jahrzehnten um den Westfälischen Frieden mit Erfolg auch durch den Gebrauch neuer völkerrechtlicher Termini wie souveraineté, république oder neutralité, wenn sie mit den Eidgenossen verkehrten. ${ }^{321}$ Im Reich durchschaute man nach solchen Erfahrungen die Strategie: Karl VI. protestierte 1727 gegen die «Ubernhaufenwerfung der Teutschen Verfassung», nachdem der französische Gesandte Chavigny die Reichsstände wiederholt als Corpus Germanicormm angesprochen hatte. Das sei eine List, um «das allerhöchste Oberhaupt im Römischen Reich von dessen Gliedern zu trennen, solches unter einem noch niemals gebrauchten unanständigen metaphorischen Namen und ohngewöhnlichen Stylo von Corps Germanique in eine Spaltung a Caesearea Majestate zu bringens, ${ }^{322}$

Seinerseits fürchtete der französische König ebenso die innenpolitische Sprengkraft der organologischen Metaphorik. Dies wurde deutlich, als sich die Parlamente im 18. Jahrhundert zusehends als Wahrer der Grundgesetze des Landes gegen die als «despotisch» kritisierte Herrschaft des absolutistischen Herrschers und des Conseil $d u$ Roi stilisierten. Mit gallikanischkonziliaristischen Argumenten deuteten sie die Nation analog zur universellen Kirche und beanspruchten für sich, in ihrem Namen die Rechtsprechung des Königs so zu prüfen wie das Konzil den Papst. Dazu benutzten sie den droit de remontrance, ihr Recht, einen königlichen Gesetzeserlass unter Berufung auf die Interessen der Nation oder der Krone zur Überarbeitung zurückzuweisen, bevor das Parlament das Gesetz regis-

320 Für die Quellenbelege vgl. Oechsli, Benennung, 168-177.

321 Dazu Maissen, Geburt, 182-253.

322 Johann Jacob Moser, Reichs-Fama, Leipzig 1727, Bd. 7, 379-381; zitiert nach Dohrnvan Rossum, Art. Organ, 554. 
trierte. ${ }^{323}$ Diesen Ansprüchen widersetzte sich Ludwig XV., besonders nachdrücklich in der Séance de la flagellation vom 3. März 1766, als er dem Pariser Parlament sein Rollenverständnis diktierte. Er verwarf den Anspruch der Parlamente, einen zusammengehörigen und unteilbaren Körper zu bilden, der die Freiheit und die Rechte der Nation schütze und als Schiedsrichter zwischen dem König und seinem Volk agiere. Vielmehr liege die Souveränität bei ihm allein. Von ihm gehe die Gesetzgebung aus und jede Amtsgewalt, auch diejenige der Parlamente. Diese hätten sich erdreistet, die Nation als eigenen Körper («un corps imaginaire [...] séparé du monarque») zu deuten und dem König gegenüberzustellen; doch die Rechte und Interessen der Nation seien zwingend mit denen des Königs verbunden und ruhten letztlich allein in dessen Händen. ${ }^{324}$

Die Auseinandersetzung darüber, wer die Nation bilde und vor allem repräsentiere, wurde in den folgenden drei Jahrzehnten zur politischen Kernfrage in Frankreich. Den Vertretungsmonopolen des absolutistischen Königs einerseits, der historisch privilegierten Stände andererseits stellte Sieyès 1789 das folgenreiche Postulat entgegen, dass der Dritte Stand die komplette Nation sei und die anderen Stände nur insofern dazugehörten, als sie dem Dritten Stand hinsichtlich ihrer ökonomischen oder administrativen Funktionen gleich waren. ${ }^{325}$ Im selben Jahr stellte Jacques-Vincent Delacroix in seinem Catéchisme Patriotique eine ähnliche Frage: «Qu'est-ce que la nation? Le roi \& le peuple. Qu'est-ce que le roi ? C'est le chef que le peuple s'est choisi pour faire exécuter la loi, \& maintenir l'ordre prescrit par elle. Qu'est-ce que le peuple ? C'est tout ce qui forme la nation, excepté le roi.» ${ }^{326}$ Wenn dem Volk - dem Gemeinwesen - nur die selbst gewählte Exekutive - das Haupt - fehlte, um eine ganze, autarke Nation zu sein, dann gab es auf Dauer keinen Grund, weshalb dieses Haupt ein Erbmo-

323 Vgl. für das Umfeld auch Chaline, Art. Parlements, 960-965.

324 Flammermont, Remontrances 556-558: «Je ne souffrirai pas qu'il se forme, dans mon royaume une association qui ferait dégénérer en une association de résistance le lien naturel des mêmes devoirs et des obligations communes, ni qu'il s'introduise dans la Monarchie un corps imaginaire qui ne pourrait qu'en troubler l'harmonie; la magistrature ne forme point un corps ni un ordre séparé des trois ordres du Royaume; les magistrats sont mes officiers, chargés de m'acquitter du devoir vraiment royal de rendre la justice à mes sujets; fonction qui les attache à ma personne [...] comme s'il était permis d'oublier [...] que les droits et les intérêts de la nation, dont on ose faire, sont nécessairement unis avec les miens, et ne reposent qu'en mes mains.» Vgl. auch Koschorke, Staat, 260.

325 Sieyès, Tiers état, 27f.: «Le tiers état est une nation complète.»

326 Delacroix, Catéchisme Patriotique 6; vgl. auch Koschorke, Staat, 265. 
narch von Gottes Gnaden sein musste oder sein durfte. Es dauerte zwei bis drei Jahre, ehe diese Konsequenzen aus den zitierten Überlegungen klar ins Bewusstsein der Franzosen traten. Doch an dieser Spannung scheiterte schliesslich der Versuch, die historische, dynastische Legitimität der Monarchie mit der modernen der Volkssouveränität zu kombinieren; und damit die erste, gemässigte Phase der Revolution, deren Ergebnis - die konstitutionelle Monarchie nach der Verfassung von 1791 - Makulatur war, kaum dass sie fertig vorlag.

Der Hinweis auf die Nachwirkungen organologischen Denkens im Revolutionszeitalter soll noch einmal unterstreichen, dass die dazugehörige Metaphorik dazu beitrug, dass die Bodin'sche Souveränitätslehre in ihrer monarchischen und vor allem republikanischen Variante plausibel und akzeptabel wurde. Das lief einer radikalen, monarchischen Interpretation des Souveränitätsgedankens insofern zuwider, als Bodin die kontraktualistischen Bindungen des Fürsten ausschliessen wollte, die im organologischen Denken unvermeidlich waren. Notwendig war also eine Deutung der Souveränität als "puissance absolue et perpétuelle d'une République», als die dem Gemeinwesen innewohnende oder aus ihm hervorgehende uneingeschränkte und zeitlich unbegrenzte Gewalt - und nicht als die dem Gemeinwesen von oben auferlegte, ja es erst formende Macht. ${ }^{327}$ Uneingeschränkt hiess, dass diese Gewalt unmittelbar zu Gott war, dass kein irdischer Herrscher einem Souverän etwas dreinzureden hatte und dass keine untergeordnete Institution von seiner Gesetzgebung ausgespart war. Zeitlich uneingeschränkt bedeutete, dass diese Gewalt nicht mit dem natürlichen Körper ihres Trägers verschied, sondern im politischen Körper, in der Respublica, weiterexistierte. $\mathrm{Zu}$ Gott unmittelbar, unversehrt und ewig, das war in der omnipräsenten christlichen Vorstellungswelt, auch der protestantischen, die Jungfrau Maria: Herrscherin als Regina coeli, als Schutzmantelmadonna Bewahrerin der Bedrohten und selbst beschütztes Gut im bortus conclusus. Diese Bildtraditionen reichten zum Teil weit ins Mittelalter zurück. Aber ihre hier behandelte Politisierung, die Ausbildung eigentlicher Staatspersonifikationen als Vorläuferinnen der revolutionär-nationalen Marianne setzte in Frankreich, in Venedig und in den Niederlanden erst im letzten Viertel des 16. Jahrhunderts ein, im Reich, in England und in der Eidgenossenschaft gar erst im 17. Jahrhundert. Das war das Zeitalter Jean Bodins, zu dessen Souveränitätslehre diese Allegorien sich verhalten mussten. Die Staatspersonifikationen, die mystische Ehe, die Jungfraumetaphorik der Madonna und Miner- 
vas mit den entsprechenden Attributen und der bortus conclusus als keusches Territorium - das waren Metaphern und ikonografische Programme, um Souveränität zu beanspruchen und als Forderung zu vermitteln; um darüber hinaus den öffentlichen Bereich und die politische Ordnung zu sakralisieren und ihnen eine eigene Dignität zu verleihen, die mehr sein und mehr erreichen wollte als die notwendige, aber vorübergehende Verwaltung einer stets imperfekten civitas terrena. Die keusche Allegorie stand im Sinn der maiestas realis für die Grundlagen politischer (und ökonomischer) Autonomie im Inneren und für die ungeteilte Verfügungsgewalt des einen Gatten über dieses Potenzial, selbst wenn er ein kollektiver, republikanischer Bräutigam war; und sie stand für die Notwendigkeit, diese keusche, nämlich exklusiv dem Gemeinwesen verpflichtete maiestas gegen fremde Freier, also äussere Bedrohungen, zu verteidigen. 


\section{Literatur}

Astell, Ann W., The Song of Songs in the Middle Ages, Ithaca, Cornell University Press, 1990.

Atlas van Stolk. Katalogus der Historie-, Spot- en Zinneprenten betrekkelijk de Geschiedenis van Nederland, Amsterdam, 1895, http://cardweb. hmr.rotterdam.nl/collectie/vrij_index_gb.html (30.07.2012).

Augustinus, Aurelius, De civitate Dei, Corpus scriptorum ecclesiasticorum latinorum (CSEL), Bd. 40, hg. v. E. Hoffmann, Wien, Verlag der Österreichischen Akademie der Wissenschaften, 1899/1900.

Augustinus, Aurelius, In epistolam Ioannis ad Parthos, PL 35.

Bar, Virginie, La peinture allégorique au Grand Siècle, Dijon, Faton, 2003.

Baynes Coiro, Ann, A Ball of Strife. Caroline Poetry and Royal Marriage, in:

Corns, Thomas, Hg., The Royal Image. Representations of Charles I, Cambridge, Cambridge University Press, 1999, 26-46.

Beaune, Colette, Naissance de la nation France, Paris, Gallimard, 1985.

Belting, Hans, Bild und Kult. Eine Geschichte des Bildes vor dem Zeitalter der Kunst, München, C. H. Beck, 1990.

Benson, Robert Louis, The Bishop Elect. A Study in Medieval Ecclesiastical Office, Princeton NJ, Princeton University Press, 1968.

Bentley, Thomas, The Monument of Matrones, Conteining Seven Severall Lamps of Virginitie, London, H. Denham, 1582.

Bernard, Guillaume, Du roi juge au roi législateur en France au second XVIe siècle: «une foi, une loi, un roi»? Thèse, Rennes, 2000.

Beyerhaus, Gisbert, Studien zur Staatsanschauung Calvins mit besonderer Berücksichtigung seines Souveränitätsbegriffs, Berlin, Trowitzsch \& Sohn, 1910.

Blumenfeld, Renate, Enemies Without/Enemies Within. Threats to the Body Politic in Christine de Pizan, in: Medievalia et Humanistica n.s., 26, 1999, 1-15.

Blumenfeld, Renate, Dramatic Troubles of Ecclesia: Gendered Performances of the Divided Church, in: Burns, E. Jane et al., Hg., Cultural Performances in Medieval France. Essays in Honor of Nancy Freeman Regalado, Woodbridge, D.S. Brewer, 2007, 185-198.

Boccalini, Traiano, Ragguagli di parnaso e scritti minori, Bd. 3, hg. v. Luigi Firpo, Bari, Laterza, 1948.

Bodin, Jean, De republica libri sex, Lyon, 1586.

Bodin, Jean, Les six livres de la République (Corpus des cuvres de philosophie en langue française, Bd. 1-6), Paris, Arthème Fayard, 1986. 
Bor, Peter, Oorspronck, begin ende aenvang der Nederlantscher oorlogen, beroerten ende borgerlijcke oneenicheyden. Warachtighe ende historische beschrijvinghe door Peter BorChristiaensz,,Den Haag, B.C.Nieulandt,1603.

Bossuet, Jacques Bénigne, La Politique trée des propres paroles de l'Écriture sainte, in: ders., Euvres complètes, Bd. 10, Paris, F. Didot, 1836.

Bossuet, Jacques Bénigne, Correspondance, Bd. 1, hg. v. E. Levesque/ Ch. Urbain, Paris, Hachette \& Cie, 1909.

Boureau, Alain, Le simple corps du roi. L'impossible sacralité des souverains français, XVe-XVIII siècle, Paris, Edition de Paris, 2000.

Brandt, Bettina, Germania und ihre Söhne. Repräsentationen von Nation, Geschlecht und Politik in der Moderne, Göttingen, Vandenhoeck \& Ruprecht, 2010.

Britannia, Passionately and Historically, Remembering her Misery and Happinesse in Former Ages, and Declaring her Calamities, and Expectations Now, London, 1643.

Brutus, Stephanus Iunius (Mornay, Philippe de), Vindiciae contra tyrannos. Traduction française de 1581 (Les classiques de la pensée politique, Bd. 11), Genf, Droz, 1979.

Bühl, Gudrun, Constantinopolis und Roma. Stadtpersonifikation der Spätantike, Kilchberg, Akanthus, 1995.

Burkhardt, Johannes, Der Dreissigjährige Krieg (Moderne Deutsche Geschichte, Bd. 2), Frankfurt a. M., Suhrkamp, 1992.

Burkhardt, Johannes, Auf dem Wege zu einer Bildkultur des Staatensystems. Der Westfälische Frieden und die Druckmedien, in: Duchhardt, Heinz, Hg., Der Westfälische Friede: Diplomatie, politische Zäsur, kulturelles Umfeld, Rezeptionsgeschichte (Historische Zeitschrift, Beiheft, 26, 1998), 81-114.

Bussmann, Klaus/Schilling, Heinz, Hg., 1648. Krieg und Frieden in Europa. Ausstellungskatalog, Münster, Westfälisches Landesmuseum für Kunst und Kulturgeschichte, 1998.

Calvin, Jean, Institutio religionis christianae (1559), Opera quae supersunt omnia, hg. von Wilhelm Baum, Eduard Cunitz und Eduard Reuss (CO, Bd. 2), Braunschweig, C. A. Schwetschke, 1864.

Calvin, Jean, Tractatus theologici minores, Bd. 2 (CO, Bd. 6), Braunschweig, C. A. Schwetschke, 1867.

Calvin, Jean, Commentarius in Exodi librum (CO, Bd. 24), Braunschweig, C. A. Schwetschke, 1882.

Calvin, Jean, Sermons sur le Deuteronome (CO, Bd. 26), Braunschweig, C. A. Schwetschke, 1885. 
Canning, Joseph, The Political Thought of Baldus de Ubaldis, Cambridge, Cambridge University Press, 1987.

Chaline, Olivier, Art. Parlements, in: Bély, Lucien, Hg., Dictionnaire de l'Ancien Régime, Paris, Presses Universitaires de France, 22005, 960-965.

Chasseneux, Barthélemy de, Catalogus gloriae mundi, Frankfurt, S. Feyerabendt, 1586.

Choppin, René, De domanio Franciae libri III, Paris, 1588.

Cillessen, Wolfgang, Hg., Krieg der Bilder. Druckgraphik als Medium politischer Auseinandersetzung im Europa des Absolutismus, Berlin, $\mathrm{G}+\mathrm{H}$ Verlag, 1997.

Cino da Pistoia, In Codicem \& aliquot titulos primi Pandectorum tomi, id est Digesti veteris, doctissima commentaria, Frankfurt, S. Feyerabendt, 1578. Conring, Hermann, De Imperii Germanici republica acroamata sex historico-politica, Yverdon, apud societatem, 1654.

Cook, Edward, Argumentum Anti-normannicum Or, an Argument Proving, from Ancient Histories and Records, that William, Duke of Normandy, Made No Absolute Conquest of England by the Sword, London, 1682.

Cope, Esther S./Coates, Willson H., Hg., Proceedings of the Short Parliament of 1640, London, Royal Historical Society, 1977.

Corns, Thomas N., Duke, Prince and King, in: Corns, Thomas N., Hg., The Royal Image. Representations of Charles I, Cambridge, Cambridge University Press, 1999, 1-25.

Coryate, Thomas, Crudities, s. 1. 1611.

Daley, Brian E., The «Closed Garden» and the Sealed Fountain: Song of Songs 4:12 in the Late Medieval Iconography of Mary, in: MacDougall, Elizabeth B., Hg., Medieval Gardens, Washington D.C., Dumbarton Oaks Research Library and Collection, 1986, 253-278.

De Luca, Giovanni Battista, Il cavaliere e la Dama, Rom, Dragondelli, 1675. De Luca, Giovanni Battista, Il Principe cristiano pratico, Rom, Stamperia della reuerenda Camera apostolica, 1680.

De Mattei, Rodolfo, L'idea democratica e contrattualista negli scrittori politici italiani del Seicento, in: Rivista storica italiana, 60, 1948, 7-55.

Delacroix, Jacques-Vincent, Catéchisme Patriotique à l'usage de tous les citoyens françois, Paris, Gueffier, 1789

Delen, Adrien J. J./Meertens, Maria, Het Blokboek «Canticum Canticorum» als godsdienstig Kunstwerk, Antwerpen, Standaard-Boekhandel, 1949.

Descimon, Robert, La fonction de la métaphore du mariage politique du roi et de la République, France, XVe-XVIIIIe siècles, in: Annales ESC, 47, 1992, 1127-1147. 
Desmarets de Saint-Sorlin, Jean, Théâtre complet (1636-1643). Textes établis, présentés et annotés, hg. v. Claire Chaineaux, Sources classiques; 64, Paris, H. Champion, 2005, S. 842 (Abb. 11 : Frontispiz der Ausgabe von 1643).

Desmarets de Saint-Sorlin, Jean, Europe. Comédie héroüuqe. Attribuée à Armand du Plessis, cardinal de Richelieu et Jean Desmarets, sieur de Saint-Sorlin, hg. v. Sylvie Taussig, Turnhout 2006.

Dlugaiczyk, Martina, Der Waffenstillstand (1609-1621) als Medienereignis. Politische Bildpropaganda in den Niederlanden, München, Waxmann, 2005.

Dohrn-van Rossum, Gerhard, Art. Organ, in: Brunner, Otto/Conze, Werner/Koselleck, Reinhart, Hg., Geschichtliche Grundbegriffe. Historisches Lexikon zur politisch-sozialen Sprache in Deutschland. Studienausgabe, Bd. 4, Stuttgart, Klett-Cotta, 2004, 519-560.

Dolezalek, Gero/Bregger, Hans-Martin, Art. Vikar/Vikarin, in: Theologische Realenzyldlopädie (TRE), Bd. 35, Berlin/New York, De Gruyter, 2003, 84-89.

Drayton, Michael, Poly-Olbion, London, Browne, Helme \& Busbie, 1613. Dresser, Madge, Britannia, in: Samuel, Raphael, Hg., Patriotism. The Making and Unmaking of British National Identity, Bd. 3: National Fictions, London, Routledge, 1989, 26-49.

Dreux du Radier, Jean François, L'Europe illustre, Paris, 1755.

Duerr, Hans Peter, Obszönität und Gewalt (Der Mythos vom Zivilisationsprozess, Bd. 3), Frankfurt a. M., Suhrkamp, 21993

Duits, Henk, «De Vryheid, wiens waardy geen mensch te recht bevat». Vriheid' op het Nederlands toneel tussen 1570 en 1700, in: HaitsmaMulier, E. O. G./Velema, W. R. E., Hg., Vrijheid. Een geschiedenis van de vijtiende tot de twintigste eeuw, Amsterdam, University of Amsterdam Press, 1999, 99-131.

Eickmeyer, Jost, Der jesuitische Heroidenbrief. Zur Christianisierung und Konstextualisierung einer antiken Gattung in der Frühen Neuzeit, Berlin/ New York, De Gruyter, 2012.

Emich, Birgit, Hochzeit in Trümmern. Die Zerstörung Magdeburgs 1631 im medialen Kampf der Deutungen, in: Parthenopolis. Jahrbuch für Kultur- und Stadtgeschichte Magdeburgs, 1, 2007/2008, 13-36.

Emich, Birgit, Bilder einer Hochzeit. Die Zerstörung Magdeburgs 1631 zwischen Konstruktion, (Inter-) Medialität und Performanz, in: dies./ Signori, Gabriela, Hg., Kriegs/Bilder in Mittelalter und Früher Neuzeit (Beiheft der Zeitschrift für Historische Forschung, 42), Berlin, Duncker \& Humblot, 2009, 197-235. 
Felbinger, Rolf, Quellenautopsie «Jean Desmarets de Saint-Sorlin (1643)», in: Schmale, Wolfgang (Dir.), Europabegriffe und Europavorstellungen im 17. Jahrhundert, Web-Projekt, http://www.univie.ac.at/igl. geschichte/ europaquellen/quellen17/desmaretsdesaint-sorlin1643.htm (30.07.2012). Fenlon, Iain, The Ceremonial City. History, Memory and Myth in Renaissance Venice, New Haven, Yale University Press, 2007.

Flammermont, Jules, Hg., Remontrances du Parlement de Paris au XVIII siècle, Paris, Imprimerie impériale, 1895.

Fleming, Paul, Epistula Germaniae Exsulis, Leipzig, 1631.

Fleming, Paul, Lateinische Gedichte, hg. v. J. M. Lappenberg, Amsterdam, Rodopi, 1969.

Flood, Finbarr Barry, Between Cult and Culture. Bamiyan, Islamic Iconoclasm and the Museum, in: Art Bulletin, 84, 2002, 641-659.

Flor, Ingrid, Die Symbolik der Marienkrönung im Mittelalter, in: Sancta Crux. Zeitschrift des Stiftes Heiligenkreuz, 65, 2004, 90-116.

Flügel, Axel, Art. Grundbesitz, in: Jäger, Friedrich, Hg., Enzyldlopädie der Neuzeit, Bd. 4, Stuttgart 2006, 1151-1156.

Fortescue, John, De natura legis naturae, in: The Works of John Fortescue, hg. v. Thomas Lord Clermont, Bd. 1, London, Whittingham and Wilkins, 1869.

Fortescue, John, De laudibus legum Anglie, hg. v. Stanley B. Chrimes, Cambridge, University Press, 1942.

Foucault, Michel, In Verteidigung der Gesellschaft. Vorlesungen am Collège de France (1975/76), Frankfurt a. M., Suhrkamp, 2001

Franzoi, Umberto/Pignatti, Terisio/Wolters, Wolfgang, Il Palazzo Ducale di Venezia, Treviso, Canova, 1989.

Frauenfelder, Reinhard, Die Symbolik des Gobelins «Mystischer Garten Mariae» vom Jahre 1480 im schweizerischen Landesmuseum, in: Anzeiger für schweizerische Altertumskunde N. F., 38, 1936, 133-136.

Freschot, Casimir, Nouvelle relation de la ville \& republique de Venise, Utrecht, Poolsum, 1709.

Funck, David, Der grosse helvetische Bund: oder gründliche Fürstellung der löblichen Eydgenossschafft, zugewandten Ort, und Gemeinen Landvogtheyen, Nürnberg, 1690.

Gall, Lothar, Die Germania als Symbol nationaler Identität im 19. und 20. Jahrhundert, Göttingen, Vandenhoeck \& Ruprecht, 1993.

Gamboni, Dario/Germann, Georg/De Capitani, François, Hg., Zeichen der Freiheit. Das Bild der Republik in der Kunst des 16. bis 20. Jahrhunderts, Bern, Stämpfli, 1991. 
Gaudemet, Jean, Le symbolique du mariage entre l'évêque et son église, in: Kanon, 7, 1985, 110-123.

Gierke, Otto von, Das deutsche Genossenschaftsrecht, Bd. 3, Berlin, Weidmann, 1881.

Giesey, Ralph E., Medieval Jurisprudence in Bodin's Concept of Sovereignty, in: Jean Bodin. Verhandlungen der internationalen Bodin Tagung in München, hg. von H. Denzer, Munich, Beck, 1973, 167-186.

Giesey, Ralph E., The French Estates and the Corpus Mysticum Regni, in: ders., Rulership in France, 15th-17th centuries, Aldershot, Ashgate Variorum, 2004, 1-17.

Giesey, Ralph E., The King Imagined, in: ders., Rulership in France, 15th17th centuries, Aldershot, Ashgate Variorum, 2004, 219-237.

Giesey, Ralph E., The Two Bodies of the French King, in: ders., Rulership in France, 15 ${ }^{\text {th }}-17^{\text {th }}$ centuries, Aldershot, Ashgate Variorum, 2004, 301-316.

Giordano, Gregorio, Propheceyung vnd Weissagung von erschrecklichen vnd grewlichen widerwertigkeiten, s. 1. 1591.

Giordano, Gregorio, Prophetiae seu Vaticinia XIIII Tabellis expressa de horrendis Calamitatibus orbi terrarum impendentibus, s.1.1622.

Glanz, Katharina A., De arte honeste amandi. Studien zur Ikonographie der höfischen Liebe, Frankfurt a. M., Lang, 2005.

Gojosso, Éric, Le concept de république en France (XVIe-XVIIIe siècle), Aix-en-Provence, Presses universitaires d'Aix-Marseille, 1998.

Grassaille, Charles de, Regalium Franciae libri duo, Paris, Galeotum Pratensem, 1545.

Gregor IX., Decretales, in: Corpus iuris canonici, hg. v. Emil Ludwig Richter und Emil Friedberg, 2. Teil, Leipzig, Bernhard Tauchnitz, 1881.

Griffiths, Gordon, Humanists and Representative Government in the Sixteenth Century. Bodin, Marnix, and the Invitation to the Duke of Anjou to become Ruler of the Low Countries, in: Representative Institutions in Theory and Practice (Etudes présentées à la commission internationale pour l'histoire des assemblées d'états, Bd. 39), Brüssel, Les Editions de la Librairie Encyclopédique, 1970, 61-83.

Grijzenhout, Frans, De verbeelding van de Vrijheid in de Nederlandse kunst, 1570-1870, in: Haitsma-Mulier, E. O. G./Velema, W. R. E., Vrijheid. Een geschiedenis van de vijtiende tot de twintigste eeuw, Amsterdam, University of Amsterdam Press, 1999, 253-285.

Gude, Heinrich Ludwig, Einleitung zu den europäischen Staaten und derselben Beschluss, Halle, Renger, 1708. 
Gude, Heinrich Ludwig, Staat der vereinigten Niederländer, Halle, Renger, 1708.

Guenée, Bernard, Politique et histoire au Moyen Âge. Recueil d'articles sur l'histoire politique et l'historiographie médiévale (1956-1981), Paris, Publications de la Sorbonne, 1982.

Hackett, Helen, Virgin Mother, Maiden Queen. Elizabeth I and the Cult of the Virgin Mary, Basingstoke, Macmillan, 1995.

Hagenow, Elisabeth von, Bildniskommentare. Allegorisch gerahmte Herrscherbildnisse in der Graphik des Barock. Entstehung und Bedeutung (Studien zur Kunstgeschichte, Bd. 79), Hildesheim/Zürich, Georg Olms, 1999.

Hamm, Berndt, Von der spätmittelalterlichen reformatio zur Reformation. Der Prozess normativer Zentrierung von Religion und Gesellschaft in Deutschland, in: Archiv für Reformationsgeschichte (ARG), 84, 1993, 7-82.

Hamm, Berndt, Einheit und Vielfalt der Reformation - oder: was die Reformation zur Reformation machte, in: ders./Moeller, Bernd/Wendebourg, Dorothea, Hg., Reformationstheorien. Ein kirchenhistorischer Disput über Einheit und Vielfalt der Reformation, Göttingen, Vandenhoeck \& Ruprecht, 1995, 57-127.

Hanley, Sarah, The Lit de Justice of the Kings of France. Constitutional Ideology in Legend, Ritual, and Discourse, Princeton NJ, Princeton University Press, 1983.

Hanley, Sarah, The Monarchic State in Early Modern France. Marital Regime Government and Male Right, in: Bakos, Adrianna, Hg., Politics, Ideology and the Law in Early Modern Europe. Essays in Honor of J. H. M. Salmon, Rochester N.Y., University of Rochester Press, 1994, 107-126.

Harms, Wolfgang, Hg., Deutsche Illustrierte Flugblätter des 16. und 17. Jahrhunderts, 4 Bde., München, Kraus International Publications, 1980-1997.

Harrington, James, The Commonwealth of Oceana and a System of Politics, hg. v. John G. A. Pocock, Cambridge, Cambridge University Press, 1992. Henkel, Arthur/Schöne, Albrecht, Hg., Emblemata. Handbuch zur Sinnbildkunst des XVI. und XVII. Jahrhunderts, Stuttgart, Metzler, 1978.

Hess, Stefan, Sicherung der Rechtskontinuität oder die Macht der Gewohnheit. Marienbilder im nachreformatorischen Basel, in: Ganz, David et al., Hg., Rahmen-Diskurse. Kultbilder im konfessionellen Zeitalter, [Berlin], Reimer, 2004, 331-357.

Hoffmann von Fallersleben, August Heinrich, Geschichte des deutschen Kirchenlieds bis auf Luthers Zeit, Hannover, 1854. 
Hofmann, Hasso, Repräsentation. Studien zur Wort- und Begriffsgeschichte von der Antike bis ins 19.Jahrhundert, Berlin, Duncker und Humblot, 1974.

Hoke, Rudolf, Johannes Limnaeus, in: Stolleis, Michael, Hg., Staatsdenker in der frühen Neuzeit, München, C. H. Beck, 1995, 100-117.

Honorius von Autun, Expositio in Cantica Canticorum, PL 172.

Honorius von Autun, Sigillum beatae Mariae, PL 172.

Hugo von St. Viktor, De Sacramentis, PL 176.

Hulsen, Esaias van/Merian, Matthäus, Repraesentatio der furstlichen Aufzug und Ritter-spil. Die Kupferstichfolge von 1616, hg. v. Ludwig Krapf und Christian Wagenknecht (Stuttgarter Hoffeste. Texte und Materialien zur höfischen Repräsentation im frühen 17. Jahrhundert), Tübingen, Niemeyer, 1979.

Humbertus a Silva Candida, Libri III adversus simoniacos, in: MGH Scriptores. Libelli de lite imperatorum et pontificum saeculis XI. et XII. conscripti, Bd. 1, Hannover, Hahn, 1891, 95-253.

Hutten, Ulrich von, Briefe von 1506 bis 1520, hg. v. Eduard Böcking, Bd. 1, Leipzig, B. G. Teubner, 1859.

Israel, Jonathan, The Dutch Republic. Its Rise, Greatness and Fall 14771806, Oxford, Clarendon Press, 1995.

Jacobus de Voragine, Legenda aurea, hg. v. Giovanni Paolo Maggioni, Florenz, SISMEL, 1998.

James VI and I, Political Writings, hg. v. Johann P. Sommerville (Cambridge Texts in the History of Political Thought), Cambridge, Cambridge University Press, ${ }^{3} 2006$.

Johannes Paul II., Vita consecrata, Rom, Libreria Editrice Vaticana, 1996.

Juvénal des Ursins, Jean, Loquar in tribulacione, in: Ecrits politiques, hg. v. P. S. Lewis, Paris, C. Klincksieck, 1978, 295-436.

Kantorowicz, Ernst Hartwig, Die zwei Körper des Königs. Eine Studie zur politischen Theologie des Mittelalters, München, Deutscher Taschenbuch Verlag, 1990.

Kaufmann, Thomas, Konfession und Kultur. Lutherischer Protestantismus in der zweiten Hälfte des Reformationsjahrhunderts, Tübingen, Mohr Siebeck, 2006.

Kempe, Michael/Maissen, Thomas, Die Collegia der Insulaner, Vertraulichen und Wohlgesinnten in Zürich, 1679-1709. Die ersten deutschsprachigen Aufklärungsgesellschaften zwischen Naturwissenschaften, Bibelkritik, Geschichte und Politik, Zürich, Verlag NZZ, 2002. 
King, J. Christopher, Origen on the Song of Songs as the Spirit of Scripture. The Bridegroom's Perfect Marriage-Song, Oxford/New York, Oxford University Press, 2005.

King, John N., Queen Elizabeth I. Representations of the Virgin Queen, in: Renaissance Quarterly, 43, 1990, 30-74.

King, John N., Thomas Bentley's Monument of Matrons. The Earliest Anthology of English Women's Texts, in: Benson, Pamela Joseph/ Kirkham, Victoria, Hg., Strong Voices, Weak History. Early Women Writers and Canons in England, France and Italy, Ann Arbor, University of Michigan, 2005, 216-239.

Kittsteiner, Heinz Dieter, Die Stabilisierungsmoderne. Deutschland und Europa 1618-1715, München, Carl Hanser Verlag, 2010.

Klippel, Diethelm, Art. Souveränität, in: Brunner, Otto/Conze, Werner/ Koselleck, Reinhart, Hg., Geschichtliche Grundbegriffe. Historisches Lexikon zur politisch-sozialen Sprache in Deutschland. Studienausgabe, Bd. 6, Stuttgart, Klett-Cotta, 2004, 98-128.

Kocher, Gernot, Zeichen und Symbole des Rechts. Eine historische Ikonographie, München, C. H. Beck, 1992.

Koenigsberger, Helmut G., Republicanism, Monarchism and Liberty, in: Oresko, Robert et al., Hg., Royal and Republican Sovereignty in Early Modern Europe, Cambridge, Cambridge University Press, 1997, 43-74.

Koschorke, Albrecht et al., Der fiktive Staat. Konstruktionen des politischen Körpers in der Geschichte Europas, Frankfurt a. M., Fischer, 2007. Kossmann, Ernst Heinrich, Popular Sovereignty at the Beginning of the Dutch Ancien Régime, in: ders., Political Thought in the Dutch Republic. Three Studies (Verhandelingen der Koninklijke Nederlandse Akademie van Wetenschappen, afd. Letterkunde, Bd. 179), Amsterdam, Koninklijke Nederlandse akademie van wetenschappen, 2000, 131-166.

Krasa-Florian, Selma, Die Allegorie der Austria. Die Entstehung des Gesamtstaatsgedankens in der österreichisch-ungarischen Monarchie und die bildende Kunst, Wien, Böhlau Verlag, 2007.

Kreis, Georg, Helvetia im Wandel der Zeiten. Die Geschichte einer nationalen Repräsentationsfigur, Zürich, Verlag NZZ, 1991.

Krynen, Jacques, Idéal du prince et pouvoir royal en France à la fin du Moyen Age, 1380-1440. Etude de la littérature politique du temps, Paris, A. et J. Picard, 1981.

Lau, Thomas, «Stiefbrüder». Nation und Konfession in der Schweiz und in Europa (1656-1712), Köln, Böhlau Verlag, 2008. 
Lavin, Marilyn Aronberg, Maria-Ecclesia and the Meaning of Marriage in the Late 13th Century, in: Sande, Siri/Hodne, Lasse, Hg., Mater Christi, Rom, Bardi, 2009, 153-170.

Le Bret, Cardin, De la Souverainete du Roy, Paris, 1632.

Le Clerc, Jean, Explication historique des principales médailles frapées pour servir à l'histoire des Provinces-Unies des Pays-Bas, Amsterdam, 1723.

Leest, Anton van, Declaratie van die triumphante Incompst vande(n) Doorluchtighen ende Hoogheboren Prince van Oraingnien, Antwerpen, 1579. Lenz, Claus, Die Jungfrau und der Poet. Martin Opitz über die Eroberung Magdeburgs, in: Simpliciania, 9, 1987, 193-203.

Les délices de la Hollande, Bd. 2, Amsterdam, Pierre Mortier, 1728.

Limnaeus, Johannes, Iuris Publici Imperii Romano-Germanici, Bd. 4/5, Strassburg, 1666/1670.

Lowenthal, Anne W., Wtewael's Netherlandish history reconsidered, in: Nederlands Kunsthistorisch Jaarboek, 38, 1987, 215-223.

Luther, Martin, Wider den falsch genannten geistlichen Stand des Papsts und der Bischöfe, 1522, in: ders., Werke, Bd. 10/II, Weimar, Hermann Böhlau, 1907.

Mager, Wolfgang, Genossenschaft, Republikanismus und konsensgestütztes Ratsregiment. Zur Konzeptionalisierung der politischen Ordnung in der mittelalterlichen und frühneuzeitlichen deutschen Stadt, in: SchornSchütte, Luise, Hg., Aspekte der politischen Kommunikation im Europa des 16. und 17. Jahrhunderts. Politische Theologie, Res Publica-Verständnis, konsensgestützte Herrschaft (Historische Zeitschrift, Beiheft, Bd. 39), München, R. Oldenbourg Verlag, 2004, 13-122.

Maissen, Thomas, Von wackeren alten Eidgenossen und souveränen Jungfrauen. Zu Datierung und Deutung der frühesten «Helvetia»-Darstellungen, in: Zeitschrift für schweizerische Archäologie und Kunstgeschichte, 56, 1999, 265-302.

Maissen, Thomas, Konfessionskulturen in der frühneuzeitlichen Eidgenossenschaft. Eine Einführung, in: Schweizerische Zeitschrift für Religionsund Kulturgeschichte, 101, 2007, 225-246.

Maissen, Thomas, Die Geburt der Republic. Staatsverständnis und Repräsentation in der frühneuzeitlichen Eidgenossenschaft, Göttingen, Vandenhoeck \& Ruprecht, 22008.

Maissen, Thomas, Inventing the Sovereign Republic. Imperial Structures, French Challenges, Dutch Models, and the Early Modern Swiss Confederation, in: Holenstein, André et al., Hg., The Republican Alternative. 
The Netherlands and Switzerland compared, Amsterdam, Amsterdam University Press, 2008, 125-150.

Maissen, Thomas, Souveräner Gesetzgeber und absolute Macht. Calvin, Bodin und die mittelalterliche Tradition, in: Strohm, Christoph/Wall, Heinrich de, $\mathrm{Hg}$., Konfessionalität und Jurisprudenz in der Frühen Neuzeit, Berlin, Duncker \& Humblot, 2009, 91-113.

Maissen, Thomas, Wie aus dem heimtückischen ein weiser Fuchs wurde. Die Erfindung der eidgenössischen Neutralitätstradition als Anpassung an das entstehende Völkerrecht des 17. Jahrhunderts, in: Jucker, Michael/ Kintzinger, Martin, Hg., Rechtsformen internationaler Politik. Theorie, Norm, und Praxis vom 12. bis zum 18. Jahrhundert, Berlin, Duncker \& Humblot, 2011, 241-272.

Major, Emma, Madam Britannia. Women, Church, and Nation, 1712-1812,

Oxford, Oxford University Press, 2011.

Manow, Philip, Im Schatten des Königs. Die politische Anatomie demokratischer Repräsentation, Frankfurt a. M., Suhrkamp, 2008.

Marin, Louis, Das Porträt des Königs, Berlin, Diaphanes, 2005.

McGrath, Elizabeth, A Netherlandish History by Joachim Wtewael, in: Journal of the Warburg and Courtauld Institutes, 38, 1975, 182-217.

McLaren, Anne, Monogamy, Polygamy and the True State. James I's Rhetoric of Empire, in: History of Political Thought, 25, 2004, 446-480. Medick, Hans, Historisches Ereignis und zeitgenössische Erfahrung, in: ders./Benigna von Krusenstjern, Hg., Zwischen Alltag und Katastrophe, Göttingen, Vandenhoeck \& Ruprecht, 1999, 389-394.

Mérot, Alain, Décors pour le Louvre de Louis XIV (1653-1660). La mythologie politique à la fin de la Fronde, in: Grell, Chantal/Laplanche, François, Hg., La monarchie absolutiste et l'histoire en France. Théories $\mathrm{du}$ pouvoir, propagandes monarchiques et mythologies nationales, Bd. 1, Paris, Presses de l'Université de Paris-Sorbonne, 1987, 113-137.

Miège, Guy, The New State of England, London, 1691.

Miethke, Jürgen, Art. Souveränität, in: Lexikon des Mittelalters, Bd. 7, München/Zürich, Artemis, 1995, Sp. 2068-2071.

Milovanovic, Nicolas, Du Louvre à Versailles. Lecture des grands décors monarchiques, Paris, Belles Lettres, 2005.

Möbius, Helga, Frauenbilder für die Republik, in: Gamboni, Dario et al., Hg., Zeichen der Freiheit. Das Bild der Republik in der Kunst des 16. bis 20. Jahrhunderts, Bern, Stämpfli, 1991, 53-73.

Molé, Mathieu, Mémoires, Paris, Jules Renouard, 1855. 
Montrose, Louis, Elizabeth hinter dem Spiegel. Die Ein-Bildung der zwei Körper der Königin, in: Schulte, Regina, Hg., Der Körper der Königin. Geschlecht und Herrschaft in der höfischen Welt seit 1500 (Campus Historische Studien, Bd. 31), Frankfurt a. M., Campus, 2002, 67-98.

Morel, Henri, La place de la «lex regia» dans l'histoire des idées politiques, in: L'influence de l'Antiquité sur la pensée politique européenne (XVIeXXe siècles) (Collection d'histoire des idées politiques, Bd. 9), Aix/Marseille, Presses universitaires d'Aix-Marseille, 1996, 159-174.

Mörke, Olaf, Bataver, Eidgenossen und Goten. Gründungs- und Begründungsmythen in den Niederlanden, der Schweiz und Schweden in der Frühen Neuzeit, in: Berding, Helmut, Hg., Mythos und Nation. Studien zur Entwicklung des kollektiven Bewusstseins in der Neuzeit, Bd. 3, Frankfurt a. M., Suhrkamp, 1996, 104-132.

Morrill, John, The Oxford Illustrated History of Tudor \& Stuart Britain, Oxford/New York, Oxford University Press, 1996.

Moser, Johann Jacob, Reichs-Fama, oder das Merckwürdigste vom ReichsConvent, Kayserlichen Hof und Ständen des Reichs, Frankfurt/Leipzig 1727-1738.

Muir, Edward, Civic Ritual in Renaissance Venice, Princeton, Princeton University Press, 1981.

Müller, Rainer A., Das «Heilige Römische Reich Deutscher Nation» in allegorischen Darstellungen, in: ders., Hg., Bilder des Reiches (Irseer Schriften, Bd. 4), Sigmaringen, Jan Thorbecke Verlag, 1997, 397-432.

Nalson, John, Impartial Collection of the Great Affairs of State, London, 1682.

Nowicki, Pawel, Zu Römisch-Hungarisch-Königl. Vermählung Glückwünschendes Europa. Ein Gelegenheitsgedicht von Hans Assmann Freiherr von Abschatz, in: Czarnecka, Miroslawa/Szafarz, Jolanta, Hg., Hochzeit als ritus und casus. $\mathrm{Zu}$ interkulturellen und multimedialen Präsentationsformen im Barock, Breslau, Oficyna Wydawn. ATUT, 2001, 161-168.

Oechsli, Wilhelm, Die Benennung der Alten Eidgenossenschaft und ihrer Glieder, in: Jahrbuch für Schweizer Geschichte, 42, 1917, 89-258.

Ohly, Friedrich, Die Perle des Wortes. Zur Geschichte eines Bildes und seiner Deutung, Frankfurt a. M., Insel Verlag, 2002, 33-52.

Onder den Oranje boom. Niederländische Kunst und Kultur im 17. und 18. Jahrhundert an deutschen Fürstenhöfen, München, Hirmer, 1999.

Ost, Hans, Borrominis römische Universitätskirche S. Ivo alla Sapienza, in: Zeitschrift für Kunstgeschichte, 30, 1967, 101-142. 
Oxford Encyclopedia of the Reformation, New York/Oxford, Oxford University Press, 1996.

Paas, John Roger, Hg., The German Political Broadsheet, Wiesbaden, Otto Harrassowitz, 1996.

Pange, Jean de, Le Roi très chrétien, Paris, A. Fayard, 1949.

Papon, Jean, Recueil d'arestz notables des courtz souveraines de France, Paris, 1566.

Paravicini Bagliani, Agostino, Der Leib des Papstes. Eine Theologie der Hinfälligkeit, München, C. H. Beck, 1997.

Patrologia Latina (PL), hg. von Jacques-Paul Migne, Paris, 1844-1855.

Peacham, Henry, Minerva Britannia, or a Garden of Heroical Devises, London, 1612.

Penne, Luca da, Super tres libros Codicis x., videlicet xi., et xii. hanc laboriosissimam edidit lecturam, Paris, 1509.

Petrarca, Francesco, Epistole, hg. v. Ugo Dotti, Turin, UTET, 1978.

Petrarca, Francesco, Epistulae metricae, hg. v. Otto und Eva Schönberger, Würzburg, Königshausen \& Neumann, 2004.

Piccolomini, Enea Silvio, De ortu et auctoritate Imperii Romani, in: Kallen,

Gerhard, Aeneas Silvius Piccolomini als Publizist, Stuttgart, Deutsche Verlagsanstalt, 1939.

Pieken, Gorch, «Ehrsame, hier habt ihr Herzog Alba auf seinem tyrannischen Thron», in: ders., «Voor een' vryen Staet». Die Niederlande, das Reich und «Tyrannen» in den Krisenjahren 1572 und 1672 = Magazin. Mitteilungen des Deutschen Historischen Museums, 7. Jahrgang, Heft 21, 1997.

Prodi, Paolo, Eine Geschichte der Gerechtigkeit. Vom Recht Gottes zum modernen Rechtsstaat, München, C. H. Beck, 22005.

Quaritsch, Helmut, Souveränität. Entstehung und Entwicklung des Begriffs in Frankreich und Deutschland vom 13. Jh. bis 1806 (Schriften zur Verfassungsgeschichte, Bd. 38), Berlin, Duncker und Humblot, 1986.

Reincke, Heinrich, Die Schutzpatrone der Stadt Hamburg, in: Hamburger geschichtliche Beiträge. Hans Nirrnheim zum siebzigsten Geburtstage am 29. Juli 1935 dargebracht, Hamburg, Boysen \& Maasch, 1935.

Reinhard, Wolfgang, Ausgewählte Abhandlungen, Berlin, Duncker und Humblot, 1997.

Ripa, Cesare, Iconologia overo descrittione di diverse imagini cavate dall'antichità, \& di propria intentione, Rom, Lepido Facii, 1603.

Rist, Johann, Das Friedewünschende Teutschland, Hamburg 1649, in: ders., Sämtliche Werke, Bd. 2: Dramatische Dichtungen, hg. v. Eberhard Mannack, Berlin/New York, Walter de Gruyter, 1972. 
Roeck, Bernd, Titelkupfer reichspublizistischer Werke der Barockzeit als historische Quellen, in: Archiv für Kulturgeschichte, 65, 1983, 329-361.

Roncaglia, Constantino, Admirables efectos de la provindencia sucedidos en la vida, e imperio de Leopoldo primero invictissimo emperador de romanos, Mailand, 1696.

Rosand, David, Venetia Figurata. The Iconography of a Myth, in: ders., Hg., Interpretazioni veneziane. Studi di storia dell'arte in onore di Michelangelo Muraro, Venezia, Arsenale editrice, 1984, 177-196.

Rosand, David, Myths of Venice. The Figuration of a State, Chapel Hill, University of North Carolina Press, 2001.

Rubinstein, Nicolai, The History of the Word politicus, in: Pagden, Anthony, Hg., The Languages of Political Theory in Early-Modern Europe, Cambridge, University Press, 1987, 41-56.

Sabatier, Gérard, Versailles ou la figure du roi, Paris, Albin Michel, 1999. Sawyer, Andrew, The Tyranny of Alva. The Creation and Development of a Dutch Patriotic Image, in: De zeventiende eeuw, 19, 2003, 181-207. Sawyer, Andrew, Medium and Message. Political Prints in the Dutch Republic, 1568-1632, in: Pollmann, Judith/Spicer, Andrew, Hg., Public Opinion and Changing Identities in the Early Modern Netherlands. Essays in Honour of Alastair Duke, Leiden/Boston, Brill, 2007, 163-187.

Schama, Simon, Überfluss und schöner Schein. Zur Kultur der Niederlande im Goldenen Zeitalter, München, Kindler, 1988.

Schelkens, Pius, De Ecclesia Sponsa Christi, in: Augustiniana, 3, 1953, 145-164.

Schilling, Heinz, Luther, Loyola, Calvin und die europäische Neuzeit, in: Archiv für Reformationsgeschichte, 85, 1994, 5-31.

Schilling, Heinz, Ausgewählte Abhandlungen zur europäischen Reformations- und Konfessionsgeschichte, Berlin, Duncker und Humblot, 2002. Schilling, Heinz, Am Anfang war Luther, Loyola und Calvin. Ein religionssoziologisch-entwicklungsgeschichtlicher Vergleich, in: ders., Ausgewählte Abhandlungen zur europäischen Reformations- und Konfessionsgeschichte, Berlin, Duncker und Humblot, 2002, 3-10.

Schmale, Wolfgang, Europa, Braut der Fürsten. Politische Relevanz des Europamythos im 17. Jahrhundert, in: Bussmann, Klaus/Werner, Elke, Hg., Europa im 17. Jahrhundert. Ein politischer Mythos und seine Bilder, Stuttgart, Franz Steiner Verlag, 2004, 241-267.

Schmidt, Heinrich, Zur politischen Vorstellungswelt deutscher Städte im 17. Jahrhundert, in: Wegener, Wilhelm, Hg., Festschrift für Karl Gottfried Hugelmann, Bd. 2, Aalen, Scientia, 1959, 501-521. 
Schmitt, Carl, Politische Theologie. Vier Kapitel zur Lehre von der Souveränität, Berlin, Duncker \& Humblot, 82004 (urspr. 1922).

Scholz, Susanne, Den Körper schreiben. Nationale Erzählung und Subjektwerdung im frühneuzeitlichen England, in: Bielefeld, Ulrich/Engel, Gisela, Hg., Bilder der Nation. Kulturelle und politische Konstruktion des Nationalen am Beginn der europäischen Moderne, Hamburg, Hamburger Edition, 1998, 76-106.

Scholz, Susanne, Body Narratives. Writing the Nation and Fashioning the Subject in Early Modern England, Basingstoke, Macmillan, 2000.

Schönaich, Christoph Otto von, Hermann, oder das befreyte Deutschland, ein Heldengedicht, Leipzig, Breitkopf, 1753.

Schreiner, Klaus, Maria. Jungfrau, Mutter, Herrscherin, München, Carl Hanser Verlag, 1994.

Schubert, Friedrich Hermann, Die deutschen Reichstage in der Staatslehre der Frühen Neuzeit (Schriftenreihe der Historischen Kommission bei der Bayerischen Akademie der Wissenschaften, Bd. 7), Göttingen, Vandenhoeck \& Ruprecht, 1966.

Schumacher-Wolfgarten, Renate, Art. Rose, in: Kirschbaum, Engelbert, Hg., Lexikon der christlichen Ikonographie, Bd. 3, Freiburg i. Br., Herder, 1971, Sp. 563-568.

Schweizerisches Idiotikon. Wörterbuch der schweizerdeutschen Sprache, Bd. 8, Frauenfeld, Huber, 1920.

Selden, John, Of the Dominion, or Ownership of The Sea, London, 1652. Sieyès, Emmanuel Joseph, Qu'est-ce que le tiers état? Précédé de l'essai sur les privilèges, hg. v. Edmé Champion, Paris, 1888.

Sinding-Larsen, Staale, The Changes in the Iconography and Composition of Veronese's Allegory of the Battle of Lepanto in the Doge's Palace, in: Journal of the Warburg and Courtauld Institutes, 19, 1956, 298-302.

Sinding-Larsen, Staale, Christ in the Council Hall. Studies in the Religious Iconography of the Venetian Republic, Roma, «L'Erma» di Bretschneider, 1974.

Skinner, Quentin, Macht und Ruhm der Republik in den Fresken Lorenzettis, in: Skinner, Quentin, Hg., Visionen des Politischen, Frankfurt a. M., Suhrkamp, 2009, 93-135.

Spitz, Jean-Fabien, Bodin et la soveraineté, Paris, Presses Universitaire de France, 1998.

Stollberg-Rilinger, Barbara, Des Kaisers alte Kleider. Verfassungsgeschichte und Symbolsprache des Alten Reiches, München, C. H. Beck, 2008. 
Stolleis, Michael, Geschichte des öffentlichen Rechts in Deutschland, Bd. 1: Reichspublizistik und Policeywissenschaft 1600-1800, München, C. H. Beck, 1988.

Strong, Roy, The Cult of Elizabeth. Elizabethan Portraiture and Pageantry, London, Thames and Hudson, 1977.

Tietze, Hans, Programme und Entwürfe zu den grossen österreichischen Barockfresken, in: Jahrbuch der kunsthistorischen Sammlungen des allerhöchsten Kaiserhauses, 30, 1911, 1-28.

Tromp, Sebastiaan, Ecclesia sponsa virgo mater, in: Gregorianum, 18, 1937, 3-29.

Trummer, Josef, Mystisches im alten Kirchenrecht. Die geistige Ehe zwischen Bischof und Diözese, in: Österreichisches Archiv für Kirchenrecht, 2, 1951, 62-75.

Trzinski, Elke, Studien zur Ikonographie der Germania, Diss. Münster, 1990. Tschopp, Silvia Serena, Heilsgeschichtliche Deutungsmuster in der Publizistik des Dreissigjährigen Krieges. Pro- und antischwedische Propaganda in Deutschland 1628 bis 1635, Frankfurt a. M., Peter Lang, 1991.

Tschopp, Silvia Serena, Rhetorik des Bildes. Die kommunikative Funktion sprachlicher und graphischer Visualisierung in der Publizistik zur Zerstörung Magdeburgs im Jahre 1631, in: Burkhardt, Johannes et al., Hg., Kommunikation und Medien in der Frühen Neuzeit, München, R. Oldenbourg, 2005, 79-103.

Ullmann, Walter, The Medieval Idea of Law as Represented by Lucas de Penna. A Study in Fourteenth-Century Legal Scholarship, London, Methuen, 1946.

Valerius, Robert, Weibliche Herrschaft im 16. Jahrhundert. Die Regentschaft Elisabeths I. zwischen Realpolitik, Querelle des femmes und Kult der Virgin Queen (Reihe Geschichtswissenschaft, 49), Herbolzheim, Centaurus, 2002.

Valkenier, Petrus, Das verwirrte Europa, Amsterdam, Meurs, Someren \& Boom, 1677.

Verdier, Philippe, Le Couronnement de la Vierge. Les origines et les premiers développements d'un thème iconographique, Montréal/Paris, J. Vrin, 1980.

Vetter, Ewald Maria, Maria im Rosenhag, Düsseldorf, L. Schwann, 1956.

Viroli, Maurizio, From Politics to Reason of State. The Acquisition and Transformation of the Language of Politics 1250-1600, Cambridge, Cambridge University Press, 1992. 
Warner, Marina, In weiblicher Gestalt. Die Verkörperung des Wahren, Guten und Schönen, Reinbek bei Hamburg, Rowohlt, 1989.

Weissenbach, Johann Caspar, Auffnemmende Helvetia, das ist: Kurtzer Entwurff, welcher gestalten ein hochlobliche Eydgnossschafft ... in einen gantz sovrainen Stand und freye Republic erhebt worden, Luzern, 1702. Weissenbach, Johann Caspar, Eydgnosssisches Contrafeth auff- unnd abnemmender Jungfrawen Helvetiae, hg. v. Hellmut Thomke, Zürich, Chronos, 2007 (Reprint der Ausgabe Zug 1673).

Wende, Peter, Das Herrscherbild des 17. Jahrhunderts in England, in: Repgen, Konrad, Hg., Das Herrscherbild im 17. Jahrhundert (Schriftenreihe der Vereinigung zur Erforschung der Neueren Geschichte, 19), Münster, Aschendorff, 1991, 58-78.

Wesel-Roth, Ruth, Thomas Erastus. Ein Beitrag zur Geschichte der reformierten Kirche und zur Lehre von der Staatssouveränität, Lahr, Schauenburg, 1954.

Wilckens, Alexander, Quellenautopsie «Michael Praun (1660)», in: Schmale, Wolfgang (Dir.), Europabegriffe und Europavorstellungen im 17. Jahrhundert. Web-Projekt, http://www.univie.ac.at/igl.geschichte/europaquellen/quellen17/praun 1660. htm (25.07.2012).

Winter, Pieter Jan van, De hollandse Tuin, in: Nederlands Kunsthistorisch Jaarboek, 8, 1957, 29-121.

Wolgast, Eike, Politisches Kalkül und religiöse Entscheidung im Reformationszeitalter, in: Luther. Zeitschrift der Luthergesellschaft, 76, 2005, 66-79.

Wolters, Wolfgang, Der Bilderschmuck des Dogenpalastes. Untersuchungen zur Selbstdarstellung der Republik Venedig im 16. Jahrhundert, Wiesbaden, Franz Steiner, 1983.

Wurmann, Jakob, Bulschafft der sich representierden Eidtgnössischen Dam, welcher eine hochloblichen Eidtgnoschaft ihre Herzensgedanken in treuen eröffnet, mit vermelden, dasz sie Ihr verlobte tragende Jungfrauschaft gegen allen ihren auszländischen Bulen rein behalten, sich in Ehestand nit einlassen, sonder by ihrem bis dahin tragenden Kreuz ihr Leib, Ihr Gut und Blut aufsezen darbey leben und sterben wolle, Wissendangen, in Verlegung Caspar Wurmanns, 1676.

Wüthrich, Lucas/Ruoss, Mylène, Katalog der Gemälde. Schweizerisches Landesmuseum, Zürich, Bundesamt für Kultur, 1996.

Wyss, Robert L., Vier Hortus-Conclusus-Darstellungen im schweizerischen Landesmuseum, in: Zeitschrift für schweizerische Archäologie und Kunstgeschichte, 20, 1960, 113-124. 
Yates, Frances Amelia, Astraea. The Imperial Theme in the Sixteenth Century, London, Routledge and Kegan Paul, 1975.

Zanger, Abby E., Scenes from the Mariage of Louis XIV. Nuptial Fictions and the Making of Absolutist Power, Stanford, Stanford University Press, 1997.

Ziegler, Walter, Die Entscheidung deutscher Länder für oder gegen Luther. Studien zu Reformation und Konfessionalisierung im 16. und 17. Jahrhundert. Gesammelte Aufsätze, Münster, Aschendorff, 2008.

Zurlauben, Beat Fidel Anton von, Tableaux de la Suisse, ou, Voyage pittoresque fait dans les treize cantons et états alliés du Corps Helvétique, Paris, 1780.

\section{Abbildungsverzeichnis}

1. Honorius von Autun, Expositio in Cantica Canticorum (Opera exegetica); (C) Bayerische Staatsbibliothek München, Clm 4550, vorderer Spiegel

2. Lucas de Heere, Salomo (Philipp II.) empfängt die Königin von Saba, Kathedrale von Gent, 1559; http://es.wikipedia.org/wiki/Archivo: Gantesalomon.jpg

3. Argumentum anti-Normannicum: or An argument proving, from ancient histories and records ... (1682). By permission of the Folger Shakespeare Library

4. Heinrich IV. mit Francia und dem ligistischen Ehebrecher, Flugblatt 1589, BNF, Hennin, Bd. IX, 920; (C) Bibliothèque nationale de France

5. Michael Drayton, Poly-Olbion, 1612; Early English Books Online

6. Jan Tengnagel, Allegorie auf die Blüte der Republik unter Moritz von Oranien, ca. 1618, Gemälde; (C) Museum Het Prinsenhof, Delft, the Netherlands

7. Ghy Patriotten thans «kijck uyt, kijck uuy, Siet wat een vreemden Dans» om de Hollandtsche Bruut, Flugblatt, 1615, Atlas Van Stolk, Nr. 1308; (C) Atlas Van Stolk, Rotterdam.

8. Maechts Antwoort tegen op en aen de aenspraek van een courtisaen, Flugblatt 1617, aus: Frederik Muller, De Nederlandsche geschiedenis in platen, Rijksmuseum Amsterdam/Atlas Van Stolk, Nr. 1328; (C) Atlas Van Stolk, Rotterdam

9. Das Testament des Friedens oder Anstands, 1615, in: Wolfgang Harms, Deutsche Illustrierte Flugblätter des 16. und 17. Jahrhunderts, München 1980-1997, Bd. 2, 182f. (II, 104); (C) Germanisches Nationalmuseum Nürnberg, gm1165013 
10. Capitualtiones, wasgestalt Herrn General Graffen Tilly die alte Junckfrau zu Magdeburg verheiratet worden, 1631, in: W. Harms, Illustrierte Flugblätter, Bd. 2, 400f. (II, 227); (C) Herzog August Bibliothek, Wolfenbüttel: IH 175

11. Execution vnd verfolgung die der Duc de Alba gethan hat vuider die Euangelisten im Niderland, 1569, Atlas Van Stolk, Nr. 409; (C) Atlas Van Stolk, Rotterdam

12. Niederländische Medaille, 1583, in: Explication historique des principales médailles frapées pour servir à l'histoire des Provinces-Unies des Pays-Bas, Amsterdam 21736, S. 48f., Nr. 79; (C) Zentralbibliothek Zürich

13. Le Duc d'Anjou offre son bouclier, casques et epée à la Belgique, 1579, BNF, Estampes, Hennin 723; (C) Bibliothèque nationale de France

14. Jacopo Tintoretto, Freiwillige Unterwerfung der Provinzen unter Venetia, Dogenpalast, Venedig, um 1580; C Fondazione Musei Civici di Venezia

15. Wunder Schweizerland, Öl auf Leinwand; (C) Schweizerisches Nationalmuseum, LM-65151; Foto Schweizerisches Nationalmuseum, DIG-3865

16. Conrad Meyer, Titelblatt zu Jacob Wurmann, Bulschafft der sich representirenden Eidtgnössischen Dam, 1676; (C) Zentralbibliothek Zürich

17a. Hans Georg Krauer oder J. R. Morrini, Sapientia/Lucerna, Neue Kanzlei Luzern, 1698, Neue Kanzlei Rathaus Stadt Luzern; (C) Stadt Luzern

17b. Andrea Sacchi, Divina Sapienza, Palazzo Barberini, 1633; (C) Archivio Fotografico Soprintentenza Sepciale per il Patrimonio Storico, Artistico ed Etnoantropologico e per il Polo Museale della città di Roma

18. Magnificentissimo et amplissimo Senatul populoque Tigurino ..., in: Johann Melchior Füssli/David Herrliberger, Zürcher Staatskalender, 1724, Kalender 1724 III, 2 Schweiz; (C) ZB Zürich, Graphische Sammlung und Fotoarchiv

19. Jean Desmarets de Saint-Sorlin, Europe. Comedie Heroique, 1643; (C) Bibliothèque nationale de France

20. L'Ambassade du ciel aux potentats d'Europe, 1654; BNF, Estampes, Hennin 3725; (C) Bibliothèque nationale de France

21. Heinrich Ludwig Gude (?), Einleitung zu den europäischen Staaten und derselben Beschluss, s. 1. 1708, Frontispiz; (C) Herzog August Bibliothek, Wolfenbüttel: M: Gb 298 (1) 
